This item was submitted to Loughborough's Research Repository by the author.

Items in Figshare are protected by copyright, with all rights reserved, unless otherwise indicated.

\title{
Recent developments in manufacturing micro- and nano-particles from emulsion droplets
}

PLEASE CITE THE PUBLISHED VERSION

http://www.crcpress.com/product/isbn/9781420065008

PUBLISHER

CRC Press (@ Taylor and Francis)

VERSION

AM (Accepted Manuscript)

LICENCE

CC BY-NC-ND 4.0

REPOSITORY RECORD

Vladisavljevic, Goran T., and Richard A. Williams. 2010. "Recent Developments in Manufacturing Micro- and Nano-particles from Emulsion Droplets”. figshare. https://hdl.handle.net/2134/7317. 
This item was submitted to Loughborough's Institutional Repository (https://dspace.lboro.ac.uk/) by the author and is made available under the following Creative Commons Licence conditions.

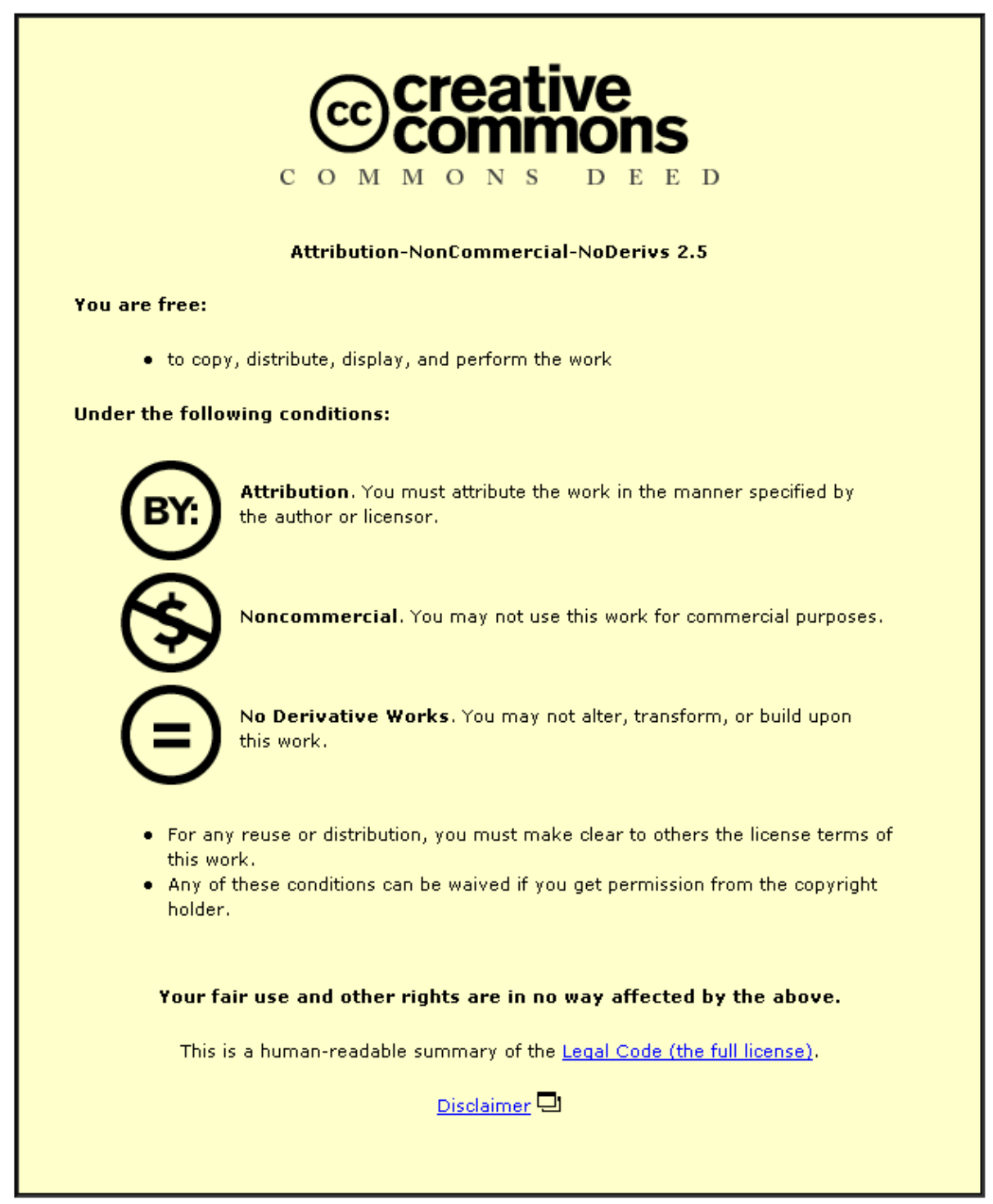

For the full text of this licence, please go to: http://creativecommons.org/licenses/by-nc-nd/2.5/ 


\section{Recent developments in manufacturing micro- and nano-particles from emulsion droplets}

Goran T. Vladisavljević ${ }^{1}$, Richard A. Williams ${ }^{2}$

${ }^{1}$ Chemical Engineering Department, Loughborough University, Loughborough, Leicestershire, LE11 3TU, United Kingdom. e-mail: G.Vladisavljevic@lboro.ac.uk. Phone: (+44) (0)1509222 518

${ }^{2}$ Institute of Particle Science \& Engineering, School of Process, Environmental \& Materials Engineering, Clarendon Road, University of Leeds, Leeds, LS2 9JT, United Kingdom. r.a.williams@leeds.ac.uk

Manuscript information: 11,850 words, 6 Tables, 28 Figures Running title: Manufacturing micro- and nano-particles from droplets

Kewords: membrane emulsification; microchannel emulsification; microfluidics; polymer microspheres; solid lipid microcapsules; polymerosomes; colloidosomes.

Abstract

Membrane and microfluidic devices are relatively new tools for highly controlled production of particles. This review focuses on the recent developments in this area, ranging from the production of simple and double emulsions of different types and morphologies (e.g. multiple core-shell structures, outer drops with controlled number of internal droplets, etc) to highly sophisticated functional products such as polymerosomes, asymmetric lipid vesicles, and core-shell particles. Other emerging technologies that extend the capabilities into different 
membrane materials and operation methods (such as rotating stainless steel membrane with laser drilled pores) and manufacturing approaches (extrusion of pure to-be-dispersed phase or coarsely emulsified feeds) are introduced. The use of microfluidic T-junctions, flow focusing devices and silicon microchannel array devices is also reviewed. The results of experimental work carried out by cited researchers in the field together with those of the current authors are presented in a tabular form in a rigorous and systematic manner. These demonstrate a wide range of products that can be manufactured from emulsions using different solidification techniques. 


\section{INTRODUCTION}

Micro- and nano-particles find many applications in electronics, chemistry, biology, medicine, e.g. as packing in high performance analytical columns, supports for catalysts, enzymes and whole cells, drug carriers, bio-bar codes, particles for electronic paper displays, solder particles for microelectronic assemblies, etc. In all these applications, a high degree of monodispersity and a close control of particle size, shape, and functionality is required. One of the main routes for the generation of solid micro- and nanoparticles is via emulsification followed by a variety of solidification processes or reactions, such as polymerisation, gelation, crystallisation, coagulation, self assembly, etc. Conventional emulsification devices such as high pressure homogenisers and high speed rotor-stator devices generally use inhomogeneous extensional and shear forces and high energy per unit volume to rupture droplets (Karbstein and Schubert, 1995). As a result, they produce emulsions with small particles (up to several $\mu \mathrm{m}$ ) but wide particle size distributions and particle size and morphology cannot be precisely controlled. Further, the yield on internal droplets in multiple emulsions produced in conventional devices is often very low, due to the shear-induced expulsion of the internal droplets from the multiple emulsion drops. Therefore, new drop-bydrop approaches are necessary for the controlled production of highly uniform droplets over a wide range of sizes. This chapters is focused on the latest developments in manufacturing particulate products from emulsion droplets using membrane and microfluidic devices.

Table 1 illustrates the wide range of particulate products that have been manufactured using membrane and microfluidic devices, from food spreads to complex colloidal assemblies and vesicles. Some examples of particulate products manufactured by using emulsion droplets as templates are presented schematically in Figures 1 and 2. The majority of these functional 
particles can be produced with a controlled size distribution using membrane and microfluidic devices. It can be seen that a variety of particulate materials can be fabricated by means of sequential secondary reactions/processes in the emulsified droplets, such as polymerisation, swelling, gelation, crystallization, coacervation, coagulation, self assembly, etc (Table 1). These processes can be used individually or in combination (e.g. droplet swelling followed by polymerisation or colloidal self assembly followed by gelation (Cayre et al., 2004). For example, non-aqueous droplets can be converted to polymer microspheres by polymerisation, if they contain a monomer mixture, or by solvent evaporation, if they are composed of a preformed polymer dissolved in a volatile solvent. Oil droplets can be composed of a hot melted oil and can be transformed into solid lipid particles by cooling to room temperature (Sugiura et al., 2000; Kukizaki and Goto, 2007). Similarly, hot droplets of a metal solder are solidified to produce fine solder powder. Aqueous droplets can also be subjected to a number of solidification processes, depending on their formulation, such as gelation, polymerisation, crystallisation, heat coagulation, particle self assembly (either inside the droplet or at the droplet surface), etc.

It has been stated that the development of emulsification methods for controlled production of uniform droplets must be rooted in one of two possible manufacturing approaches (Williams et al., 2001b): (a) reduction of process length scales of the turbulent perturbations and enhancement of their uniformity in the mixing processes that rupture the liquids, and (b) the creation of droplets individually, i.e. drop by drop. The production of emulsions using direct membrane emulsification and microfluidic techniques represents a typical example of the second approach. This chapter aims to introduce the latest development on the utilisation of membrane and microfluidic emulsification techniques for the preparation of micro/nanoparticles from emulsion precursors. 
The polydispersity of the droplets throughout this paper will be expressed in terms of the coefficient of variation (relative standard deviation) or the relative span factor. For a specific size distribution the coefficient of variation is defined as $\mathrm{CV}=\left(\sigma / \mathrm{d}_{\mathrm{av}}\right) \times 100$, where $\sigma$ is the standard deviation of the droplet diameters and $d_{a v}$ is the number-average mean droplet diameter. The relative span factor is given by $\left(d_{90}-d_{10}\right) / d_{50}$, where $d_{x 0}$ is the diameter corresponding to $\mathrm{x} 0 \mathrm{vol} . \%$ on a relative cumulative droplet diameter distribution curve.

\section{PRINCIPLES AND OPERATING METHODS FOR MEMBRANE EMULSIFICATION}

The first investigation on using membrane emulsification can be traced back to the $1980 \mathrm{~s}$ when Nakashima and Shimizu (1986) fabricated a glass membrane from 'shirasu', lime, and boric acid, called Shirasu Porous Glass (SPG), and produced uniform-sized kerosene-in-water and water-in-kerosene emulsions (Nakashima et al., 1991a,b,c). Shirasu is a volcanic ash that occurs naturally in the southern areas of Kyushu, Japan containing about $86 \%$ of $\mathrm{SiO}_{2}$ and $\mathrm{Al}_{2} \mathrm{O}_{3}$ in addition to some other inorganic oxides. Since this time the method has continued to attract attention due to its effectiveness in producing narrow particle size distributions over a wide range of mean particle sizes at low energy consumption. Although the majority of investigations on using membrane emulsification have been undertaken by Japanese workers, other novel research is being carried out in European countries (Williams et al., 1998; Schröder et al., 1998; Joscelyne and Trägårdh, 1999; Abrahamse et al., 2002; Christov et al., 2002; Giorno et al., 2003) and elsewhere (Jing et al., 2005). To date, in addition to experimentation using SPG membranes, investigations of a broad range of other types of membranes, such as ceramic, metallic, polymeric and microengineered devices, have been reported (Table 2). The table indicates the form of the membrane, the nature of its surface 
(hydrophilic or hydrophobic), mean pore size and a typical effective membrane surface area deployed in the example cited in the table. Other type of microengineered materials can also be utilized such as parallel arrays of microgrooves formed by etching on a single-crystal silicon plate (Kawakatsu et al., 2000) and microfluidic devices of quartz glass (Nisisako et al., 2004), poly(dimethyl siloxane) (PDMS) (Yi et al., 2003), polyurethane (PU) (Nie et al., 2005), etc. Microgroove array devices and soft microfluidic devices are not considered in Table 2.

Membrane emulsification (ME) methods are described schematically in Figure 3. In conventional direct ME (Fig. 3 (a)), fine droplets are created in situ at the membranecontinuous phase interface by pressing a pure liquid (the dispersed phase) through the membrane. Hydrophobic membranes are needed to produce water-in-oil (W/O) emulsions, whereas hydrophilic membranes are needed to produce oil-in-water $(\mathrm{O} / \mathrm{W})$ emulsions, as in the example shown in Fig. 3 (a). In order to ensure a regular droplet detachment from the pore outlets, shear stress is generated at the membrane-continuous phase interface by recirculating the continuous phase/emulsion along the membrane using a low shear pump (Fig. 4 (a)) (Nakashima et al., 1991a) or by agitation in a stirring vessel (Fig. 4 (b)) (Fuchigami et al., 2000; Kosvintsev et al., 2005; Ha et al., 1999; Ito and Makino, 2004; Ma et al., 1999c; Wang et al., 2005; You et al., 2001). The advantage of using stirring cells is a low minimum volume of the continuous phase in the vessel of only several milliliters in some commercial ME devices, which is convenient for expensive emulsions. The rate of mixing should be high enough to provide the required tangential shear on the membrane surface, but not too excessive to induce further droplet break up. The continuous phase is usually agitated by a magnetic stirrer and the pressurized dispersed phase flow either through the inside (You et al., 2001) or the outside (Wang et al., 2005) of the membrane tube. Recently, a dispersion cell with a paddle rotating above a flat membrane was commercialised (Kosvintsev et al., 2005). 
Another approach is based on a moving membrane (Fig. 4 (c)), in which case the droplet detachment from the pore outlets is stimulated by rotation (Fig. 5) (Williams et al., 2001a, Vladisavljević and Williams, 2006; Schadler and Windhab, 2004) or vibration (Zhu and Barrow, 2005) of the membrane in a stationary continuous phase vessel. In our recent investigation (Vladisavljević and Williams, 2006), a stainless steel membrane with $100 \mu \mathrm{m}$ laser drilled pores was used to produce $\mathrm{O} / \mathrm{W}$ emulsions with relatively large $(80-260 \mu \mathrm{m})$ droplets. The membrane tube, $1 \mathrm{~cm}$ in diameter, was rotated inside a stationary glass cylinder (Fig. 5 (c)), diameter of $3 \mathrm{~cm}$, at a constant speed in the range of 50-1500 rpm. The droplet diameter decreased with increasing the rotational speed and the viscosity of the continuous phase. Compared with cross ME, this system can be advantageous to the production of multiple emulsions and shear-sensitive microparticles, because the necessity of recirculating the product is eliminated in a continuous operation. Kosvintsev et al. (2005) modified a Weissenberg cone and plate rheometer by replacing normally impervious plate underneath the cone with the membrane and permitting the injection of oil from underneath the membrane, as shown in Fig. 4 (c) right. However, it has been shown that the simple paddle-stirred cell provided the same degree of monodispersity as the modified Weissenberg rheometer with a constant shear stress operation. The nickel membranes used in the experiments contained a regular array of nontortuous pores uniformly spaced and provided oil fluxes up to $1000 \mathrm{Lm}^{-}$ ${ }^{2} \mathrm{~h}^{-1}$. Zhu and Barrow (2005) introduced membrane vibration, through piezoactuation, to help the detachment of droplets and provide an extra control over droplet detachment in cross membrane emulsification. The preliminary results showed that a vibrating membrane had a significant effect in reducing the average size of emulsion droplets but only at very low frequencies $(0-100 \mathrm{~Hz})$. 
Even in the absence of any tangential shear, droplets can be spontaneously detached from the pore outlets at small disperse phase fluxes (Fig. 5 (d)), particularly in the presence of fastadsorbing emulsifiers in the continuous phase and for a pronounced non-circular pore geometries, such as narrow rectangular microslots. Kobayashi et al. (2003a) found that the aspect ratio (length/width ratio) of the slots exceeding 3 was needed to generate monodisperse droplets with a CV below $2 \%$.

A potential disadvantage of 'direct' ME is a relatively low maximum dispersed phase flux through the membrane of typically $10-100 \mathrm{Lm}^{-2} \mathrm{~h}^{-1}$, that has to be restrained to avoid the transition from a 'dripping' to 'continuous outflow' regime (Kobayashi et al., 2003a) or to avoid the steric hindrance among droplets that may be formed simultaneously at the adjacent pores (Abrahamse et al., 2002). It is demonstrated that the generation of uniform droplets is only possible in the dripping regime, in which the mean droplet size is almost independent on the dispersed phase flux and proportional to the mean pore size (Vladisavljević et al., 2004a). In the ME experiments with a microsieve (Abrahamse et al., 2002) and SPG membranes (Katoh et al., 1996) the dispersed phase flux was $2500 \mathrm{Lm}^{-2} \mathrm{~h}^{-1}$, but polydisperse droplets were generated. Due to the low productivity, i.e. long production times, direct ME is suitable for the preparation of relatively diluted emulsions with the disperse phase content up to 20 vol. $\%$. The process enables emulsions very narrow droplet size distributions to be produced over a wide range of mean droplet sizes. In the case of SPG membranes with a mean pore sizes between 0.1 and $20 \mu \mathrm{m}$, the mean droplet size of both $\mathrm{O} / \mathrm{W}$ and $\mathrm{W} / \mathrm{O}$ emulsions can range from less than $1 \mu \mathrm{m}$ to over $60 \mu \mathrm{m}$, with the relative span factors under optimal conditions of typically 0.26-0.45 (Nakashima et al., 1993; Shimizu et al., 2002b,c; Vladisavljević and Schubert, 2002b,2003b). For ceramic membranes the droplet size range can be $0.2 \sim 100 \mu \mathrm{m}$ with a range of spans (Williams, 2002). 
Suzuki et al. (1996) implemented 'premix' ME, in which a preliminarily emulsified coarse emulsion (rather than a single pure disperse phase) is forced through the membrane (Fig. 3 (b)) and the small droplets are formed by reducing the size of the large droplets in pre-existing emulsions. This is achieved by gently mixing the two immiscible liquids using a conventional stirrer mixer and then passing this preliminarily emulsified emulsion through the membrane under the pressure difference of typically less than 10 bars, which is much lower than in highpressure homogenisers (typically several hundred bars). Recently, Jing et al. (2005) used the direct ME under jetting flow conditions to prepare a coarse $\mathrm{O} / \mathrm{W}$ emulsion. In the second stage, this coarse emulsion was dispersed through the ceramic $\alpha-\mathrm{Al}_{2} \mathrm{O}_{3}$ membrane into stirring continuous phase to obtain a monodisperse emulsion.

When disperse phase of the coarse emulsion wets the membrane wall and suitable surfactants are dissolved in both immiscible phases, the process may result in a phase inversion, i.e. a coarse $\mathrm{O} / \mathrm{W}$ emulsion may be inverted into a fine W/O emulsion (Fig. 3 (c)) and vice versa (Suzuki et al., 1999). The main advantage of this method is that a fine emulsion can easily be prepared from a low concentration coarse emulsion at high rates. For polytetrafluoroethylene (PTFE) membrane filters with a pore size of $1 \mu \mathrm{m}$, the maximum dispersed phase volume fraction in the phase-inverted emulsions was 0.9 and 0.84 for $\mathrm{O} / \mathrm{W}$ and $\mathrm{W} / \mathrm{O}$ emulsions, respectively (Suzuki et al., 1999). Flow-induced phase-inversion (FIPI) phenomenon was observed earlier by Akay (1998) using a multiple expansion-contraction static mixer (MECSM). Hino et al. (2000) and Kawashima et al. (1991) inverted a W/O/W emulsion consisting of liquid paraffin, Span 80 (a hydrophobic surfactant) and Tween 20 (a hydrophilic surfactant) into a $\mathrm{W} / \mathrm{O}$ emulsion by extrusion the multiple emulsion through polycarbonate membranes with a mean pore size of 3 and $8 \mu \mathrm{m}$. Inside the membrane pores, surfactant 
molecules are oriented with their hydrophobic groups toward the hydrophobic wall surface and with hydrophilic groups toward the solubilised water molecules As a result, a lamellar structure is formed inside the pores, which is ruptured at the pore outlets followed by the creation of reversed micelles, as shown in Fig. 6. This W/O emulsion can be redispersed into an aqueous solution of Tween 20 to form a redispersed $\mathrm{W} / \mathrm{O} / \mathrm{W}$ emulsion containing more uniform internal droplets than the original $\mathrm{W} / \mathrm{O} / \mathrm{W}$ emulsion.

Premix ME holds several advantages over 'direct' ME: the optimal transmembrane fluxes with regard to droplet size uniformity are typically above $1 \mathrm{~m}^{3} \mathrm{~m}^{-2} \mathrm{~h}^{-1}$, which is $1-2$ orders of magnitude higher than in direct ME; the mean droplet sizes that can be achieved using the same membrane and emulsion formulation are smaller than in direct ME, which can be advantageous; the experimental set-up is generally simpler than in direct ME, e.g. no moving parts such as cross-flow pump or stirrer are needed, except for the preparation of preemulsion, and finally; the premix ME process is easier to control and operate than direct ME, since the driving pressure and emulsifier properties are not so critical for the successful operation as in the direct ME process.

In the first premix ME experiments (Suzuki et al., 1996) a cross-flow system was used, in which coarse emulsion was diluted by permeation into a pure continuous phase/diluted emulsion recirculating at the low-pressure side of the membrane. In the majority of the subsequent investigations (Table 3), a dead-end system was used, in which a fine emulsion was withdrawn as a product after passing through the membrane, without any recirculation and/or dilution with the continuous phase. It enables fast preparation of emulsions with a dispersed phase content of 50 vol. \% or more (Vladisavljević et al., 2004b). 
One of the disadvantages of premix ME is a higher droplet polydispersity compared to direct ME. In order to combine the advantages of both techniques, i.e. high throughput of the premix process and a tight particle size distribution of direct ME, a multi-pass (repeated) premix ME can be applied (Altenbach-Rehm et al., 2002a,b; Park et al., 2001; Yafei et al., 2006; Vladisavljević et al., 2004b,2006a,b). In this process, a fine emulsion is repeatedly passed through the same membrane several times to achieve additional droplet size reduction and enhance droplet size uniformity. The repeated membrane homogenisation was originally developed for the production of multilamellar lipid vesicles (liposomes) using track-etch polycarbonate filters (Walde and Ichikawa, 2001). In this process, the coarse liposome suspension is passed under moderate pressure repetitively, usually 10 times, through the filters with progressively smaller pore sizes which leads to a gradual break up of the large vesicles into smaller ones.

\section{SINGLE EMULSION PRODUCTION USING MEMBRANES}

The most commonly used membranes for cross membrane emulsification (XME) are SPG and sintered ceramic alumina membranes. As shown in Fig. 7, SPG membrane contains uniform tortuous intreconnected pores with a mean pore tortuosity of about 1.3 and the wall porosity ranging from 50 to $60 \%$. It can be fabricated with the mean pore sizes in a wide interval between 0.1 and $20 \mu \mathrm{m}$ and it can easily be rendered hydrophobic by coating with a silicone resin (Vladisavljević et al., 2005). It was shown that the hydrophobic treatment of SPG membrane with silicone resin was not followed by the pore plugging, even in the submicron range of mean pore sizes (Vladisavljević et al., 2005). However care does has to be taken in this silinisation process to avoid blockages. 
The adequate choice of emulsifiers is of primary importance for the success of ME. A chosen emulsifier should rapidly adsorb to the newly formed oil-water interface to reduce the interfacial tension to an optimum level. However, the emulsifier molecules should not adsorb to the membrane surface by electrostatic interactions, because it can cause the alteration of membrane polarity from hydrophilic to hydrophobic and pore blocking. The effect of dynamic interfacial tension of emulsifiers on direct ME has been investigated by several authors (Schröder et al., 1998; Van der Graaf et al., 2004; Rayner et al., 2005). As a rule, the faster the emulsifier molecules adsorb at newly formed interfaces, the smaller the mean droplet size of the resultant emulsion. The effect of emulsifier charge on droplet formation in direct ME has been investigated by Nakashima et al. (1993) for SPG membranes and by Kobayashi et al. (2003a) for silicon microchannels. They have concluded that functional groups of the chosen emulsifiers must not carry the charge opposite to that of the membrane surface in order to avoid electrostatic attractions between the emulsifier molecules and the membrane wall. For an example, an untreated SPG membrane has a negative surface potential of -15 to $-35 \mathrm{mV}$ within a $\mathrm{pH}$ range of 2 to 8 , due to the dissociation of acid silanol groups $\left(\mathrm{Si}-\mathrm{OH} \leftrightarrows \mathrm{SiO}^{-}+\mathrm{H}^{+}\right)$. Hence, for this case, the use of cationic emulsifiers such as alkylsubstituted quaternary ammonium salts must be avoided and the same conclusion is valid for silicon microchips.

The minimum transmembrane pressure for driving the dispersed phase through the pores (the capillary pressure) is given by the Laplace equation: $p_{\text {cap }}=4 \gamma \cos \theta / d_{p}$, where $\gamma$ is the equilibrium interfacial tension between the continuous and dispersed phase, $d_{p}$ is the mean pore size, and $\theta$ is the contact angle between the dispersed phase and the membrane surface. The optimal ratio of transmembrane to capillary pressure $\left(\Delta \mathrm{p}_{\mathrm{tm}} / \mathrm{p}_{\text {cap }}\right)$ for the generation of uniform droplets in XME using SPG membranes ranges from 2 to 6 (Vladisavljević et al., 
2004a), depending on the shear stress. The higher the wall shear stress, the higher the $\Delta \mathrm{p}_{\mathrm{tm}}$ value that can be applied. The wall shear stress, $\sigma_{\mathrm{w}}$, is related to the mean velocity of the continuous phase inside the membrane tube, $v_{t}$, with the equation: $\sigma_{w}=\lambda\left(\rho_{c} v_{t}^{2} / 8\right)$, where $\rho_{c}$ is the continuous phase density and $\lambda$ is the Moody friction factor. In the special case of laminar flow inside the membrane tube $\left(\operatorname{Re}_{t}<2300\right), \lambda=64 / \operatorname{Re}_{t}$ and $\sigma_{w}=8 \eta_{c} V_{t} / d_{i}$, where $d_{i}$ is the inner diameter of membrane tube and $\eta_{c}$ is the continuous phase viscosity. The optimal wall shear stress in XME using SPG and ceramic membranes usually ranges between 10 and $40 \mathrm{~Pa}$. The influence of various process parameters on droplet generation in ME was reviewed by several authors (Joscelyne and Trägårdh, 2000; Charcosset et al., 2004; Lambrich and Vladisavljević, 2004; Gijsbertsen-Abrahamse et al., 2004).

\section{SINGLE EMULSION PRODUCTION USING MICROFLUIDIC DEVICES}

Many attempts have recently been made to develop microfluidic devices for generation of uniform droplets (Atencia, 2005). These microfluidic devices are based on T-junction designs (Thorsen et al., 2001; Link et al., 2004; Yi et al., 2003; Tice et al., 2004; He et al., 2005; Van der Graaf et al., 2005b; Dendukuri et al., 2005), flow focusing designs (Garstecki et al., 2005; Tan et al., 2006; Davidson et al., 2005; Lewis et al., 2005; Anna et al., 2003 ; Xu and Nakajima, 2004), and parallel microchannel arrays (Kawakatsu et al., 1997; Sugiura et al., 2002b; Sugiura et al., 2004b). Applications have emerged that can take advantage of precision generation of droplets. These applications range from capillary electrophoresis (Kameoka et al., 2001) and immunoassays (Hatch et al., 2001) to cellomics (Andersson and van den Berg, 2003), proteomics (Figeys and Pinto, 2001), and DNA analysis (McClain et al., 2001), to mention just few examples. The simplest microfluidic device for producing and manipulating droplets is the 'T-junction' (Fig. 8(a)): the T-shaped channel geometry forces two flows of 
immiscible liquids to merge in such a way that one liquid forms droplets dispersed in the other. The droplet-forming phase should not wet the channel walls at the junction, for example hydrophobic T-junctions are needed to generate water droplets. The use of two Tjunctions in series with alternating surface wettabilities produces monodisperse multiple emulsions in a single device (Okushima et al., 2004; Nisisako et al., 2005) (see Section 6). When reversing the flow direction, T-junctions with differently sized exit channels will passively sort droplets according to size (Tan et al., 2004) or break large droplets into smaller ones with controlled sizes (Link et al., 2004) (Fig. 8(b)). Droplets can also be generated using a microfluidic extension of Rayleigh's approach (Rayleigh, 1879), with two streams of one liquid flanking a stream of a second immiscible liquid and the combined two-phase flow is then forced through a small orifice (Fig. 8(c)) (Garstecki et al., 2005). The pressure and viscous forces exerted by the outer fluid ultimately force the inner fluid to break into droplets, either in or just downstream of the orifice. The use of two sheath-flow junctions in series allows double emulsions or gas-in-oil-in-water dispersions to be produced, e.g. microbubbles stabilized with a thin oil shell and dispersed in an outer water phase for drug and gene delivery applications (Xu, 2006). The 'Y-junction' is a microfluidic device convenient for insitu mixing two fluid streams of different compositions (fluids 1 and 2 in Fig. 6(d)), for example mixing of two differently coloured monomer solutions in the production of bichromal particles for 'electronic paper' (Nisisako et al., 2004). The fabrication of a planar microchannel system uses simple soft lithography, making it straightforward to adjust the geometry of the microchannel design to ensure selective generation of droplets over a range of different sizes.

In addition to soft microfluidic devices fabricated in elastomeric materials by soft lithography (Whitesides and Stroock, 1997), microfluidic devices can be fabricated in silicon (Kawakatsu 
et al., 1997), stainless steel (Tong et al., 2001), quartz glass, and glassy polymers such as poly(methyl methacrylate) (PMMA) by photolithography, etching or micromachining. Using photolithography and anisotropic wet-etching processing, parallel arrays of microgrooves were fabricated in a single-crystal silicon substrate (Fig. 9(a) and 9(b)) and microchannels (MCs) were formed by tightly covering the MC plate containing microgrooves with a glass plate. The first MC plate for droplet generation was fabricated with a MC width of $6 \mu \mathrm{m}$ and with a terrace region (Kawakatsu et al., 1997). Other MC types without terrace (Sugiura et al., 2000), with partition walls between MCs (Fig. 9(b)) (Nakagawa et al., 2004; Sugiura et al., 2001), and with different MC widths (1-100 $\mu \mathrm{m})$ were developed in Nakajima Lab and fabricated by EP. Tech Co., Ltd., Hitachi, Japan. Using deep ion etching (RIE), new 'throughtype' MCs vertical to the plate surface and similar to microengineered membrane were developed in 2000 (Kobayashi et al., 2002a; Kobayashi et al., 2003a; Kobayashi et al., 2005a) (Fig. 7 (c)). The primary problem in straight-through MC emulsification is the generation of uniform droplets when the dispersed phase viscosity is less than $1 \mathrm{mPa}$. To overcome this problem, an array of 'asymmetric' through holes fabricated on a silicon plate have recently been developed (Kobayashi et al., 2005b, Vladisavljević et al., 2007). As shown in Fig. 7 (d), each asymmetric MC is composed of a rectangular microslot at the top side of the plate and a circular channel at the bottom side.

MC emulsification exploits the interfacial tension as the driving force for droplet formation. During droplet formation the dispersed phase is forced to take a nonspherical (disk-like) shape at the terrace or microslots. This disk-like shape has a higher interfacial area than a spherical shape, resulting in an instability from the interfacial free energy point of view. As a result, the dispersed phase spontaneously breaks down into spherical droplets. The droplet formation behaviour drastically changes above the critical flow velocity, due to a transition 
from dripping to continuous flow regime and the critical flow rate can be predicted from the critical capillary number (Sugiura et al., 2002a).

Microfluidic devices can generate highly uniform droplets with a degree of monodispersity in the dropping regime of less than $3 \%$. Although the frequency of droplet generation can be as high as $12,000 \mathrm{~Hz}$ for water-in-oil droplets (Yobas et al., 2006), the throughput in terms of volume flow rate of the disperse phase is very low because the droplets are formed from a single microchannel. Microchannel array devices are more convenient for larger-scale applications, because in these devices, the droplets are simultaneously formed from hundreds or even hundreds of thousands of microchannels (Kobayashi et al., 2005a).

\section{PRODUCTION OF MULTIPLE EMULSIONS USING MEMBRANE AND MICROCHANNEL ARRAY DEVICES}

A double (multiple or complex) emulsion is an emulsion in an emulsion (McClements, 2004; Garti, 1997). Two main types of double emulsions can be distinguished: water-in-oil-in-water $(\mathrm{W} / \mathrm{O} / \mathrm{W})$ and oil-in-water-in-oil $(\mathrm{O} / \mathrm{W} / \mathrm{O})$. A W/O/W emulsion consists of water droplets dispersed within larger oil droplets, which are themselves dispersed in an aqueous continuous phase. In an $\mathrm{O} / \mathrm{W} / \mathrm{O}$ emulsion, larger water droplets enclosing smaller oil droplets are dispersed in a continuous oil phase. W/O/W emulsions are more common than $\mathrm{O} / \mathrm{W} / \mathrm{O}$ emulsions. Other types of double emulsions such as oil-in-water-in-water (Kim et al., 2006) and ethanol-in-oil-in-water (Nakajima et al., 2003), have also been formulated and investigated.

5.1. Production of water-in-oil-in-water emulsions 
$\mathrm{W} / \mathrm{O} / \mathrm{W}$ emulsions are usually prepared in a two-step emulsification process (Garti, 1997) using two surfactants; a hydrophobic one with a high HLB (Hydrophile-Lipophile Balance) value to stabilize the internal droplets and a hydrophilic one to stabilize the external interface of the oil globules. A primary W/O emulsion is prepared under high-shear conditions to obtain very small droplets, while the secondary emulsification step is carried out with less shear to avoid rupture of the oil membrane between the two water phases. In conventional emulsification devices such as rotor-stator and high-pressure homogenisation devices high shear stresses are needed to decrease the droplet size of the coarse emulsion. However, external flow (shear) causes internal streaming in the droplets, which increases the frequency of collision (and thus coalescence) of internal droplets with the outer water phase (Van der Graaf et al., 2005a). Besides, elongation of the droplets increases the interface available for release of internal droplets. Therefore, the release rate of internal droplets increases with increasing the applied shear stress and only moderate shear can be used for the production of double emulsions if a reasonable percentage of internal phase is required. This is the reason why double emulsions manufactured using conventional emulsification processes are in general polydisperse.

$\mathrm{W} / \mathrm{O} / \mathrm{W}$ emulsions can be made by passing a W/O emulsion through a hydrophilic membrane or through microchannel arrays (Fig. 10). These techniques produce droplets with much less shear so that the droplets are intact and both a high entrapment efficiency and monodispersity can be achieved (Gladman and Williams, 2003). In addition, the size of external droplets can be precisely controlled by the mean pore size (Table 4) or the size and geometry of MCs (Table 5). This form of manufacture is inherently scalable, since throughputs are proportional to the membrane or MC plate surface area (Gladman, 2003). Consequently, products that have 
been formed in this way lend themselves to scale-up, and also deliver the target quality whilst minimising material wastage (e.g. associated with off-specification batches).

Mine at al. (1996) produced multiple emulsions by XME using SPG membranes. First, a W/O emulsion with the mean droplet size of $0.52 \mu \mathrm{m}$ was prepared using a Microfluidizer. This W/O emulsion was then dispersed into the outer aqueous phase through SPG membrane with the mean pore size of $1 \mu \mathrm{m}$ and a $\mathrm{W} / \mathrm{O} / \mathrm{W}$ emulsion with the mean pore size of $4.8 \mu \mathrm{m}$ was formed. This emulsion was stable for at least 6 weeks when stored at $5^{\circ} \mathrm{C}$. The concentration of internal water droplets should be between 30 and $50 \%$ in order to obtain a stable multiple emulsion and the membrane pore size must be no less than twice the diameter of the internal droplets. W/O/W emulsions are particularly important to the pharmaceutical industry to initiate contained and targeted drug delivery (Higashi and Setoguchi, 2000). Higashi et al. (1999, 1995) prepared W/O/W emulsions for hepatic arterial chemotherapy using SPG membrane (Fig. 11). A submicron W/O emulsion was first prepared using sonication. The water phase contained an anticancer drug (epirubicin), and the oil phase was made up of an iodised poppy seed oil (Lipiodol) with polyoxyethylene (40) hydrogenated caster oil being used as the hydrophobic surfactant. This was then followed by further emulsification through hydrophilic SPG membrane with a mean pore size of $20 \mu \mathrm{m}$ using the $\mathrm{W} / \mathrm{O}$ emulsion as the dispersed phase. Clinical trials showed that this multiple drug emulsion, when administered directly into the liver via the hepatic artery, was effective in contracting the liver cancer texture. It was concluded that ME enabled the production of a controlled release vehicle at the much higher encapsulation efficiency in comparison with other traditional methods.

Vladisavljević et al. (2004b, 2006) prepared uniform W/O/W emulsions for controlled delivery systems by repeated SPG homogenisation. A coarse W/O/W emulsion was passed 5 
times through SPG membrane with a mean pore size of 5.4-20.3 $\mu \mathrm{m}$ using the homogeniser shown in Fig. 12. The encapsulation efficiency of a marker substance $\left(\mathrm{CaNa}_{2}\right.$-EDTA) in freshly prepared samples after 5 passes was $83-84 \%$ at the transmembrane fluxes exceeding $200 \mathrm{~m}^{3} \mathrm{~m}^{-2} \mathrm{~h}^{-2}$. Under optimal conditions the span of the particle size distribution of external droplets in the product emulsions was as low as 0.28 .

To produce a stable multiple emulsion it is usually necessary to ensure that the $\mathrm{W} / \mathrm{O}$ emulsion from which it is prepared is also stable. The incorporation of a thickening or gelling polymer (e.g., xanthan, alginate, gelatine, agarose, bovine serum albumin, sodium caseinate) within the dispersed aqueous phase of the primary emulsion has been proposed as a way of improving the long-term stability of W/O emulsions, especially if the added polymer forms a network throughout the internal water droplet or a gel-like layer at the inner oil-water interface either by cross-linking with enzyme or calcium ions or by thermal processing. This technique offers the possibility of improving water droplet resistance to mechanically induced stresses during homogenisation, as well as to droplet coalescence after homogenisation. In addition, it also offers the possibility of creating novel encapsulation systems with adjustable release properties. Surh et al. (2007) have incorporated whey protein isolate (WPI) into the water phase of primary $\mathrm{W} / \mathrm{O}$ emulsions to form gelled particles at $80{ }^{\circ} \mathrm{C}$ and then used these $\mathrm{W} / \mathrm{O}$ emulsions to form $\mathrm{W} / \mathrm{O} / \mathrm{W}$ emulsions (Fig. 13). The W/O emulsions and aqueous surfactant solution were first premixed using a stirring bar followed by five passes through a membrane homogenizer at $100 \mathrm{kPa}$. The internal water droplets in the $\mathrm{W} / \mathrm{O} / \mathrm{W}$ emulsions were highly stable to expulsion during homogenization and their yield was $98.3 \%$.

Multiple emulsions can also be produced using a silicon microchip in much the same way as that done using a porous membrane. Kawakatsu et al. (2001) and Sugiura et al. (2004a) 
investigated production of W/O/W emulsions using grooved-type MC plates. Monodisperse oil droplets with a CV of 5-8\% were prepared using 5 wt. \% TGPR dissolved in decane, MCT oil or ethyl oleate as an oil phase (Sugiura et al., 2004a). When triolein was used, larger droplets with a CV of $19 \%$ were formed. Internal droplets larger than the resultant $\mathrm{W} / \mathrm{O} / \mathrm{W}$ droplets also penetrated through the channels and were divided into several smaller droplets without disrupting the thin oil film. For decane, ethyl oleate, and MCT oil, internal water droplets larger than the resultant external droplets were divided into almost the same size as the external droplets and the oil phase formed a thin layer between the two aqueous phases. For MCT and triolein, internal droplets larger than the resulting $\mathrm{W} / \mathrm{O} / \mathrm{W}$ droplet were divided into several smaller droplets. The yield was measured fluorometrically using calcein solution, and estimated to be $91 \%$. Monodisperse W/O/W emulsions were also prepared using straightthrough MC emulsification (Kobayashi et al., 2005c). Fig. 14 shows W/O/W emulsions with various volume fractions of internal droplets prepared using TGCR as a hydrophobic emulsifier. The mean size of external droplets ranged from $44 \mu \mathrm{m}$ for pure oil phase (Fig. 14 (a)) to $41-39 \mu \mathrm{m}$ for oil phase containing respectively 10 and 30 vol. $\%$ of internal droplets (Figs. 14 (b-d)). The decrease in mean droplet size with an increase in the volume fraction of water phase was explained by an increase in the dispersed phase viscosity. The main advantage of using straight-through MC plates is a higher production rate of emulsion in comparison with grooved-type plates.

\subsection{Production of solid-in-oil-in-water dispersions}

In a solid-in-oil-in-water dispersion, oil droplets enclosing solid micro- or nanoparticles are dispersed in a continuous aqueous phase. Toorisaka et al. (2003) prepared a S/O/W dispersion for oral administration of insulin by passing a preliminary emulsified $\mathrm{S} / \mathrm{O} / \mathrm{W}$ dispersion 
several times (usually 3 ) through SPG membrane with a mean pore size of $1.1 \mu \mathrm{m}$. The S/O suspension containing surfactant-coated insulin dispersed in soybean oil was first mixed with the aqueous solution containing a hydrophilic surfactant (sugar ester L-1695), sodium cholate and d-glucose to prepare a coarse $\mathrm{S} / \mathrm{O} / \mathrm{W}$ dispersion. This coarse $\mathrm{S} / \mathrm{O} / \mathrm{W}$ dispersion was then homogenised by passing through the SPG membrane to prepare a fine dispersion with the mean droplet size of $1.0 \mu \mathrm{m}$. The surfactant-coated insulin was prepared by mixing an aqueous solution of insulin with a hexane solution containing ER-290 (sugar ester) as a hydrophobic surfactant, followed by freeze-drying. After oral administration to rats, the $\mathrm{S} / \mathrm{O} / \mathrm{W}$ dispersion showed the hypoglycemic activity for a long period, owing to the conversion of insulin into a lipophilic complex and uniform droplets of S/O suspension.

Supsakulchai et al. (2002) incorporated titanium dioxide into polymer microparticles using SPG membrane emulsification followed by solvent evaporation. As a white pigment, $\mathrm{TiO}_{2}$ is widely used for its efficiency in scattering visible light, and imparting whiteness, brightness, and high opacity when incorporated into a plastic formulation. First, a S/O/W dispersion was prepared by extruding the S/O suspension containing fine particles of anatase-type titanium dioxide in a poly(St-co-AA)-toluene solution through SPG membrane into an aqueous phase containing PVA and SDS. The polymer microcapsules containing 10-20 wt. $\%$ of $\mathrm{TiO}_{2}$ were prepared from the $\mathrm{S} / \mathrm{O} / \mathrm{W}$ dispersion by vacuum evaporation of toluene.

\section{PRODUCTION OF MULTIPLE EMULSIONS USING MICROFLUIDIC T-JUNCTIONS} AND FLOW FOCUSING DEVICES

Microfluidic devices can generate double emulsions in a single step, allowing precision control of the outer and inner drop sizes as well as the number of droplets encapsulated in 
each larger drop. Some examples of successful formulations used for manufacturing double emulsions in microfluidic devices are listed in Table 6. Okushima et al. (2004) reported a method for preparing monodisperse double emulsions using T-junctions in series with opposite surface wettabilities and different sizes (Fig. 15(a)). The smaller upstream junction was designated for the generation of internal droplets and the larger one for external droplets. Each junction can be hydrophobised with a silane-coupling agent. In the production of W/O/W emulsions (Fig. 15(a)), aqueous drops of uniform size $\left(\mathrm{d}_{\mathrm{iw}}=52 \mu \mathrm{m}, \mathrm{CV}=2.7 \%\right.$ ) were formed at the hydrophobic junction $(60 \mu \mathrm{m}$ width $\times 25 \mu \mathrm{m}$ depth $)$ and were then carried to the second hydrophilic junction $(130 \mu \mathrm{m}$ width $\times 65 \mu \mathrm{m}$ depth $)$, while maintaining a uniform distance from each other. Each aqueous drop was then enclosed in an organic drop $\left(\mathrm{d}_{\mathrm{o}}=83 \mu \mathrm{m}, \mathrm{CV}=2.8 \%\right)$ at the downstream junction. The breakup rates at both junctions were $22 \mathrm{drops} / \mathrm{s}$, and the entrapment efficiency was $100 \%$. For successful encapsulation of inner drops, the operating conditions satisfying the following equation are desirable: $R_{1} / R_{2}=$ $\mathrm{N}$, where $\mathrm{R}_{1}$ is the breakup rate at the first junction, $\mathrm{R}_{2}$ is the breakup rate at the second junction, and $\mathrm{N}$ is a positive integer $(1,2, \ldots)$. By adjusting the ratio between the breakup rates at the two junctions, the number of enclosed drops can be controlled. With an increase in the oil flow rate for given flow rates of inner and outer aqueous phase, the size of the aqueous drops sheared at the first junction decreases. Since the volume flow rate of the inner aqueous phase was fixed, this reduction implies an increase in the breakup rate at the first junction, increasing the average number of inner aqueous drops per outer drop.

Using microfluidic device shown in Fig. 15, various double emulsions can be produced by changing the wetting and geometrical properties of the junctions. $\mathrm{O} / \mathrm{W} / \mathrm{O}$ emulsions can be generated by arranging the upstream junction to be hydrophilic and the downstream junction to be hydrophobic (Fig. 16 (c) and 16 (d)). O/W/O emulsions may find uses as precursors for 
the fabrication of uniform three-dimensional colloidal assemblies packed in aqueous droplets (Yi et al., 2003). Furthermore, an interesting double emulsion, in which two differently coloured (blue or red) aqueous drops were enclosed in a larger oil droplet, was prepared by using a cross-junction as the upstream junction (Figures 15 (b) and 16 (b)). Red drops and blue drops of similar size were alternately and periodically formed at the cross-junction (Fig. 15 (b)); they were then carried to the downstream T-junction to be jointly encapsulated in oil droplets. This indicates that multiple components can be confined as discrete vesicles within pico/nanoliter-sized drops.

Utada et al. (2005) fabricated a microfluidic device with glass microcapillaries to prepare triple emulsions of W/O/W/O type, such as water/silicon oil/water/silicon oil emulsion and water/ toluene/water/ silicon oil emulsion. The device consists of two concentric tapered tubes nested within an outer square tube, as shown in Figs. 17 (a). The innermost fluid is pumped through the inner injection tube, the middle fluid 2 is pumped through the outer injection tube, and the middle fluid 1 through the square tube outside the injection tubes. The outermost fluid is pumped through the square tube from the opposite direction, and all fluids are forced through the exit orifice formed at the entrance of the 'collection tube'. This geometry results in hydrodynamic focusing and rupture of three coaxial jets, followed by the formation of a triple emulsion drops. The volume of each phase can be tuned by changing the fluid flow rates. Typical diameters of the exit orifice range from 20 to $200 \mu \mathrm{m}$, which allows the drop size to be adjusted over a wide range. Triple emulsion can be used as a template to core-shell capsules consisting of two different shell layers. The idea is putting two different types of molecules, for example, a surfactant or a lipid in each of the intermediate (middle) phases and evaporates them. The final product can be an asymmetric vesicle shown in Fig. 1. 
The microfluidic FFD shown in Fig. 17 (b) generates double emulsions in a single step. The inner fluid is pumped through the injection tube, and the middle fluid is pumped through the square tube in the same direction. The outer fluid is pumped through the square tube from the opposite direction, and all fluids are forced through the orifice at the entrance of the collection tube. The flow passes through the exit orifice and subsequently ruptures to form drops. At low outer flow rates, double emulsion drops are formed within one orifice diameter of the entrance through the dripping mechanism; by contrast at higher flow rates, the neck is stretched into a coaxial thread that breaks further downstream through the jetting mechanism. Drops formed in the dripping regime have a lower polydispersity, generally less than $3 \%$ (Lorenceau et al., 2005). The number of small aqueous droplets contained within the larger oil drops depends on the relative frequency of drop formation for the innermost and middle fluids. If the innermost fluid breaks into droplets more rapidly than the middle fluid, large oil drops that contain many small aqueous droplets are obtained. However, if the rate of drop formation is the same, double emulsions with a single inner droplet are formed. The ratio of shell thickness to outer drop radius in these drop-in-drop emulsions can range from 3 to $40 \%$ (Utada et al., 2005).

Fig. 17 (c) shows a FFD that does not have an injection tube and the outer fluid simply focuses the inner fluid; the fluid thread breaks into drops inside the collection tube. The frequency of drop production in the dripping regime can range from 100 to $7000 \mathrm{~Hz}$, which enables formation of up to about $10^{7}$ emulsion drops per hour (Utada et al., 2005).

\section{PRODUCTION OF SOLID MICROPARTICLES FROM EMULSION DROPLETS GENERATED USING MEMBRANE AND MICROFLUIDIC DEVICES}


Vladisavljević and Williams (2005) reviewed the expanding opportunities for the production of particulate products using membranes, with a broad range of possible applications to the pharmaceutical, chemical, electronic, and food industry. Williams (2001a) listed some of the engineering and technological challenges which could be facing researchers in manufacturing 'designer particles' in large quantities. The route to success lies in applying knowledge of the fundamental principles of the process and in the formation of multiskilled teams who can address the various aspects of molecular assembly, modelling and process design (Williams, 2001a).

\subsection{Production of solid lipid microcarriers (lipospheres)}

Solid lipid nano- and micro-particles represent an alternative drug and nutrient delivery system to traditional drug carriers, such as emulsions, liposomes and polymeric microparticles (Müller et al., 2000, Jaspart et al., 2005). Solid lipid microcarriers for lipophilic drugs are prepared using solvent evaporation method and $\mathrm{O} / \mathrm{W}$ melt dispersion method, whereas solid lipid microcarriers for hydrophilic drugs are usually prepared using $\mathrm{W} / \mathrm{O} / \mathrm{W}$ double emulsion technique. Nakashima (2002) reported manufacture of solid lipid microcarriers through double emulsion routes using SPG membrane homogenisation. These carriers were investigated for oral administration of irinotecan hydrochloride (CPT-11), which is a highly effective anticancer drug with some unfavourable side effects. A preparation flow sheet is shown in Fig. 18. A submicron W/O emulsion containing at least $50 \mathrm{mg} \mathrm{L}^{-1}$ of CPT-11 dissolved in aqueous phase as a dispersed phase and $10 \mathrm{wt}$ \% TGCR in tripalmitin as a continuous phase was prepared using a conventional rotor stator emulsification device. The emulsification was carried out at $80{ }^{\circ} \mathrm{C}$ and the melting point of tripalmitin (triglyceryl palmitate) is $66^{\circ} \mathrm{C}$. This was then followed by the dispersion of the hot $\mathrm{W} / \mathrm{O}$ emulsion in an 
external water phase at $80{ }^{\circ} \mathrm{C}$ by a stirrer. The coarse polydisperse $\mathrm{W} / \mathrm{O} / \mathrm{W}$ emulsion was homogenised at $80{ }^{\circ} \mathrm{C}$ by passing through SPG membrane with a mean pore size of $11 \mu \mathrm{m}$. The microcarrier was obtained by cooling the $\mathrm{W} / \mathrm{O} / \mathrm{W}$ emulsion to room temperature and the subsequent filtration of the hardened microparticles. As shown in Fig. 19, this microcarrier is composed of micropores containing CPT-11 that are embedded in a solid lipid matrix. The estimated entrapment efficiency of CPT-11 in the carrier was more than $90 \%$ under optimal conditions (Shimizu et al., 2002a).

A microcarrier for encapsulating hydrophilic flavour-enhancing ingredients such as 5'ribonucleotide in cacao butter was developed by Kukizaki et al. (2001). This microcarrier found applications in Japan as a miso paste supplement. W/O emulsion with a mean particle size of $0.48 \mu \mathrm{m}$ was produced at $40{ }^{\circ} \mathrm{C}$ using a rotor-stator homogeniser and the melting point of cacao butter is around $34{ }^{\circ} \mathrm{C}$. The W/O emulsion was then homogenised at $40{ }^{\circ} \mathrm{C}$ and 15 $\mathrm{kPa}$ through 4.8- $\mu \mathrm{m}$ SPG membrane into outer aqueous phase containing $0.5 \mathrm{wt} . \% \mathrm{HCO}-60$, 0.59 wt. $\% \mathrm{NaCl}$, and 0.95 wt.\% glucose. The osmotic pressure of both aqueous phases was 0.68 MPa. The solid carrier was produced by freeze drying of the solidified $\mathrm{W} / \mathrm{O} / \mathrm{W}$ emulsion. The leakage rate of a hydrophilic model substance $\left(\mathrm{CaNa}_{2}\right.$-EDTA) from the microcarrier redispersed in water at $20^{\circ} \mathrm{C}$ was $3 \%$ in 10 days.

Production of solid lipid microparticles by $\mathrm{MC}$ emulsification using $\mathrm{O} / \mathrm{W}$ melt dispersion technique was investigated by Sugiura et al. (2000). Tripalmitin or hydrogenated fish oil with a melting points of $58^{\circ} \mathrm{C}$ penetrated through MCs into an aqueous solution of emulsifier at 70 ${ }^{\circ} \mathrm{C}$ and an $\mathrm{O} / \mathrm{W}$ emulsion with an average droplet diameter of $21 \square \mathrm{m}$ and a $\mathrm{CV}$ of $4 \%$ was obtained. Solid lipid microspheres with the same size and monodispersity were formed by cooling and freeze-drying of the O/W emulsion. Kobayashi et al. (2003b) produced lipid 
microparticles by solvent evaporation method. In this work, an oil phase (0.1-1 vol. \% tripalmitin dissolved in hexane) was dispersed into the continuous water phase (1 wt. \% SDS or pentaglycerol monolaurate) by $\mathrm{MC}$ emulsification at room temperature. The average diameter of oil droplets was $10-11 \square \mathrm{m}$ and the CV was below $8 \%$. Solid lipid microspheres with an average diameter of 1-3 $\square \mathrm{m}$ and the $\mathrm{CV}$ of $20 \%$ were produced by evaporation of organic solvent under atmospheric pressure and room temperature for $24 \mathrm{~h}$. The volume ratio of oil droplets with respect to solid microspheres corresponded well to the volume ratio of the dispersed phase with respect to tripalmitin. It should be noted that solvent evaporation method enables to obtain much smaller, but less uniform lipid microspheres.

\subsection{Production of gel microbeads}

Alginate beads have been used extensively in microencapsulation because they are very easy to prepare on a lab-scale, the process is very mild and virtually any ingredient can be encapsulated (Gouin, 2004). However, as easy as it to make small batch using a syringe extruder and a stirred calcium bath, the scaling up of the process is very difficult and processing costs are stupendous. Weiss et al. (2004) have developed a process in which a Naalginate solution was extruded through a hydrophobic SPG membrane into MCT oil containing 2-5\% Span 80 to form a W/O emulsion. The resultant droplets were crosslinked by adding $3 \% \mathrm{CaCl}_{2}$ solution and the microbeads were collected by filtration. The process can easily be scaled up and allow formation of uniform microbeads with an adjustable mean size in the range of $20-300 \mu \mathrm{m}$, which is difficult to achieve using conventional alginate beads processes. Liu et al. (2003) produced Ca-alginate beads with a mean size of about $55 \mu \mathrm{m}$ and the $\mathrm{CV}$ of $27 \%$ using a nickel membrane with a mean pore size of $2.9 \mu \mathrm{m}$. A W/O emulsion containing $25 \mathrm{mMCaCO}$ in $0.5-2 \% \mathrm{w} / \mathrm{v}$ Na-alginate solution as a disperse phase and $1.5 \%$ 
v/v Span 80 in paraffin oil as a continuous phase was prepared using the Ni membrane, pretreated by soaking in paraffin oil for at least $8 \mathrm{~h}$. The gelation was initiated by the addition of glacial acetic acid into the emulsion, dissolving $\mathrm{CaCO}_{3}$ to release $\mathrm{Ca}^{2+}$. Iwamoto et al. (2002) produced gelatin microbeads with a mean size of about $32 \mu \mathrm{m}$ and the CV of $7.3 \%$ by MC emulsification. A W/O emulsion containing 5 wt. \% gelatin in water as a disperse phase and 5 wt. $\%$ TGCR in IO as a continuous phase was prepared at $40{ }^{\circ} \mathrm{C}$ using hydrophobic MCs pretreated with octadecyltrichlorosilane. The gelation was induced by decreasing temperature of the emulsion to $25{ }^{\circ} \mathrm{C}$. After a slow gelation at $25^{\circ} \mathrm{C}$ overnight, the solidification of droplets was completed at $5{ }^{\circ} \mathrm{C}$.

\subsection{Production of polymer microspheres}

Uniform polymer microspheres with the mean diameter ranging from several micrometers to $100 \mu \mathrm{m}$, hydrophilic and hydrophobic, smooth and rough, solid and hollow, porous and uniform, with different morphologies (spherical, snowman-like, popcorn-like, hemispherical) were manufactured from $\mathrm{O} / \mathrm{W}$ emulsions via SPG membrane emulsification followed by suspension polymerisation (Omi, 1996). These microspheres were investigated for use as packing material for column chromatography techniques such as gel permeation chromatography (GPC), high-performance liquid chromatography (HPLC), capillary electrochromatography and size-exclusion chromatography, $\mathrm{pH}$ sensors, carriers of enzymes (glucoamylase), drug delivery systems, dry and liquid toners, spacers for liquid crystal displays, etc. (Vladisavljević and Williams, 2005).

\subsubsection{One-stage (direct) suspension polymerisation}


In one-stage polymerisation process, an oil phase containing a monomer or a mixture of monomers, an initiator (BPO, AIBN or ADVN), and other potential additives (solvents, diluents, crosslinking agents, etc) permeates through the membrane into the aqueous solution of emulsifiers and stabilisers to form uniform oil droplets. An inhibitor such as $\mathrm{NaNO}_{2}, \mathrm{DAP}$ or HQ is dissolved in the aqueous phase to prevent the secondary nucleation of polymer particles in the aqueous phase. The $\mathrm{O} / \mathrm{W}$ emulsion is then transferred to a reactor and suspension polymerisation is carried out by heating the emulsion to above the decomposition temperature of the initiator under mild agitation and nitrogen bubbling. The initial narrow droplet size distribution can be maintained throughout the polymerization stage, if the polymerisation conditions are adequate. A broad range of polymer microspheres with the CV of about $10 \%$ were produced by this method using SPG membrane (Table 7). Although a further classification is needed to obtain particles with the CV value of $4 \%$, which is a minimum requirement for LCD spacers, the classification step is less complicated and cheaper than for microspheres with a broad size distribution prepared by a conventional suspension polymerisation.

The polymer beads can be made porous by the inclusion of crosslinking agents (DVB for PSt and EGDMA for PMMA) and adequate diluents (poor solvents for the base polymer constituting a network) in the oil phase. The diluents (alkanes, middle-chain alcohols, etc) stimulate a micro-phase separation during polymerisation, resulting in the formation of a porous structure. Trifunctional crosslinker TMPTMA can be included in the monomer phase to improve the compressive strength of the particles by increasing the crosslink density, so that the microspheres can be used as spacers for LCDs (Ma et al., 2003d). Acrylic acid can be added to incorporate carboxyl groups to immobilize enzymes, and GMA is used to introduce spacer arms (Omi et al., 1997). Colouring and charge control agents are incorporated in the 
monomer phase to prepare toner particles with the desirable colouring and triboelectric discharging properties (Hatate et al., 1997). $\mathrm{TiO}_{2}$ fine particles can be included to improve whiteness, brightness, and opacity of the microspheres (Supsakulchai et al., 2003).

Suspension polymerisation is also possible in $\mathrm{W} / \mathrm{O} / \mathrm{W}$ and $\mathrm{W} / \mathrm{O}$ emulsions. Ma et al. (2004) synthesised polystyrene/polyacrylamide (PSt-PAAm) composite microspheres from a W/O/W emulsion using SPG membrane emulsification and suspension polymerisation. An acrylamide aqueous solution was emulsified into the oil phase containing styrene, polystyrene, initiator and Span 85 by ultrasonification to obtain W/O emulsion. The W/O emulsion was then dispersed through SPG membrane into the outer aqueous phase to form uniformly-sized $\mathrm{W} / \mathrm{O} / \mathrm{W}$ emulsion. Polystyrene was added to increase the viscosity of oil phase, retarding the phase separation between inner water phase and oil phase during the emulsification process. After the $\mathrm{W} / \mathrm{O} / \mathrm{W}$ emulsion was polymerised, the composite particles containing spherical PAAm-rich microdomains distributed inside and on the surface of a PSt matrix were obtained. As amides can easily be hydrolyzed to carboxylic acids or degraded to amines, these PStPAAm particles are suitable for use as immobilization media of biologically active substances such as proteins and cells.

\subsubsection{Two-stage suspension polymerization (droplet swelling method)}

Strong hydrophilic nature of SPG membrane favours the formation of uniform microspheres from hydrophobic monomers, such as styrenic monomers. More hydrophilic acrylate monomers tend to form polydisperse droplets due to wetting of the SPG surface. Omi et al. (1995) have overcome this problem by adopting the Ugelstad and Mbrk's two-stage swelling technique (Ugelstad and Mbrk, 1980), in which primary hydrophobic droplets, mainly 
composed of benzene $(\mathrm{Bz})$ and hexadecane $(\mathrm{HD})$, were swollen in the presence of secondary emulsion droplets consisted of methyl methacrylate (MMA) and other more hydrophilic components. Subsequent polymerisation resulted in PMMA spheres with a similar degree of monodispersity as that of PSt spheres (Figure 20). Application of the swelling technique to hydrophobic monomers such as styrene and DVB resulted in larger P(St-co-DVB) spheres with the mean size ranging up to $102 \mu \mathrm{m}$ (Omi et al., 1997b). Here, the seed droplets were composed of DVB, HD, and an initiator, whereas the secondary emulsion droplets consisted of more hydrophilic components, a mixture of styrene, middle chain alcohol (C6 to C8), dichlorobenzene, and isoamyl acetate (IA). Table 8 lists investigations on using the swelling technique in combination with SPG emulsification to the preparation of polymer microspheres. The primary (seed) emulsion containing uniform droplets is prepared by SPG membrane emulsification, while the secondary emulsion containing much smaller and more polydisperse droplets is obtained by a conventional rotor-stator homogenization with a very small amount of emulsifiers (around $0.02 \mathrm{wt} . \%$ ) (Figure 20). Mixing these two emulsions causes absorption of the hydrophilic monomers from the secondary emulsion in the primary emulsion droplets due to the degradative diffusion mechanism. After all the droplets in the primary emulsion disappeared, the swollen droplets are polymerized in the same way as in a single-stage polymerization process. Despite the polydispersity of the secondary emulsion, the swollen droplets retain the uniformity of the primary emulsion, even when their volume has been increased up to several thousands times due to swelling (Omi et al., 1997b).

\subsubsection{Solvent evaporation method}

In solvent evaporation method, oil droplets are composed of a polymer solution in volatile organic solvent. After the uniform droplets are prepared by membrane emulsification, a single 
volatile solvent (methylene chloride, chloroform, toluene, etc) or their mixture is evaporated. This technique has been applied to manufacture polylactide (PLA) and poly(lactide-coglycolide) (PLGA) biodegradable microspheres, polystyrene-poly(methyl methacrylate) (PStPMMA) composite microspheres, and polymer microcapsules containing magnetite $\left(\mathrm{Fe}_{3} \mathrm{O}_{4}\right)$ or $\mathrm{TiO}_{2}$ (Table 9). Uniform polyurethaneurea (PUU) microparticles were prepared by solvent evaporation from PUU-xylene (X1) droplets after the PU prepolymer underwent a chainextending reaction at room temperature with a diamine reagent (piperazine) (Yuyama et al. (2000b).

In the production of PLA and PSt-PMMA microspheres, the preformed polymer (PLA or a mixture of PSt and PMMA) was dissolved in solvent (dichloromethane) containing lauryl alcohol (LOH) or HD as a cosurfactant. The role of cosurfactant was (1) to increase the hydrophobicity of the oil phase, thereby preventing the membrane wall from being wetted with the disperse phase; and (2) to prevent the oil phase from diffusing into the aqueous phase so that the integrity of droplets could be better maintained. LOH was found to be more efficient than HD in providing uniformly sized microspheres (Ma et al., 1999c).

Liu et al. (2005a,b) prepared biodegradable poly(lactide) (PLA) microcapsules by combining a SPG membrane emulsification technique and multiple emulsion-solvent evaporation method. An aqueous phase containing lysozyme or recombinant human insulin was used as the inner water phase, and a mixture of dichloromethane and toluene dissolving PLA and Arlacel 83 was used as the oil phase. These two solutions were emulsified by a conventional rotor-stator device to form a W/O primary emulsion. The primary emulsion was permeated through SPG membrane into the external water phase to form $\mathrm{W} / \mathrm{O} / \mathrm{W}$ droplets. The PLA microcapsules were obtained by evaporating the solvent. The drug encapsulation efficiency was found to 
depend on several factors including the molecular weight of PLA, additive type and content in the inner water phase, the emulsifier type and concentration in the oil phase and the formulation of the outer water phase.

\subsection{Production of core-shell microparticles}

Polymer microcapsules with liquid cores have applications in the encapsulation of drugs, cells, pesticides, perfumes, liquid inks, paints, and toners (Peyratout and Dähne, 2004). One of the major benefits of flow focusing microfluidic devices is the ability to continuously fabricate reproducible core-shell particles. Utada et al. (2005) fabricated core-shell capsules by UV curing a Norland Optical Adhesive (Norland Products, Cranbury, NJ) in the middle fluid of core-shell droplets shown in Fig. 17 (b). The adhesive was diluted by 30\% with acetone to decrease its viscosity. Once the core-shell droplets were generated, the shells were cured insitu by exposing the emulsion to ultraviolet (UV) irradiation for approximately $10 \mathrm{~s}$. Nie et al. (2005) have employed flow of three immiscible liquids in the microfluidic device shown in Fig. 21 to obtain a coaxial jet of silicon oil and monomer in a continuous aqueous phase. The controlled break-up of the coaxial liquid thread led to the production of monodipserse droplets with various morphologies. The resultant droplets were continuously photopolymerised in the wavy channel to generate spherical polymer capsules with controllable diameters and shell thicknesses. The polymerisation time was typically from 2 to 800 s. Conversion of monomer to polymer was close to $100 \%$. Following polymerisation the dimensions of the particles decreased by ca. 5-7\%, in comparison with the corresponding droplets. The productivity of the microfluidic reactor was from 200 to $1000 \mathrm{~s}^{-1}$. Particle polydispersity did not exceed $2.5 \%$, which was close to the polydispersity of the corresponding droplets. 


\subsection{Production of termoresponsive microcapsules}

Chu et al. $(2002,2003)$ produced termosensitive core-shell microcapsules with a porous PA membrane forming a shell and linear-grafted PNIPAAm chains in the membrane pores acting as thermoresponsive gates (Figure 2). An O/W emulsion containing TDS monomer dissolved in a mixture of organic solvents as a disperse phase and an aqueous solution of emulsifier (SDS or Tween 80) and stabiliser (PVA) as a continuous phase was prepared by SPG emulsification. A buffer solution containing EMA monomer was then added to the emulsion and core-shell microcapsules with a mean pore size of $4 \mu \mathrm{m}$ were formed by interfacial polymerisation. A plasma-graft pore-filling polymerisation was then used to graft linear PNIPAAm chains into the pores of the PA membrane. The prepared PNIPAAm-grafted monodisperse microcapsules with an average diameter of about $4 \mu \mathrm{m}$ exhibited reversible and reproducible thermoresponsive release characteristics. The release of both $\mathrm{NaCl}$ and vitamin B12 from the microcapsules was slow at $25{ }^{\circ} \mathrm{C}$ and fast at $40{ }^{\circ} \mathrm{C}$, which was due to the closed/open state of the grafted "gates".

Kim et al. (2007) have generated termoresponsive PNIPAAm hydrogel particles using FFMD shown in Fig. 17 (b) with an inner diameter of the end of the injection tube of $20 \mu \mathrm{m}$ and an inner diameter of the entrance of collection tube of $200 \mu \mathrm{m}$. Silicon oil was used as the outer, or continuous-phase liquid. The middle fluid was an aqueous solution that contained a monomer (NIPAAm), a crosslinker (BIS), a reaction accelerator (TMEDA), and two comonomers (METAC and ALA). The inner fluid was an aqueous solution containing the initiator (APS). After the pre-microgel drops had formed, uniform mixing of the middle and inner fluids occurred, followed by the cross-liking reaction at room temperature. Owing to the 
speed of the polymerization, surfactants were not needed to prevent coalescence of the premicrogel drops. When drops formed close to the entrance of the collection tube, the drop size was controlled by the ratio of the flow rates of the combined inner and middle fluids:

$\mathrm{Q}_{\text {sum }} / \mathrm{Q}_{\mathrm{OF}}=\pi \mathrm{R}_{\text {thread }}^{2} /\left(\pi \mathrm{R}_{\text {orifice }}^{2}-\pi \mathrm{R}_{\text {thread }}^{2}\right)$

where $\mathrm{Q}_{\text {sum }}$ is the sum of the of inner and middle fluid flow rates, $\mathrm{R}_{\text {thread }}$ is the radius of the fluid thread that breaks into drops, and $\mathrm{R}_{\text {orifice }}$ is the radius of the collection tube where the drops are formed. This equation is valid for plug-flow, which is a reasonable assumption for drop formation close to the entrance of the collection tube. For a viscosity ratio of $\eta_{\mathrm{MF}} / \eta_{\mathrm{OF}} \approx$ 0.1 , the drop diameter is approximately twice the diameter of the thread (Tomotika et al., 1935). Kim et al. (2007) have also generated a spherical microgel shell by using an oil as the inner fluid, which is immiscible with the aqueous middle fluid; these drops pinch-off to produce uniform double emulsions, where each aqueous pre-microgel drop contains a single oil droplet. In this case, the initiator is located in the middle fluid while the accelerator is dissolved in the inner oil. Upon forming the double-emulsion drops, the acclerator diffuses from the internal oil droplet into the surrounding aqueous monomer solution layer, initiating the polymerization. After collecting the microgel shell particles, the oil was extracted by washing with an excess of isopropyl alcohol. These PNIPAAm hydrogel particles and shells are able to dramatically shrink or swell by expelling or absorbing large amounts of water in response to temperature changes. This behaviour is of great importance for potential delivery applications, allowing unstable biomaterials, such as drugs and biomolecules, to be stored in the polymer network of the hydrogel particles or in the water-filled core of the microgel shells and be delivered upon swelling. The swelling increases with decreasing temperature, enabling the drug to diffuse through the swollen network into the external environment. The transition temperature of about $50^{\circ} \mathrm{C}$ was higher than that of most common PNIPAAm microgels, 
which was due to the presence of charged co-monomers (METAC) in the polymer network that contribute to the total osmotic pressure.

\subsection{Production of giant polymeric vesicles (polymerosomes)}

The use of diblock copolymers to generate polymer vesicles is an attractive strategy to create new structures for encapsulation. These structures are called polymerosomes, and like more traditional liposomes, they can encapsulate nano- to picoliter volumes of liquid. The low toxicity of certain diblock copolymers makes these structures promising for drug or enzyme delivery applications. The flexibility afforded by the use of diblock copolymers significantly increases the control over the properties of polymerosomes. For example, the membrane thickness can be controlled by varying the degree of polymerisation of the individual diblock molecules, whereas fluidity and permeability of the membrane can be adjusted by changing the glass transition temperature of the hydrophobic block. Similarly, control over the nature of the individual polymer blocks can lead to alternative mechanisms to trigger release. The advantage of polymerosomes over liposomes is a much reduced leakage rate of encapsulated small molecules, they are more robust and versatile and not easily deformable (Discher et al., 1999).

A microfluidic device depicted in Fig. 14 (b) was used to generate W/O/W emulsions with a diblock copolymer dissolved in the intermediate hydrophobic fluid (Lorenceau et al., 2005). The inner aqueous phase was distilled water, and the outer aqueous phase was a mixture of $80 \%(\mathrm{v} / \mathrm{v})$ glycerol and distilled water. Glycerol was added to the outer fluid to increase its viscosity, which improves the efficiency of the flow focusing. The intermediate phase is a volatile organic solvent; the evaporation of the organic solvent causes the amphiphilic block 
copolymer poly(normal-butyl acrylate)-poly(acrylic acid) (PBA-PAA) to self-assemble into layers on the concentric interfaces of the double emulsion droplets, forming a polymerosome. The PBA is the hydrophobic block in the copolymer molecule, whereas the PAA is the hydrophilic block. It is critical that the dissolved macromolecules are mostly unimers as opposed to larger aggregates because such aggregates do not efficiently stabilize the inner droplets against coalescence with the outer phase. In addition to simple polymerosomes, Lorenceau et al. (2005) form a new class of polymersome structures consisting of many internal compartments from double emulsion drops that contain more than a single internal water droplet. The inner water droplets retain their integrity as the organic fluid evaporates resulting in the formation of a foamlike, multi-compartmentalized vesicular structure. Production of enzyme-loaded polymerosomes is depicted in Figure 22.

\subsection{Production of giant lipid vesicles}

In recent years, giant lipid vesicles $(\mathrm{GVs})$ have attracted the attention of several research groups as artificial cells, carriers of drugs and genes and biological microreactors (Fischer et al., 2002). The advantages of GVs in comparison with conventional liposomes are that they are potentially better models for biological membranes as a result of their much larger size and curvature radius (above $1 \mu \mathrm{m}$ ) and that they allow observation in real time by optical microscopy. Kuroiwa et al. (2006) have developed a novel method for production of giant lipid vesicles based on generation of water droplets in n-hexane using $\mathrm{MC}$ emulsification (Figure 22). The water droplets stabilised by Span 80 and SteAm were first frozen in liquid nitrogen to avoid their coalescence, followed by the replacement of Span 80 by the bilayerforming lipid mixture consisting of egg PC, cholesterol, and SteAm. In the next step, hexane as a continuous phase solvent was removed by evaporation at $-10^{\circ} \mathrm{C}$ and it was then followed 
by the hydration of lipid layers at around $0{ }^{\circ} \mathrm{C}$. To make a dispersion of GVs, an additional amount of aqueous phase was added to the hydrated vesicles at room temperature (Figure 24). Using this technique, GVs with a high entrapment efficiency and a controlled size can be fabricated. The vesicle size is controlled by the size of the microchannels used for generation of W/O emulsions.

The conventional methods of vesicle production lead to a symmetric distribution of lipids on the inner and outer leaflets of the bilayer. Realistic models of biological membranes must incorporate lipid asymmetry (Pautot et al., 2003); moreover, asymmetric vesicles consisting of completely different types of molecules on the inner and outer leaflets would greatly increase the flexibility of vesicle drug delivery systems. Partial asymmetry can be achieved by altering the distribution of specific phospholipids using $\mathrm{pH}$ gradients or molecules that promote lipid redistribution (Pautot et al., 2003). However, the chemical constraints of these methods severely limit the applicability of such systems. Weitz et al. (2007) have proposed a microfluidic process for fabrication of asymmetric lipid vesicles shown in Figure 25. The process is based on the formation of triple emulsion droplets in FFMD shown in Figure 17 (a). The inner leaflet of these asymmetric vesicles is composed of POPC (1-Palmitoyl-2-Oleoylsn-Glycero-3-Phosphocholine) and the outer leaflet is composed of POPS (1-Palmitoyl-2Oleoyl-sn-Glycero-3-Phospho-L-Serine).

7.8. Production of colloidal assemblies

\subsubsection{Production of ball-like (3D) aggregates of particles}


Uniform-sized 3D colloidal assemblies have a number of potential applications as particles for "electronic paper" and size-exclusion chromatography, model colloids for complex colloidal particles, nano-bar codes for the recognition of biological molecules, photonic bandgap materials, etc. Yi et al. (2003a) have reported the fabrication of uniform 3D colloidal assemblies, in which monodisperse PSt beads with a diameter of 1 or $2 \mu \mathrm{m}$ were assembled into a regular arrangement. Mono-sized aqueous droplets containing the latex beads were first dispersed into silicon oil using a microfluidic T-junction, as shown in Figure 27. Then, the S/W/O dispersion was converted to uniform colloidal assemblies of latex spheres by slowly removing water from the aqueous droplets. Similarly, Yi et al. (2003b) produced uniform 3D assemblies of sub-micrometer monodisperse colloidal particles, so-called photonic balls that may be used as photonic crystals and light diffusers in a wide variety of applications.

\subsubsection{Production of colloidosomes}

Colloidosomes are hollow micro-shells fabricated by self-assembly of colloidal particles onto the interface of emulsion droplets. Dinsmore et al. (2002) have developed a fabrication process for enzyme-loaded colloidosomes involving three main steps (Figure 27): (i) an aqueous suspension of enzymes is emulsified in an immiscible fluid (oil) containing colloidal particles that adsorb on the surface of the emulsion droplets; (ii) after the droplet surface is completely covered by particles, an elastic shell is formed by locking the particles together usually by Van der Waals interactions, sintering, or electrostatically binding a polyelectrolyte of the opposite charge to the particles; (iii) finally, the capsules are washed with alcohol and transferred by centrifugation into the external water phase. The particles spontaneously adsorb on the interface, provided that the surface energy between the two fluids, $\sigma_{i, e}$, exceeds the difference of the surface energies between the particle and the internal fluid, $\sigma_{\mathrm{p}, \mathrm{i}}$, and between 
the particle and the external fluid, $\sigma_{\mathrm{p}, \mathrm{e}}$. Thus, adsorption is energetically favoured if $\sigma_{i, \mathrm{e}}>\left|\sigma_{\mathrm{p}, \mathrm{i}}-\sigma_{\mathrm{p}, \mathrm{e}}\right|$

Alternatively, to encapsulate hydrophobic material, oil droplets are emulsified in aqueous solutions containing particles. For example, Dinsmore et al. (2002) made colloidosomes from oil droplets in an aqueous phase containing 0.9- $\mu \mathrm{m}$-diameter PSt particles. The adsorbed particles were locked together by sintering at $105^{\circ} \mathrm{C}$ for $5 \mathrm{~min}$; this temperature was above the glass transition temperature of the PSt of around $100^{\circ} \mathrm{C}$. Upon heating, the particles coalesced partially, creating approximately 150-nm-diameter "necks" between them. The resultant colloidosome membrane, therefore, contained a regular array of uniform holes. Decreasing the particle diameter or increasing the sintering time leads to smaller pores: after $20 \mathrm{~min}$, the 0.9- $\mu \mathrm{m}$-diameter particles coalesced completely and the holes were fully closed (Dinsmore et al., 2002). It demonstrates the ability to precisely control the permeability and selectivity of colloidosome membranes over a wide range. By using particles with the lower glass transition temperature, the sintering temperature can be decreased, which can be advantageous for heat sensitive encapsulated material.

Other methods can be used to lock the interfacial particles together. Coupling of the particles can be achieved by electrostatically binding a polyelectrolyte of the opposite charge to the particles. To illustrate this, Dinsmore et al. (2002) emulsified an aqueous solution of poly-Llysine in a toluene-octanol mixture containing PSt particles. The poly-L-lysine molecules adsorbed to the particles at the interface and locked them together by bridging flocculation.

An important feature of colloidosomes, which makes them promising as microcapsules is the wide variety of potential mechanisms for release. Sustained release through the pores is the 
most direct method, but release may also be triggered by rupture of elastic shells through shear stress. The elastic modulus for $60-\mu \mathrm{m}$-diameter colloidosomes fabricated with lightly sintered PSt particles was found to be $10^{6}$ to $10^{7} \mathrm{~Pa}$ (Dinsmore et al., 2007). This value can be increased by well over a factor of 10 by sintering for longer times, depositing multiple layers of colloidal particles or by additional coating with polyelectrolytes or other polymers. Other release strategies are possible, for example, particles could be made of a microgel that changes its volume in response to external stimuli such as $\mathrm{pH}$ and temperature changes, as in alkali-swellable (Rodriguez et al., 1994) or thermoresponsive (Kim et al., 2007) microgel particles. Slight swelling would increase the pore sizes; greater swelling would introduce substantial surface stresses that would tear holes in the capsule and release the contents. Alternatively, the particles could be made of a material easily dissolved or swollen in situ either chemically or photochemically, thereby releasing the contents (Dinsmore et al., 2007). Noble et al. (2004) fabricated "hairy" colloidosomes that consist of aqueous gel cores and shells of polymeric microrods. This has been achieved by templating water-in-oil emulsions stabilized by rodlike particles followed by gelling of the aqueous phase, dissolution of the oil phase in ethanol, and redispersion of the obtained colloidosome microcapsules in water. The microrod shell around the colloidosomes may impart better mechanical stability compared to the previously used microspheres.

Glaser et al. (2006) made colloidosomes from Janus nanoparticles, i.e. bifacial particles consisting of a hydrophobic gold and a hydrophilic iron oxide moiety (Figure 1). The mean diameter of the gold particle was around $4 \mathrm{~nm}$, and the diameter of iron oxide was about 10 $\mathrm{nm}$, resulting in an overall diameter of about $14 \mathrm{~nm}$. To increase the amphiphilic character of the Janus particles further, Glaser et al. (2006) have attached DDT and ODT molecules to the gold part via ligand exchange. They have shown that the amphiphilicity derived from the 
Janus character of the particles leads to a significantly higher interfacial activity compared to that of the homogeneous particles of the same size. The self-assembly of Janus particles at the hexane-water interface resulted in a significant decrease in the interfacial tension.

\subsubsection{Production of composite aggregates of particles}

Velev et al. (1996a) fabricated composite colloidal assemblies consisting of a core of amidine latex particles surrounded by a shell of sulphate latex particles (Figure 28). The process first included the formation of ball-like aggregates from the amidine latex inside the octanol droplets. The amidine latex was destabilised with a SDS solution at low concentration to allow the amidine beads to penetrate inside the octanol droplets. After that, the sulphate latex beads were subjected to hydrophobic treatment with lysine hydrochloride solution to allow their aggregation. The dispersion of the octanol/amidine latex and the hydrophobised sulphate latex suspension was mixed in a ratio of $1: 1$. The composite particles were sterically stabilised by adsorption of casein and the sulphate shells were strongly coagulated by a mixture of $\mathrm{HCl}$ and $\mathrm{CaCl}_{2}$ solution. The octanol droplets inside the locked composite particles were dissolved by addition of ethanol. The production yield was below $10 \%$ due to losses by deposition and heterocoagulation (Velev et al., 1996a).

\section{CONCLUSIONS}

Membrane and microfluidic devices offer great potential in manufacturing 'made-to-measure' simple and multiple emulsions with a controlled particle size distribution. Microfluidic T junctions and flow focusing devices can generate double and even triple emulsion droplets in a single step with a polydispersity in the dripping regime of generally less than $3 \%$ and 100 
$\%$ entrapment efficiency allowing precision control over the outer and inner drop sizes and the number of droplets encapsulated in each larger drop. Microchannel arrays can generate emulsions with a coefficient of variation of less than $5 \%$ at much higher production rates due to large number of channels on a single microchip.

Membrane and microfluidic devices have been adopted for the precision manufacture of functional solids from emulsion droplet templates. Many different types of particles have been successfully produced by incorporating the use of various membrane and microfluidic devices in processes of polymerisation, gel formation, crystallisation, and molecular or particle self-assembly. Membrane emulsification is more suited to the fabrication of less sophisticated particulates, such as solid lipid micro/nano- particles, gel microbeads, coherent polymeric microspheres, inorganic particles, etc. Microfluidic devices allow more sophisticated particle designs to be created, such as colloidosomes, polymerosomes, 3D colloidal assemblies, asymmetric vesicles, core-shell microgel particles, bichromal particles, etc. The advantage of using emulsion droplets as templates to the fabrication of micro/nano particles is the control of particle size and size uniformity, which is of great importance in all applications.

\section{Acknowledgement}

Research work of GTV in the area of membrane and microchannel emulsification has been supported by the Alexander von Humboldt Foundation (Bonn, Germany), the Japan Society for the Promotion of Science (Tokyo, Japan), the Royal Society (UK, London), and the Fulbright Agency (Washington, US). GTV sincerely thanks to these funding organisations for their support. 


\section{REFERENCES}

Abrahamse, A.J., Van Lierop, R., Van der Sman, R.G.M., van der Padt A. and Boom, R.M. (2002) 'Analysis of droplet formation and interactions during cross-flow membrane emulsification', J. Membr. Sci., 204: 125-137.

Akay, G. (1998) 'Flow-induced phase inversion in the intensive processing of concentrated emulsions', Chem. Eng. Sci., 53: 203-223.

Altenbach-Rehm, J., Schubert, H. and Suzuki, K. (2002a) 'Premix-Membranemulgieren mittels hydrophiler und hydrophober PTFE-Membranen zur Herstellung von O/W-

Emulsionen mit enger Tropfengrößenverteilung', Chem. Ing. Tech., 74: 587-588.

Altenbach-Rehm, J., Suzuki, K. and Schubert, H. 'Production of O/W-emulsions with narrow droplet size distribution by repeated premix membrane emulsification', paper presented at the $3^{\text {rd }}$ World Congress on Emulsions, Lyon, 2002b.

Andersson, H. and van den Berg, A. (2003) 'Microfluidic devices for cellomics: a review', Sensors and Actuators B, 92: 315-325.

Anna, S.L., Bontoux, N. and Stone, H.A. (2003) 'Formation of dispersions using “'flow focusing", in microchannels', Appl. Phys. Lett., 82: 364-366.

Atencia, J., Beebe, D.J. (2005) 'Controlled microfluidic interfaces', Nature, 437: 648-655.

Berot, S., Giraudet, S., Riaublanc, A., Anton, M. and Popineau, Y. (2003) 'Key factors in membrane emulsification', Chem. Eng. Res. Des., 81 A: 1077-1082.

Cayre, O.J., Noble, P.F. and Paunov, V.N. (2004) 'Fabrication of novel colloidosome microcapsules with gelled aqueous cores', J. Mater. Chem., 14: 3351-3355

Charcosset, C., Limayem, I. and Fessi H. (2004) 'The membrane emulsification process - a review', J. Chem. Technol. Biotechnol., 79: 209-218. 
Christov, N.C., Ganchev, D.N., Vassileva, N.D., Denkov, N.D., Danov, K.D. and Kralchevsky, P.A. (2002) 'Capillary mechanisms in membrane emulsification: oil-in-water emulsions stabilized by Tween 20 and milk proteins', Colloid. Surf. A, 209: 83-104.

Chu, L.Y., Park, S.H., Yamaguchi, T. and Nakao S. (2002) 'Preparation of micron-sized monodispersed thermoresponsive core-shell microcapsules', Langmuir, 18: 1856-1864. Chu, L.Y., Rui, X., Zhu, J.H., Chen, W.M., Yamaguchi, T. and Nakao, S. (2003) 'Study of SPG membrane emulsification processes for the preparation of monodisperse core-shell microcapsules', J. Colloid Interface Sci., 265: 187-196.

Davidson, M.R., Harvie, D.J.E. and Cooper-White, J.J. (2005) 'Flow focusing in microchannels', ANZIAM, J 46: C47-C58.

Dendukuri, D., Tsoi, K., Hatton, T.A. and Doyle, P.S. (2005) 'Controlled synthesis of nonspherical microparticles using microfluidics', Langmuir, 21: 2113-2116.

Dinsmore, A.D., Hsu, M.F., Nikolaides, M.G., Marquez, M., Bausch, A.R. and Weitz, D.A. (2002) 'Colloidosomes: selectively permeable capsules composed of colloidal particles', Science, 298: 1006-1009.

Discher, B.M., Won, Y.Y., Ege, D.S., Lee. J.C.M, Bates, F.S., Discher, D.E. and Hammer, D.A. (1999) 'Polymersomes: tough vesicles made from diblock copolymers', Science, 284: $1143-1146$.

Dowding, P.J., Goodwin, J.W. and Vincent, B. (2001) 'Polymer beads with a narrow size distribution using a cross-flow membrane and a continuous tubular reactor', Colloid. Surf. A, 180: 301-309.

El-Mahdy, M., Ibrahim, E.S., Safwat, S., el-Sayed, A., Ohshima, H., Makino, K., Muramatsu, N. and Kondo, T. (1998) 'Effects of preparation conditions on the monodispersity of albumin microspheres', J. Microencapsul., 15: 661-673.

Figeys, D. and Pinto, D. (2001) 'Proteomics on a chip: Promising developments', 
Electrophoresis, 22: 208-216.

Fuchigami, T., Toki, M. and Nakanishi, K. (2000) 'Membrane emulsification using sol-gel derived macroporous silica glass', J. Sol-Gel Sci. Techn., 19: 337-341.

Fukui, K., Matsugano, K., Shimizu, M. and Matsuda, S. 'Preparation of anthocyaninencapsulated emulsion and suppression of anthocyanin leakage', paper presented at the $36^{\text {th }}$ SPG Forum "Various Applications of Membrane and Particles in Healthcare Fields", Miyazaki, 2001 (66-69).

Garstecki, P., Stone, H.A. and Whitesides, G.M. (2005) 'Mechanism for flow-rate controlled breakup in confined geometries: A route to monodisperse emulsions', Phys. Rev. Lett., 94: Art. No. 164501.

Garti, N. (1997) 'Double emulsions: scope, limitations and new achievements', Colloid. Surf. A, 123-124: 233-246.

Gijsbertsen-Abrahamse, A.J., Van der Padt, A. and Boom, R.M. (2003) 'Influence of membrane morphology on pore activation in membrane emulsification', J. Membr. Sci., 217: 141-150.

Gijsbertsen-Abrahamse, A.J., Van der Padt, A. and Boom, R.M. (2004) 'Status of cross-flow membrane emulsification and outlook for industrial application', J. Membr. Sci., 230: 149159.

Giorno, L., Li, N. and Drioli, E. (2003) 'Preparation of oil-in-water emulsions using polyamide $10 \mathrm{kDa}$ hollow fiber membrane', J. Membr. Sci, 217: 173-180.

Fischer, A., Franco, A. and Oberholzer, T. (2002) 'Giant vesicles as microreactors for enzymatic mRNA synthesis', Chem. Bio. Chem., 3: 409-417.

Gladman, D. and Williams R. (2003) 'Manufacturing with membranes', Chemical Engineer (London), n. 748, Octobar 2003: 32-34. 
Glaser, N., Adams, D.J., Böker, A., and Krausch, G. (2006) 'Janus particles at liquid-liquid interfaces', Langmuir, 22: 5227-5229.

Gouin, S. (2004) Microencapsulation: industrial appraisal of existing technologies and trends, Trends Food. Sci. Technol., 15: 330-347.

Ha, Y.K., Lee, H.J. and Kim, J.H. (1998) 'Large and monodispersed polymeric microspheres with high butadiene rubber content via membrane emulsification', Colloid. Surf. A, 145: 281284.

Ha, Y.K., Song, H.S., Lee, H.J. and Kim, J.H. (1999) 'Preparation of core particles for toner application by membrane emulsification', Colloid Surf A, 162: 289-295.

Hatate, Y., Ohta, H., Uemura, Y., Ijichi, K. and Yoshizawa, H. (1997) 'Preparation of monodispersed polymeric microspheres for toner particles by the shirasu Porous Glass membrane emulsification technique', J. Appl. Polym. Sci., 64: 1107-1113.

Hatch, A., Kamholz, A.E., Hawkins, K.R., Munson, M.S., Schilling, E.A., Weigl, B.H. and Yager, P. (2001) 'A rapid diffusion immunoassay in a T-sensor', Nature Biotechnology, 19: 461-465.

He, M., Edgar, J.S., Jeffries, G.D.M., Lorenz, R.M., Shelby, J.P. and Chiu, D.T. (2005) 'Selective encapsulation of single cells and subcellular organelles into picoliter- and femtoliter-volume droplets', Anal. Chem., 77: 1539-1544.

Higashi, S., Shimizu, M., Nakashima, T., Iwata, K., Uchiyama, F., Tateno, S. and Setoguchi, T. (1995) 'Arterial-injection chemotherapy for hepatocellular-carcinoma using monodispersed poppy-seed oil microdroplets containing fine aqueous vesicles of epirubicin - initial medical application of a membrane-emulsification technique', Cancer, 75: 1245-1254.

Higashi, S., Tabata, N., Kondo, K., Maeda, Y., Shimizu, M., Nakashima, T. and Setoguchi, T. (1999) 'Size of lipid microdroplets effects results of hepatic arterial chemotherapy with an 
anticancer agent in water-in-oil-in-water emulsion to hepatocellular carcinoma'. $J$. Pharmacol. Exp. Ther., 289: 816-819.

Higashi, S. and Setoguchi, T. (2000) 'Hepatic arterial injection chemotherapy for hepatocellular carcinoma with epirubicin aqueous solution as numerous vesicles in iodinated poppy-seed oil microdroplets: clinical application of water-in-oil-in-water emulsion prepared using a membrane emulsification technique', Adv. Drug Deliv. Rev., 45: 57-64.

Hino, T., Kawashima, Y. and Shimabayashi, S. (2000) 'Basic study for stabilization of w/o/w emulsion and its application to transcatheter arterial embolization therapy', Adv. Drug Del. Rev., 45: 27-45.

Hosoya, K., Bendo, M., Tanaka, N., Watabe, Y., Ikegami, T., Minakuchi, H. and Nakanishi, K. (2005) 'An application of silica-based monolithic membrane emulsification technique for easy and efficient preparation of uniformly sized polymer particles', Macromol. Mater. Eng., 290: 753-758.

Ito, F. and Makino, K. (2004) 'Preparation and properties of monodispersed rifampicinloaded poly(lactide-co-glycolide) microspheres', Colloid Surf B, 39: 17-21.

Iwamoto, S., Nakagawa, K., Sugiura, S. and Nakajima, M. (2002) 'Preparation of gelatin microbeads with a narrow size distribution using microchannel emulsification', AAPS PharmSci, article 25, 3: 1-5.

Jaspart S., Piel, G., Delattre, L. and Evrard B. (2005) Solid lipid microparticles: formulation, preparation, characterisation, drug release and applications, Expert Opin. Drug Deliv., 2: 7587.

Jing, W., Wu, J., Xing, W., Jin, W. and Xu, N. (2005) 'Emulsions prepared by two-stage ceramic membrane jet-flow emulsification', AIChE J., 51: 1339-1345.

Joscelyne, S.M. and Trägårdh G. (1999) 'Food emulsions using membrane emulsification: conditions for producing small droplets', J. Food Eng., 39: 59-64. 
Joscelyne, S.M. and Trägårdh, G. (2000) 'Membrane emulsification - a literature review', $J$. Membr. Sci., 169: 107-117.

Kameoka, J., Craighead, H.G., Zhang, H.W. and Henion, J. (2001) 'A polymeric microfluidic chip for CE/MS determination of small molecules', Anal. Chem., 73: 1935-1941.

Kandori, K., Kishi, K. and Ishikawa T. (1992) 'Preparation of uniform silica hydrogel particles by SPG filter emulsification method', Colloid. Surf., 62: 259-262.

Karbstein, H. and Schubert H. (1995) 'Developments in the continuous mechanical production of oil-water macro-emulsions', Chem. Eng. Process., 34: 205-211.

Katoh, R., Asano, Y., Furuya, A., Sotoyama, K. and Tomita, M. (1996) 'Preparation of food emulsions using a membrane emulsification system', J. Membr. Sci., 113: 131-135.

Kawakatsu, T., Kikuchi, Y. and Nakajima, M. (1997) 'Regular-sized cell creation in microchannel emulsification by visual microprocessing method', J. Am. Oil Chem. Soc., 74: 317-321.

Kawakatsu, T., Trägårdh, G., Kikuchi, Y., Nakajima, M., Komori, H. and Yonemoto T. (2000) 'Effect of microchannel structure on droplet size during crossflow microchannel emulsification', J. Surfactants Deterg., 3: 295-302.

Kawakatsu, T., Trägårdh, G. and Trägårdh, C. (2001) 'Production of W/O/W emulsions and S/O/W pectin microcapsules by microchannel emulsification' Colloid. Surf. A, 189: 257-264. Kawashima, Y., Hino, T., Takeuchi, H., Niwa, T. and Horibe, K. (1991) 'Shear-induced phase inversion and size control of water/oil/water emulsion droplets with porous membrane', $J$. Colloid Interface Sci., 145: 512-523.

Kim, H.J., Decker, E.A. and McClements, D.J. (2006) 'Preparation of multiple emulsions based on thermodynamic incompatibility of heat-denatured whey protein and pectin solutions', Food Hydrocolloid., 20: 586-595. 
Kim, J.W., Utada, A.S., Alberto Fernández-Nieves, A., Hu, Z. and Weitz, D.A. (2007)

'Fabrication of monodisperse gel shells and functional microgels in microfluidic devices', Angew. Chem. Int. Ed., 46: 1819-1822.

Kobayashi, I., Nakajima, M., Chun, K., Kikuchi, Y. and Fujita, H. (2002a) 'Silicon array of elongated through-holes for monodisperse emulsion droplets', AIChE J., 48: 1639-1644.

Kobayashi, I., Yasuno, M., Iwamoto, S., Shono, A., Satoh, K. and Nakajima, M. (2002b) 'Microscopic observation of emulsion droplet formation from a polycarbonate membrane', Colloid. Surf. A, 207: 185-196.

Kobayashi, I., Nakajima, M. and Mukataka, S. (2003a) 'Preparation characteristics of oil-inwater emulsions using differently charged surfactants in straight-through microchannel emulsification', Colloid. Surf. A, 229: 33-41.

Kobayashi, I., Iitaka, Y., Iwamoto, S., Kimura, S. and Nakajima, M. (2003b) 'Preparation characteristics of lipid microspheres using microchannel emulsification and solvent evaporation methods', J. Chem. Eng. Jpn., 36: 996-1000.

Kobayashi, I., Mukataka, S. and Nakajima, M. (2005a) 'Production of monodisperse oil-inwater emulsions using a large silicon straight-through microchannel plate', Ind. Eng. Chem. Res., 44: 5852-5856.

Kobayashi, I., Mukataka, S. and Nakajima, M. (2005b) 'Novel asymmetric through-hole array microfabricated on a silicon plate for formulating monodisperse emulsions', Langmuir, 21: 7629-7632.

Kobayashi, I., Lou, X.F., Mukataka, S. and Nakajima, M. (2005c) 'Preparation of monodisperse water-in-oil-in-water emulsions using microfluidization and straight-through microchannel emulsification', J. Am. Oil Chem. Soc., 82: 65-71. 
Kosvintsev, S.R., Gasparini, G., Holdich, R.G., Cumming, I.W. and Stillwell, M.T. (2005)

'Liquid-liquid membrane dispersion in a stirred cell with and without controlled shear', Ing. Eng. Chem. Res., 44: 9323-9330.

Kukizaki, M., Shimizu, M. and Nakashima, T. 'Preparation of W/O/W emulsion using hardened oil and supression of leakage of encapsulated material', paper presented at the $36^{\text {th }}$ SPG Forum "Various Applications of Membrane and Particles in Healthcare Fields", Miyazaki, 2001 (58-61).

Kukizaki, M. and Goto, M. (2007) 'Preparation and evaluation of uniformly sized solid lipid microcapsules using membrane emulsification', Colloid. Surf. A, 293: 87-94.

Kuroiwa, T., Sugiura, S., Nakajima, M., Sato, S., Mukataka, S. and Ichikawa, S. 'Preparation of giant vesicles with a controlled size and a high entrapment yield from monodisperse emulsions', paper presented at the $6^{\text {th }}$ European Symposium on Biochemical Engineering Science, Salzburg, Austria, August 2006.

Lambrich, U. and Vladisavljević, G.T. (2004) 'Emulsification using microstructured systems', Chem. Ing. Tech., 76: 376-383.

Lewis, P.C., Graham, R.R., Nie, Z., Xu, S., Seo, M. and Kumacheva, E. (2005) 'Continuous synthesis of copolymer particles in microfluidic reactors', Macromolecules, 38: 4536-4538. Link, D.R., Anna, S.L., Weitz, D.A. and Stone, H.A. (2004) 'Geometrically mediated breakup of drops in microfluidic devices', Phys. Rev. Lett., 92: Art. No. 054503.

Liu, X.D., Bao, D.C., Xue, W.M., Xiong, Y., Yu, W.T., Yu, X.J., Ma, X.J. and Yuan, Q. (2003) 'Preparation of uniform calcium alginate gel beads by membrane emulsification coupled with internal gelation', J. Appl. Polym. Sci., 87: 848-852.

Liu, R., Ma, G.H., Wan, Y.H., Su and Z.G. (2005a) 'Influence of process parameters on the size distribution of PLA microcapsules prepared by combining membrane emulsification technique and double emulsion-solvent evaporation method', Colloid. Surf. B, 45: 144-153. 
Liu, R., Ma, G.H., Meng, F.T. and Su, Z.G. (2005b) 'Preparation of uniform-sized PLA microcapsules by combining Shirasu Porous Glass membrane emulsification technique and multiple emulsion-solvent evaporation method', J. Controll. Release, 103: 31-43.

Lorenceau, E., Utada, A.S., Link, D.R., Cristobal, G., Joanicot, M. and Weitz, D.A. (2005) 'Generation of polymerosomes from double emulsions', Langmuir, 21: 9183-9186.

Ma, G.H., Nagai, M. and Omi, S. (1997) ‘Synthesis of uniform microspheres with higher content of 2-hydroxyethyl methacrylate by employing SPG (Shirasu Porous Glass) emulsification technique followed by swelling process of droplets', J. Appl. Polym. Sci., 66: $1325-1341$.

Ma, G.H., Nagai, M. and Omi, S. (1999a) 'Study on preparation and morphology of uniform artificial polystyrene-poly(methyl methacrylate) composite microspheres by employing the SPG (Shirasu Porous Glass) membrane emulsification technique', J. Colloid Interface Sci., 214: $264-282$.

Ma, G.H., Nagai, M. and Omi, S. (1999b) 'Effect of lauryl alcohol on morphology of uniform polystyrene-poly(methyl methacrylate) composite microspheres prepared by Porous glass membrane emulsification technique', J. Colloid Interface Sci., 219: 110-128.

Ma, G.H., Nagai, M. and Omi, S. (1999c) 'Preparation of uniform poly(lactide) microspheres by employing the shirasu porous glass (SPG) emulsification technique', Colloid. Surf. A, 153: 383-394.

Ma, G.H., Nagai, M. and Omi, S. (2001) ‘Study on preparation of monodispersed poly(styrene-co-N-dimethylaminoethyl methacrylate) composite microspheres by SPG (shirasu porous glass) emulsification technique', J. Appl. Polym. Sci., 79: 2408-2424. Ma, G.H., Omi, S., Dimonie, V.L., Sudol, E.D. and El-Aasser, M.S. (2002) 'Study of the preparation and mechanism of formation of hollow monodisperse polystyrene microspheres by SPG (Shirasu Porous Glass) emulsification technique', J. Appl. Polym. Sci., 85: 1530-1543. 
Ma, G.H., An, C.J., Yuyama, H., Su, Z.G. and Omi, S. (2003a) 'Synthesis and characterization of polyurethaneurea-vinyl polymer (PUU-VP) uniform hybrid microspheres by SPG emulsification technique and subsequent suspension polymerization', J. Appl. Polym. Sci., 89: 163-178.

Ma, G.H., Su, Z.G., Omi, S., Sundberg, D. and Stubbs, J. (2003b) 'Microencapsulation of oil with poly (styrene-N, N-dimethylaminoethyl methacrylate) by SPG emulsification technique: Effects of conversion and composition of oil phase', J. Colloid Interface Sci., 266: 282-294. Ma, G.H., Chen, A.Y., Su, Z.G. and Omi, S. (2003c) 'Preparation of uniform hollow polystyrene particles with large voids by a glass-membrane emulsification technique and a subsequent suspension polymerization', J. Appl. Polym. Sci., 87: 244-251.

Ma, G.H., Fujiwara, J., Su, Z.G. and Omi S. (2003d) 'Synthesis and characterization of crosslinked uniform polymeric microspheres containing a polyimide prepolymer by a new emulsification process', J. Appl. Polym. Sci., 41: 2588-2598.

Ma, G.H., Sone, H. and Omi, S. (2004) 'Preparation of uniform-sized polystyrenepolyacrylamide composite microspheres from a $\mathrm{W} / \mathrm{O} / \mathrm{W}$ emulsion by membrane emulsification technique and subsequent suspension polymerization', Macromolecules, 37: 2954-2964.

McClain, M.A., Culbertson, C.T., Jacobson, S.C. and Ramsey, J.M. (2001) 'Flow cytometry of Escherichia coli on microfluidic devices', Anal. Chem. 73: 5334-5338.

McClements, D.J. 'Food Emulsions: Principles, Practices, and Techniques, CRC Press, 2004. Mine, Y., Shimizu, M. and Nakashima, T. (1996) 'Preparation and stabilization of simple and multiple emulsions using a microporous glass membrane', Colloid. Surf. B, 6: 261-268. Müller, R.H., Mäder, K. and Gohla, S. (2000) 'Solid lipid nanoparticles (SLN) for controlled drug delivery: a review of the state of the art', Eur. J. Pharm. Biopharm., 50: 161-177. 
Muramatsu, N. and Kondo, T. (1995) 'An approach to prepare microparticles of uniform size', J. Microencapsul., 2: 129-136.

Muramatsu, N. and Nakauchi, K. (1998) 'A novel method to prepare monodisperse microparticles', J. Microencapsul., 15: 715-723.

Nagashima, S., Ando, S., Tsukamoto, T., Ohshima, H. and Makino, K. (1998) 'Preparation of monodisperse poly(acrylamide-co-acrylic acid) hydrogel microspheres by a membrane emulsification technique and their size-dependent surface properties', Colloid. Surf. B, 11: 4756.

Nakagawa, K., Iwamoto, S., Nakajima, M., Shono, A. and Satoh, K. (2004) 'Microchannel emulsification using gelatin and surfactant-free coacervate microencapsulation', J. Colloid Interface Sci., 278: 198-205.

Nakajima, M., Nabetani, H., Ichikawa, S. and Xu, Q.Y. (2003) 'Functional emulsions', US Patent 6,538,019.

Nakashima, T. 'History of SPG technology and its recent advances', paper presented at the $38^{\text {th }}$ Int. SPG Forum "Membrane and Particle Science and Technology in Food and Medical Care", Miyazaki, 2002 (63).

Nakashima T. and Shimizu M. (1986) 'Porous glass from calcium alumino boro-silicate glass', Ceramics Japan, 21: 408-412 (in Japanese).

Nakashima T., Shimizu M. and Kukizaki M. (1991a) Membrane Emulsification Operation Manual, Miyazaki: Department of Chemistry, Industrial Research Institute of Miyazaki Prefecture.

Nakashima T., Shimizu M. and Kukizaki M. 'Membrane emulsification by microporous glass', paper presented at the $2^{\text {nd }}$ International Conference on Inorganic Membranes, Montpellier, 1991b. (513-516). 
Nakashima T., Shimizu M. and Kukizaki, M. (1991c) 'Membrane emulsification by microporous glass', Key Eng. Mater., 61-62: 513-516.

Nakashima, T., Shimizu, M. and Kukizaki M. (1993) 'Effect of surfactant on production of monodispersed O/W emulsion in membrane emulsification', Kag. Kog. Ronbunshu, 19: 991997 (in Japanese).

Nakashima, T., Shimizu, M. and Kukizaki, M. (2000) 'Particle control of emulsion by membrane emulsification and its applications', Adv. Drug Deliv. Rev., 45: 47-56.

Nie, Z., Xu, S., Seo, M., Lewis, P.C. and Kumacheva, E. (2005) 'Polymer particles with various shapes and morphologies produced in continuous microfluidic reactors', J. Am. Chem. Soc., 127: 8058-8063.

Nisisako, T., Torii, T. and Higuchi, T. (2004) 'Novel microreactors for functional polymer beads', Chem. Eng. J., 101: 23-29.

Nisisako, T., Okushima, S. and Torii T. (2005) 'Controlled formulation of monodisperse double emulsions in a multiple-phase microfluidic system', Soft Matter, 1: 23-27. Noble, P.F., Cayre, O.J., Alargova, R.G., Velev, O.D. and Paunov, V.N. (2004) 'Fabrication of "hairy" colloidosomes with shells of polymeric microrods', J. Am. Chem. Soc., 126: 80928093.

Nuisin, R., Ma, G.H., Omi, S. and Kiatkamjornwong, S.J. (2000) 'Dependence of morphological changes of polymer particles on hydrophobic/hydrophilic additives', J. Appl. Polym. Sci., 77: 1013-1028.

Nuisin, R., Omi, S. and Kiatkamjornwong, S. (2003) 'Synthesis and property behavior of dioctyl phthalate plasticized styrene-acrylate particles by shirasu porous glass emulsification and subsequent suspension copolymerization', J. Appl. Polym. Sci., 90: 3037-3050. 
Okonogi, S., Katoh, R., Asano, Y., Yuguchi, H., Kumazawa, R., Sotoyama, K., Takahashi, K. and Fujimoto, M. (1994) 'Methods for producing emulsions, low-fat spread and oil-in-waterin-oil type spread', US Patent 5,279,847.

Okushima, S., Nisisako, T., Torii, T. and Higuchi, T. (2004) 'Controlled production of monodisperse double emulsions by two-step droplet breakup in microfluidic devices', Langmuir, 20: 9905-9908.

Omi, S., Katami, K., Yamamoto, A. and Iso, M. (1994) 'Synthesis of polymeric microspheres employing SPG emulsification technique', J. Appl. Polym. Sci., 51: 1-11.

Omi, S., Katami, K., Taguchi, T., Kaneko, K. and Iso, M. (1995) 'Synthesis of uniform PMMA microspheres employing modified SPG (Shirasu Porous Glass) emulsification technique', J. Appl. Polym. Sci., 57: 1013-1024.

Omi, S. (1996) 'Preparation of monodisperse microspheres using the Shirasu porous glass emulsification technique', Colloid. Surf. A, 109: 97-107.

Omi, S., Kaneko, K., Nakayama, A., Katami, K., Taguchi, T., Iso, M., Nagai M. and Ma, G.H. (1997a) 'Application of porous microspheres prepared by SPG (Shirasu porous glass) emulsification as immobilizing carriers of glucoamylase (GluA)', J. Appl. Polym. Sci., 65: 2655-2664.

Omi, S., Taguchi, T, Nagai, M. and Ma, G.H. (1997b) 'Synthesis of $100 \mu$ m uniform porous spheres by SPG emulsification with subsequent swelling of the droplets', J. Appl. Polym. Sci., 63: 931-942.

Omi, S., Kanetaka, A., Shimamori, Y., Supsakulchai, A., Nagai, M. and Ma, G.H. (2001) 'Magnetite $\left(\mathrm{Fe}_{3} \mathrm{O}_{4}\right)$ microcapsules prepared using a glass membrane and solvent removal, $J$. Microencapsul., 19: 749-765.

Park, S.H., Yamaguchi, T. and Nakao, S. (2001) 'Transport mechanism of deformable droplets in microfiltration of emulsions', Chem. Eng. Sci., 56: 3539-3548. 
Pautot, S., Frisken, B.J., Weitz, D.A. (2003) 'Engineering asymmetric vesicles' PNAS, 100: 10718-10721.

Peyratout, C.S. and Dähne, L. (2004) 'Tailor-made polyelectrolyte microcapsules: From multilayers to smart containers', Angew. Chem., 43: 3762-3783.

Rayleigh, L. (1879) 'On the instability of jets', Proc. London Math. Soc., 10: 4-13.

Rayner, M., Trägårdh, G. and Trägårdh, C. (2005) 'The impact of mass transfer and interfacial expansion rate on droplet size in membrane emulsification processes', Colloids $\operatorname{Surf} A, 266: 1-17$.

Ribeiro, H.S., Rico, L.G., Badolato, G.G. and Schubert, H. (2005) 'Production of O/W emulsions containing astaxanthin by repeated premix membrane emulsification', J. Food Sci., 70, E117-123.

Rodriguez, B.E., Wolfe, M.S. and Fryd, M. (1994) 'Nonuniform swelling of alkali swellable microgels', Macromolecules, 27: 6642-6641.

Schadler, V. and Windhab, E.J. (2004) 'Kontinuierliches Membran-Emulgieren mittels rotierender Mikromembranen mit definierten Porenabständen', Chem. Ing. Tech., 76: 13921392.

Schröder, V., Behrend, O. and Schubert H. (1998) 'Effect of dynamic interfacial tension on the emulsification process using microporous, ceramic membrane', J. Colloid Interface Sci., 202: $334-340$.

Schröder, V. (1999) 'Herstellen von Öl-in-Wasser-Emulsionen mit mikroporösen Membranen', Ph.D. Thesis, University of Karlsruhe (T.H.).

Senathirajah, C.S. (2004) 'Precision manufacture of solid particulates using cross membrane crystallization (XMC)', Ph.D. thesis, University of Leeds.

Seo, M., Nie, Z., Xu, S., Mok, M., Lewis, P.C., Graham, R. and Kumacheva, E. (2005) ‘Continuous microfluidic reactors for polymer particles', Langmuir, 21: 11614-11622. 
Shima, M., Kobayashi, Y., Fujii, T., Tanaka, M., Kimura, Y., Adachi, S. and Matsuno, R. (2004) 'Preparation of fine $\mathrm{W} / \mathrm{O} / \mathrm{W}$ emulsion through membrane filtration of coarse $\mathrm{W} / \mathrm{O} / \mathrm{W}$ emulsion and disappearance of the inclusion of outer phase solution', Food Hydrocolloid., 18: $61-70$.

Shimizu, M., Kukizaki, M., Nakashima, T. and Alvarez-Nakase, A.M. 'Leakage of inclosed irinotecan hydrochloride and remedial measures taken during production of the W/O type oral medicine', paper presented at the $38^{\text {th }}$ Int. SPG Forum "Membrane and Particle Science and Technology in Food and Medical Care, Miyazaki, Japan (2002a) (70-73).

Shimizu, M., Nakashima, T. and Kukizaki, M. (2002b) 'Particle size control of W/O emulsion by means of osmotic pressure as driving force', Kag Kog Ronbunshu, 28: 304-309.

Shimizu, M., Nakashima, T. and Kukizaki, M. (2002c) 'Preparation of W/O emulsion by membrane emulsification and optimum conditions for its monodispersion', Kag. Kog. Ronbunshu, 28: 310-316 (in Japanese).

Song, S.H., Cho, Y.H. and Park, J. (2003) 'Microencapsulation of lactobacillus casei YIT 9018 using a microporous glass membrane emulsification system', J. Food Sci., 68: 195-200. Sugiura, S., Nakajima, M., Tong, J., Nabetani, H. and Seki, M. (2000) 'Preparation of monodispersed solid lipid microspheres using a microchannel emulsification technique', $J$. Colloid Interface. Sci., 227: 95-103.

Sugiura, S., Nakajima, M., Itou, H. and Seki, M. (2001) 'Synthesis of polymeric microspheres with narrow size distributions employing microchannel emulsification', Macromol. Rapid Commun., 22: 773-778.

Sugiura, S., Nakajima, M., Kumazawa, N., Iwamoto, S. and Seki, M. (2002a) 'Characterization of spontaneous transformation-based droplet formation during microchannel emulsification', J. Phys. Chem. B, 106: 9405-9409. 
Sugiura, S., Nakajima, M. and Seki, M. (2002b) 'Prediction of droplet diameter for microchannel emulsification', Langmuir, 18: 3854-3859.

Sugiura, S., Nakajima, M., Yamamoto, K., Iwamoto, S., Oda, T., Satake, M. and Seki, M. (2004a) 'Preparation characteristics of water-in-oil-in-water multiple emulsions using microchannel emulsification', J. Colloid Interface Sci., 270: 221-228.

Sugiura, S., Nakajima, M. and Seki, M. (2004b) 'Preparation of monodispersed polymeric microspheres over $50 \mu \mathrm{m}$ employing microchannel emulsification', Ind. Eng. Chem. Res., 43: 4043-4047.

Sugiura, S., Oda, T., Izumida, Y., Aoyagi, Y., Satake, M., Ochiai, A., Ohkohchi, N., Nakajima, M. (2005) 'Size control of calcium alginate beads containing living cells using micro-nozzle array', Biomaterials, 26: 3327-3331.

Supsakulchai, A., Ma, G.H., Nagai, M. and Omi, S. (2002a) 'Microencapsulation of fine titanium dioxide powders from $(\mathrm{S} / \mathrm{O}) / \mathrm{W}$ emulsion with subsequent solvent evaporation', $A C S$ Sym. Ser., 801: 260-275.

Supsakulchai, A., Ma, G.H., Nagai, M. and Omi, S. (2002b) 'Uniform titanium dioxide $\left(\mathrm{TiO}_{2}\right)$ microcapsules prepared by glass membrane emulsification with subsequent solvent evaporation', J. Microencapsul., 19: 425-449.

Surh, J., Vladisavljević, G.T., Mun, S. and McClements, D.J. (2007): ‘Preparation and characterization of water/oil and water/oil/water emulsions containing biopolymer-gelled water droplets', J. Agric. Food Chem., 55: 175-184.

Suzuki, K., Shuto, I. and Hagura, Y. (1996) 'Characteristics of the membrane emulsification method combined with preliminary emulsification for preparing corn oil-in-water emulsions', Food Sci. Technol. Int. Tokyo, 2: 43-47.

Suzuki, K., Fujiki, I. and Hagura Y. (1998) 'Preparation of corn oil/water and water/corn oil emulsions using PTFE membranes', Food Sci. Technol. Int. Tokyo, 4: 164-167. 
Suzuki, K., Fujiki, I. and Hagura, Y. (1999) 'Preparation of high concentration of O/W and W/O emulsions by the membrane phase inversion emulsification using PTFE membranes', Food Sci. Technol. Int. Tokyo, 5: 234-238.

Takeuchi, S., Garstecki, P., Weibel, D.B. and Whitesides, G.M. (2005) 'An asymmetric flowfocusing microfluidic device', Adv. Mater., 17: 1067-1072.

Tan, Y.C., Fisher, J.S., Lee, A.I., Cristini, V. and Lee, A.P. (2004) 'Design of microfluidic channel geometries for the control of droplet volume, chemical concentration, and sorting', Lab Chip, 4: 292-298.

Tan, Y.C., Cristini, V. and Lee, A.P. (2006) 'Monodispersed microfluidic droplet generation by shear focusing microfluidic device', Sens. Actuator B-Chem., 114: 350-356.

Tawonsree, S., Omi, S. and Kiatkamjornwong, S. (2000) 'Control of various morphological changes of poly(meth)acrylate microspheres and their swelling degrees by SPG emulsification', J. Appl. Polym. Sci., 38: 4038-4056.

Tomotika, S. (1935) 'On the instability of a cylindrical thread of a viscous liquid surrounded by another viscous fluid', Proc. R. Soc. London Ser. A, 150: 322-337.

Thorsen, T., Roberts, R.W., Arnold, F.H. and Quake, S.R. (2001) 'Dynamic pattern formation in a vesicle-generating microfluidic device', Phys. Rev. Lett., 86: 4163-4166.

Tice, J.D., Lyon, A.D. and Ismagilov, R.F. (2004) 'Effects of viscosity on droplet formation and mixing in microfluidic channels', Anal. Chim. Acta, 507: 73-77.

Tong, J., Nakajima, M., Nabetani, H., Kikuchi, Y. and Maruta, Y. (2001) 'Production of oilin-water microspheres using a stainless steel microchannel', J. Colloid Interface Sci., 237: 239-248.

Toorisaka, E., Ono, H., Arimori, K., Kamiya, N. and Goto, M. (2003) 'Hypoglycemic effect of surfactant-coated insulin solubilized in a novel solid-in-oil-in-water $(\mathrm{S} / \mathrm{O} / \mathrm{W})$ emulsion', Int. J. Pharm., 252: 271-274. 
Ugelstad, J. and Mbrk, P.C. (1980) 'Swelling of oligomer-polymer particles. New methods of preparation of emulsions and polymer dispersions', Adv. Colloid Interface Sci., 13: 101-140. Utada, A.S., Lorenceau, E., Link, D.R., Kaplan, P.D., Stone, H.A. and Weitz, D.A. (2005) 'Monodisperse double emulsions generated from a microcapillary device', Science, 308: 537541.

Van der Graaf, S., Schroën, C.G.P.H., Van der Sman, R.G.M. and Boom, R.M. (2004) 'Influence of dynamic interfacial tension on droplet formation during membrane emulsification', J. Colloid Interface Sci., 277: 456-463.

Van der Graaf, S., Schroën, C.G.P.H. and Boom, R.M. (2005a) 'Preparation of double emulsions by membrane emulsification: a review', J. Membr. Sci., 251: 7-15.

Van der Graaf, S., Steegmans, M.L.J., Van der Sman, R.G.M., Schroën, C.G.P.H. and Boom, R.M. (2005b) 'Droplet formation in a T-shaped microchannel junction: A model system for membrane emulsification', Colloid. Surf. A, 266: 106-116.

Velev, O.D., Furusawa, K. and Nagayama, K. (1996a) 'Assembly of latex particles by using emulsion droplets as templates. 1. microstructured hollow spheres', Langmuir, 12:2374-2384. Velev, O.D., Furusawa, K. and Nagayama, K. (1996b) 'Assembly of latex particles by using emulsion droplets as templates. 2. Ball-like and composite aggregates', Langmuir, 12: 23852391.

Vladisavljević, G.T., Brösel, S. and Schubert, H. (2002a) 'Preparation of water-in-oil emulsions using microporous polypropylene hollow fibers: influence of some operating parameters on droplet size distribution', Chem. Eng. Process., 41: 231-238.

Vladisavljević, G.T. and Schubert, H. (2002b) 'Preparation and analysis of oil-in-water emulsions with a narrow droplet size distribution using Shirasu-porous-glass (SPG) membranes', Desalination, 144: 167-172. 
Vladisavljević, G.T. and Schubert, H. (2003a) 'Preparation of emulsions with a narrow particle size distribution using microporous $\alpha$-alumina membranes', J. Dispersion Sci. Technol., 24: 811-819.

Vladisavljević, G.T. and Schubert, H. (2003b) 'Influence of process parameters on droplet size distribution in SPG membrane emulsification and stability of prepared emulsion droplets', J. Membr. Sci., 225: 15-23.

Vladisavljević, G.T., Lambrich, U., Nakajima M. and Schubert H. (2004a) 'Production of $\mathrm{O} / \mathrm{W}$ emulsions using SPG membranes, ceramic $\alpha-\mathrm{Al}_{2} \mathrm{O}_{3}$ membranes, microfluidizer and a microchannel plate: a comparative study', Colloid. Surf. A, 232: 199-207.

Vladisavljević, G.T., Shimizu, M. and Nakashima, T. (2004b) 'Preparation of monodisperse multiple emulsions at high production rates by multi-stage premix membrane emulsification', J. Membr. Sci., 244: 97-106.

Vladisavljević, G.T., Shimizu, M. and Nakashima, T. (2005) ‘Permeability of hydrophilic and hydrophobic Shirasu-porous-glass (SPG) membranes to pure liquids and its microstructure', $J$. Membr. Sci., 250, 69-77.

Vladisavljević, G.T. and Williams, R.A. (2005) 'Recent developments in manufacturing emulsions and particulate products using membranes', Adv. Colloid Interface Sci., 113: 1-20. Vladisavljević, G.T. and Williams, R.A. (2006) 'Manufacture of large uniform droplets using rotating membrane emulsification', J. Colloid Interface Sci., 299: 396-402.

Vladisavljević, G.T., Shimizu, M. and Nakashima, T. (2006a) 'Production of multiple emulsions for drug delivery systems by repeated SPG membrane homogenization: Influence of mean pore size, interfacial tension and continuous phase viscosity', J. Membr. Sci., 284: 373-383.

Vladisavljević, G.T., Surh, J. and McClements, D.J. (2006b) 'Effect of emulsifier type on droplet disruption in repeated Shirasu porous glass membrane homogenization', Langmuir, 
Vladisavljević, G.T., Kobayashi, I., Nakajima, M., Williams, R.A., Shimizu, M. and Nakashima, T. (2007) 'Shirasu Porous Glass membrane: Characterisation of microstructure by high resolution x-ray microtomography and visualisation of droplet formation in real time', J. Membr. Sci., in press.

Vladisavljević, G.T., Kobayashi, I. and Nakajima, M. (2007) ‘Generation of highly uniform droplets using asymmetric microchannels fabricated on a single crystal silicon plate: effect of emulsifier and oil types', Powder Technology, in press.

Walde, P. and Ichikawa, S. (2001) 'Enzymes inside lipid vesicles: preparation, reactivity and applications', Biomol. Eng., 18: 143-177.

Wang, L.Y., Ma, G.H. and Su, Z.G. (2005) 'Preparation of uniform sized chitosan microspheres by membrane emulsification technique and application as a carrier of protein drug', J. Controll. Release, 106: 62-75.

Weiss, J., Kobow, K. and Muschiolik, G. 'Preparation of microgels by membrane emulsification', paper presented at the Food Colloids 2004 Conference, Harogate, UK (2004). Weitz, D.A. (2007) Publishing on the Internet, DEAS/Dept. of Physics, Harvard University. Online. Available HTTP:

$<$ httpp://www.seas.harvard.edu/projects/weitzlab/alvaroweb/Triple\%20and\%20Multiple\%20 Emulsions.htm> (accessed 23 May 2007).

Westover, D., Seitz, W.R. and Lavine, B.K. (2003) 'Synthesis and evaluation of nitrated poly(4-hydroxy-styrene) microspheres for pH sensing, Microchem. J., 74:121-129. Williams, R.A., Peng, S.J., Wheeler, D.A., Morley, N.C., Taylor, D., Whalley, M. and Houldsworth, D.W. (1998) 'Controlled production of emulsions using a crossflow membrane', Chem. Eng. Res. Des., 76 A: 902-910. 
Williams, R.A. (2001a) ‘Controlled dispersion using a spinning membrane reactor', UK Patent Application No. PCT/GB00/04917.

Williams, R.A. (2001b) 'Making the perfect particle', Ingenia, n. 7: 1.

Williams, R.A. 'Emulsifying with membranes' paper presented at the $3^{\text {rd }}$ World Congress on Emulsions, Lyon, 2002.

$\mathrm{Xu}, \mathrm{Q}$. 'Generation of microbubbles in microfluidic devices', seminar lecture at the National Food Research Institute, Tsukuba, Japan, 2006.

Xu, Q. and Nakajima, M. (2004) 'The generation of highly monodisperse droplets through the breakup of hydrodynamically focused microthread in a microfluidic device', Appl. Phys. Lett., 85: 3726-3728.

Xu, J.H., Luo, G.S., Chen, G.G. and Tan, B. (2005) 'Mass transfer performance and twophase flow characteristic in membrane dispersion mini-extractor', J. Membr. Sci., 249: 75-81. Yafei, W., Tao, Z. and Gang, H. (2006) 'Structural evolution of polymer-stabilized double emulsions', Langmuir, 67: 67-73.

Yamazaki, N., Yuyama, H., Nagai, M., Ma, G.H. and Omi, S. (2002) ‘A comparison of membrane emulsification obtained using SPG (Shirasu porous glass) and PTFE [poly(tetrafluoroethylene)] membranes', J. Dispersion Sci. Technol., 23: 279-292. Yamazaki, N., Naganuma, K., Nagai, M., Ma, G.H. and Omi, S. (2003) 'Preparation of W/O (water-in-oil) emulsions using a PTFE (polytetrafluoroethylene) membrane: A new emulsification device', J. Dispersion Sci. Technol., 24: 249-257.

Yanagishita, T., Tomabechi, Y., Nishio, K. and Masuda, H. (2004) 'Preparation of monodisperse $\mathrm{SiO}_{2}$ nanoparticles by membrane emulsification using ideally ordered anodic porous alumina', Langmuir, 20: 554-555. 
Yi, G.R., Thorsen, T., Manoharan, V.N., Hwang, M.J., Jeon, S.J., Pine, D.J., Quake, S.R. and Yang, S.M. (2003a) ‘Generation of uniform colloidal assemblies in soft microfluidic devices', Adv. Mater., 15: 1300-1304.

Yi, G.R., Jeon, S.J., Thorsen, T., Manoharan, V.N., Quake, S.R., Pine, D.J., Yang, S.M.

(2003b) 'Generation of uniform photonic balls by template-assisted colloidal crystallization', Synthetic Met., 139: 803-806.

Yobas, L., Martens, S., Ong, W.L. and Ranganathan, N. (2006) 'High-performance flowfocusing geometry for spontaneous generation of monodispersed droplets', Lab Chip, 6: 1073-1079.

Yoshizawa, H., Maruta, M., Ikeda, S., Hatate, Y. and Kitamura, Y. (2004) 'Preparation and pore-size control of hydrophilic monodispersed polymer microspheres for size-exclusive separation of biomolecules by the SPG membrane emulsification technique', Colloid Polym. Sci., 282: 965-971.

You, J.O., Park, S.B., Park, H.Y., Haam, S., Chung, C.H. and Kim, W.S. (2001) 'Preparation of regular sized Ca-alginate microspheres using membrane emulsification method', $J$. Microencapsul., 18: 521-532.

Yuyama, H., Hashimoto, T., Ma, G.H., Nagai, M. and Omi, S. (2000a) 'Mechanism of suspension polymerization of uniform monomer droplets prepared by glass membrane (Shirasu Porous Glass) emulsification technique', J. Appl. Polym. Sci., 78: 1025-1043. Yuyama, H., Yamamoto, K., Shirafuji, K., Nagai, M. and Ma, G.H. (2000b) 'Preparation of polyurethaneurea (PUU) uniform spheres by SPG membrane emulsification technique', $J$. Appl. Polym. Sci., 77: 2237-2245.

Zhou, Q.Z., Wang, L.Y., Ma, G.H. and Su, Z.G. (2007) 'Preparation of uniform-sized agarose beads by microporous membrane emulsification technique', J. colloid Interface Sci., 311: 118-127. 
Zhu, J. and Barrow, D. (2005) 'Analysis of droplet size during crossflow membrane emulsification using stationary and vibrating micromachined silicon nitride membranes', $J$. Membr. Sci., 261: 136-144. 
Abbreviations of Chemicals

AA: acrilic acid

ADVN: N,N'-azobis(2,4 dimethylvaleronitrile)

AIBN: 2,2’-azobis(isobutyronitrile)

ALA: allylamine

APS: ammonium persulfate

Arlacel 83: sorbitan sesquioleate

Arlacel P135: polyethylene-30, dipolyhydroxystearate

AcSt: acetoxystyrene

BA: butyl acrylate

BAc: butyl acetate

BANI-M: diphenylmethane-4,49-bis-allylnagiimide

BIS: N,N'-methylenebisacrylamide

BMA: butyl methacrylate

BPO: benzoyl peroxide

BR: butadiene rubber

BuOH: butanol

Bz: benzene

C8TG: octanoic acid triacylglycerol

CA: cetyl alcohol

$\mathrm{CaNa}_{2}$-EDTA: calcium disodium ethylendiaminetetraacetate

CHA: cyclohexyl acrylate

CPT 11: irinotecan hydrochloride

DAP: diaminophenylene 
DCM: dichloromethane

DD: dodecane

DDT: dodecanethiol

DHBSP: 2.5-dihydrozybenzenedisulfonic acid, dipotassium salt

Disperbyk-111 or 180: dispersing additives of BYK-Chemie

DMAEMA: dimethylaminoethyl methacrylate

DOP: dioctyl phthalate

DVB: divinylbenzene

E-81: a charge control agent made by Orient Kagaku K.K.

EA: ethyl acetate

EGDMA: ethyleneglycol dimethacrylate

2-EHA: 2-ethylhexyl acrylate

2-EHMA: 2-ethylhexyl methacrylate

EMA: ethyl methacrylate

GMA: glycidyl methacrylate

HCO-60: polyoxyethylene hardened castor oil

HCPK: 1-hydroxycyclohexyl phenyl ketone

HA: hexanol

HD: hexadecane

HEMA: 2-hydroxyethyl methacrylate

Hp: heptane

HQ: hydroquinone

IA: isoamyl acetate

IO: isooctane

IPSO: iodinated poppy seed oil 
LA: lauryl acrylate

LMA: lauryl methacrylate

LOH: lauryl alcohol

LPC: lysophosphatidylcholine

Lysozyme: $1,4-\beta-\mathrm{N}$-acetylmuramidase (enzyme)

MA: methyl acrylate

MCT: medium chain triglycerides

METAC: 2-(methacryloyloxy) ethyl trimethyl ammonium chloride

ML: methyl laurate

MMA: methyl methacrylate

4-MP: 4-methyl-2-pentanol

MST-1: stabiliser of Nippon NSC Ltd.

Myrj 52: PEG-40 Stearate

MSW-7S: decaglycerol monostearate

NIPAAm: N-isopropylacrylamide

OA: isooctane

ODT: octadecanethiol

PA: polyamide

PAA: poly(acrylic acid)

PAAm: polyacrylamide

PBA: poly(normal-butyl acrylate)

PC: phosphatidylcholine (lecithin)

PDA: p-phenylenediamine

PEGMMA: polyethylene glycol monomethacrylate

PEGPMMA: polyethylene glycol polymethacrylate 
PGML: pentaglycerin monolaurate

PGPR: polyglycerol polyricinoleate (E 476)

PIP: polyimide prepolymer

PLA: polylactide acid

PMMA: polymethyl methacrylate

PNIPAAm: poly( $N$-isopropylacrylamide)

POPC: 1-palmitoyl-2-oleoyl-sn-glycero-3-phosphocholine

POPS: 1-palmitoyl-2-oleoyl-sn-glycero-3-phospho-L-serine

PSt: polystyrene

PVA: polyvinyl alcohol

PVP: polyvinyl pyrrolidone

PU: polyurethan

PUU: polyurethaneurea

SBR: styrene-butadiene rubber

SDS: sodium dodecyl sulfate

SLS: sodium lauryl sulfate

Span 20: sorbitan monolaurate

Span 80: sorbitan monooleate

Span 85: sorbitan trioleate

SPBS: Sumiplast Blue S (colorant)

St: styrene

SteAm: stearylamine

t-BPP: tert-butyl peroxypivalate

TCB: trichlorobenzene

TDS: terephthaloyl dichloride 
TGCR: tetraglycerin condensed ricinoleate

THF: tetrahydrofuran

Tl: toluene

TMPTMA: trimethyolpropane trimethacrylate

TPGDA: tripropyleneglycol diacrylate

Tween 20: polyoxyethylene (20) sorbitan monolaurate

Tween 80: polyoxyethylene (20) sorbitan monooleate

Tween 85: polyoxyethylene (20) sorbitan trioleate

TGPR: tetraglycerol polyricinoleate

TMEDA: N,N,N',N'-tetramethylethylenediamine

VP: vinyl polymer

WPI: whey protein isolate

Xl: xylen

\section{Figure captions}

Figure 1: Examples of vesicles (lipid, polymeric, and colloidal) manufactured from emulsion droplets templates.

Figure 2: Examaples of polymer and solid lipid microparticles manufactured from emulsion droplets templates using membrane and microfludic devices.

Figure 3: Membrane emulsification methods: (a) Direct ME (Nakashima et al., 1991a). (b)

Premix ME (Suzuki et al., 1996). (c) Premix ME with phase inversion (Suzuki et al., 1999). 
Figure 4: ME systems for controlling tangential shear at the membrane surface in the direct ME: (a) Cross-flow system (Nakashima et al., 1991a). (b) Stirring systems (Kosvintsev et al., 2005; You et al., 2001). (c) Rotating/vibrating membrane systems (Vladisavljević and Williams, 2006; Kosvintsev et al., 2005). (d) Dead-end system (Kobayashi et al., 2003a).

Figure 5: Examples of rotating membranes used for emulsification: (a) Rotating membrane fabricated by deposition of pure carbon layer on the microporous nickel substrate (Schadler and Windhab, 2004). (b) Rotating stainless steel membrane with laser drilled pores (Vladisavljević and Williams, 2006). (c) A batch rotating membrane emulsification system in operation (Vladisavljević and Williams, 2006).

Figure 6: Schematic representation of phase inversion of $\mathrm{W} / \mathrm{O} / \mathrm{W}$ emulsion into a $\mathrm{W} / \mathrm{O}$ emulsion by extrusion the multiple emulsion through hydrophobic polycarbonate membrane.

Figure 7: Microstructure of SPG membrane observed using different techniques: (a) SEM image of membrane surface. (b) Microscopic image of droplet formation at the surface of SPG membrane. The pores are visible as dark tortuous regions (c) High resolution X-ray microtomograph of an internal cross section of SPG membrane with a mean pore size of 20 $\mu \mathrm{m}$, showing a uniform microstructure without any voids or cracks. More than 1000 pores per square mm were identified using a high resolution XMT scanner (Vladisavljević et al., 2007).

Figure 8: Different microfluidic junctions for droplet generation and manipulation: (a) Tjunction at inlet (Thorsen et al., 2001). (b) T-junction at outlet (Link et al., 2004; Tan et al., 
2004). (c) Sheath-flow junction (Xu and Nakajima, 2004; Nisisako et al., 2004). (d) Yjunction (Nisisako et al., 2004, 2005).

Figure 9: Different configurations of silicon microchannel (MC) arrays for droplet generation developed in Nakajima Lab at the National Food Research Institute in Tsukuba, Japan.

Figure 10: Production of multiple emulsions using different membrane and microfluidic methods: (a) XME (Vladisavljević and Schubert, 2003; Mine et al., 1996). (b) repeated membrane homogenisation (Vladisavljević et al., 2004b). (c) Straight-through MC emulsification (Kobayashi et al., 2005c). (d) MC emulsification using grooved-type microchannel arrays (Kawakatsu et al., 2001; Sugiura et al., 2004a).

Figure 11: W/O/W emulsion prepared by SPG membrane emulsification for transcatheter arterial injection chemotherapy of hepatocellular carcinoma (HCC): (a) Microscopic view of multiple emulsion droplets. Internal water droplets containing anti-cancer drug are visible as black dots. (b) Particle size distribution of external droplets immediately after preparation and 40 days after preparation (Nakashima et al., 2002; Higashi et al., 1995).

Figure 12: Preparation of uniform W/O/W emulsions by repeated SPG membrane homogenisation: (a) Experimental set-up and micrographs of feed and product emulsion droplets. (b) Membrane homogeniser of Kiyomoto Iron Works Company (Vladisavljević et al., 2004b, 2006).

Figure 13: Flowsheet of a membrane homogenisation process for the production of $\mathrm{W} / \mathrm{O} / \mathrm{W}$ emulsions containing biopolymer-gelled water droplets (Surh et al., 2007). 
Figure 14: Photomicrographs showing monodisperse $\mathrm{W} / \mathrm{O} / \mathrm{W}$ emulsion droplets obtained in straight-through MC emulsification process at the pressure difference across the channels of $1.3 \mathrm{kPa}$ and continuous phase cross-flow velocity of $1.2 \mathrm{~mm} / \mathrm{s}$. The concentration of internal droplets in the outer drops ranged between 0 and 30 vol. $\%$ and the channel dimensions were $42.8 \times 13.3 \mu \mathrm{m}$

Figure 15: Production of double emulsions using two T-junctions in series with opposite surface wettabilities: (a) Production of W/O/W emulsion, in which each outer drop contains a single inner droplet. (b) Production of W/O/W emulsion, in which each outer drop contains two inner droplets containing different aqueous phases I and II. Alternating generation of different inner droplets is achieved using an upstream cross-junction (Okushima et al., 2004).

Figure 16: Micrographs of droplet generation using different combinations of T-junctions: (a) Alternating formation of differently coloured droplets at a cross-junction. (b) W/O/W emulsion droplets containing differently coloured inner droplets. (c) Formation of O/W/O mutiple emulsion drops containing a single oil droplet in each outer water drop. (d) Uniform $\mathrm{O} / \mathrm{W} / \mathrm{O}$ emulsion droplets after generation (Okushima, 2004).

Figure 17: Microcapillary glass devices for generation of uniform emulsions from coaxial liquid jets developed in Weitz Lab at Harvard University. This approach allows single, double or triple emulsion droplets to be generated in a single step (Weitz, 2007).

Figure 18: Flowsheet for the manufacture of solid lipid microcarriers for hydrophilic active ingredients using $\mathrm{W} / \mathrm{O} / \mathrm{W}$ double emulsion technique and SPG membrane homogenisation. 
The dashed area represents the temperature-controlled processes carried out at $80{ }^{\circ} \mathrm{C}$ (above a melting point of oil).

Figure 19: The SEM images and size distribution curve of a solid lipid carrier with a mean size of $8.4 \mu \mathrm{m}$ for oral administration of anticancer drug irinotecan hydrochloride (CPT-11). The carrier was prepared by repetead homogenisation under $30 \mathrm{kPa}$ using SPG membrane with a mean pore size of $11.2 \mu \mathrm{m}$, followed by cooling down and filtration of the hardened W/O particles (Shimizu et al., 2002a).

Figure 20: General flowsheet for manufacture of polymer microspheres by two-stage suspension polymerization using membrane emulsification for generation of seed droplets.

Figure 21: Production of core-shell polymeric particles in a continuous microfluidic reactor (Nie et al., 2005). The composition of the liquids A, B, and C in the double emulsion is listed in Table 6.

Figure 22: Formulation of double emulsion for encapsulation of enzymes in polymerosomes using FFMD shown in Fig. 17 (b).

Figure 23: Controlled production of giant lipid vesicles using water-in-hexane emulsion droplets as tamplates. The emulsion was formed by pressing the aqueous buffer solution through silicon microchannel array into the continuous phase containing 3 wt.\% Span 80 and 0.1 wt.\% SteAm in n-hexane (Kuroiwa et al., 2006). 
Figure 24: Experimental procedure for the hydration and dispersion of giant lipid vesicles in the external water phase (adopted from Kuroiwa et al., 2006).

Figure 25: Preparation of asymmetric vesicle from a triple emulsion using flow focusing microfluidic device shown in Fig. 17 (a) (Weitz et al., 2007). The middle fluid 1 and 2 contains two different phospholipid molecules dissolved in non-aqueous solvents.

Figure 26: Generation of uniform ball-like aggregates of PSt microparticles in microfluidic Tjunction (Yi et al., 2003a).

Figure 27: Strategy for fabrication of enzyme-loaded colloidosomes. The same approach can be used in encapsulating any other hydrophilic ingredient (Dinsmore et al., 2002).

Figure 28: Generalised flow sheet for the fabrication of colloidosomes, ball-like (3D) aggregates and composite aggregates from emulsion droplets dispersed in a suspension of uniform particles (Velev et al., 1996a). 


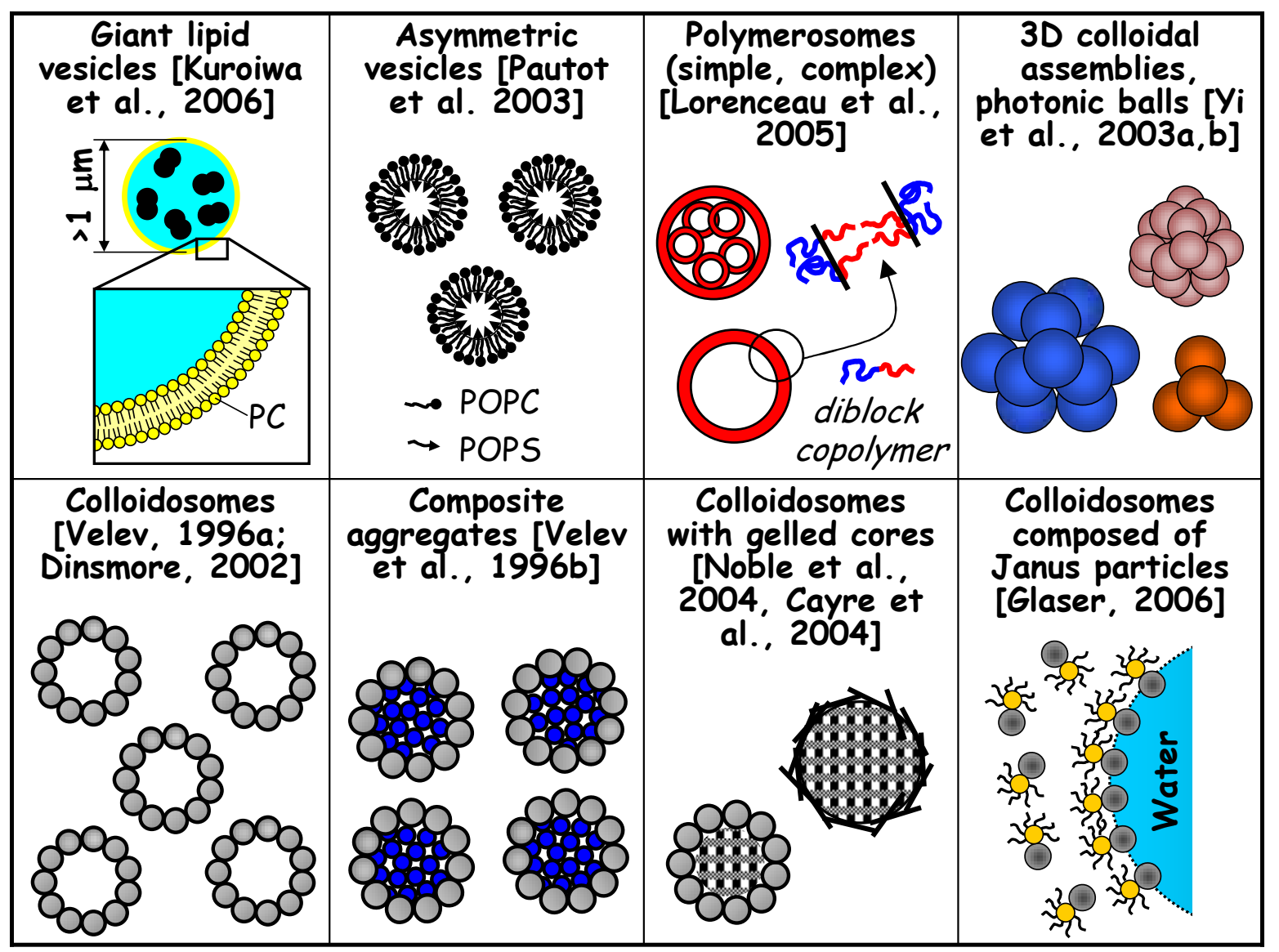

Figure 1. 


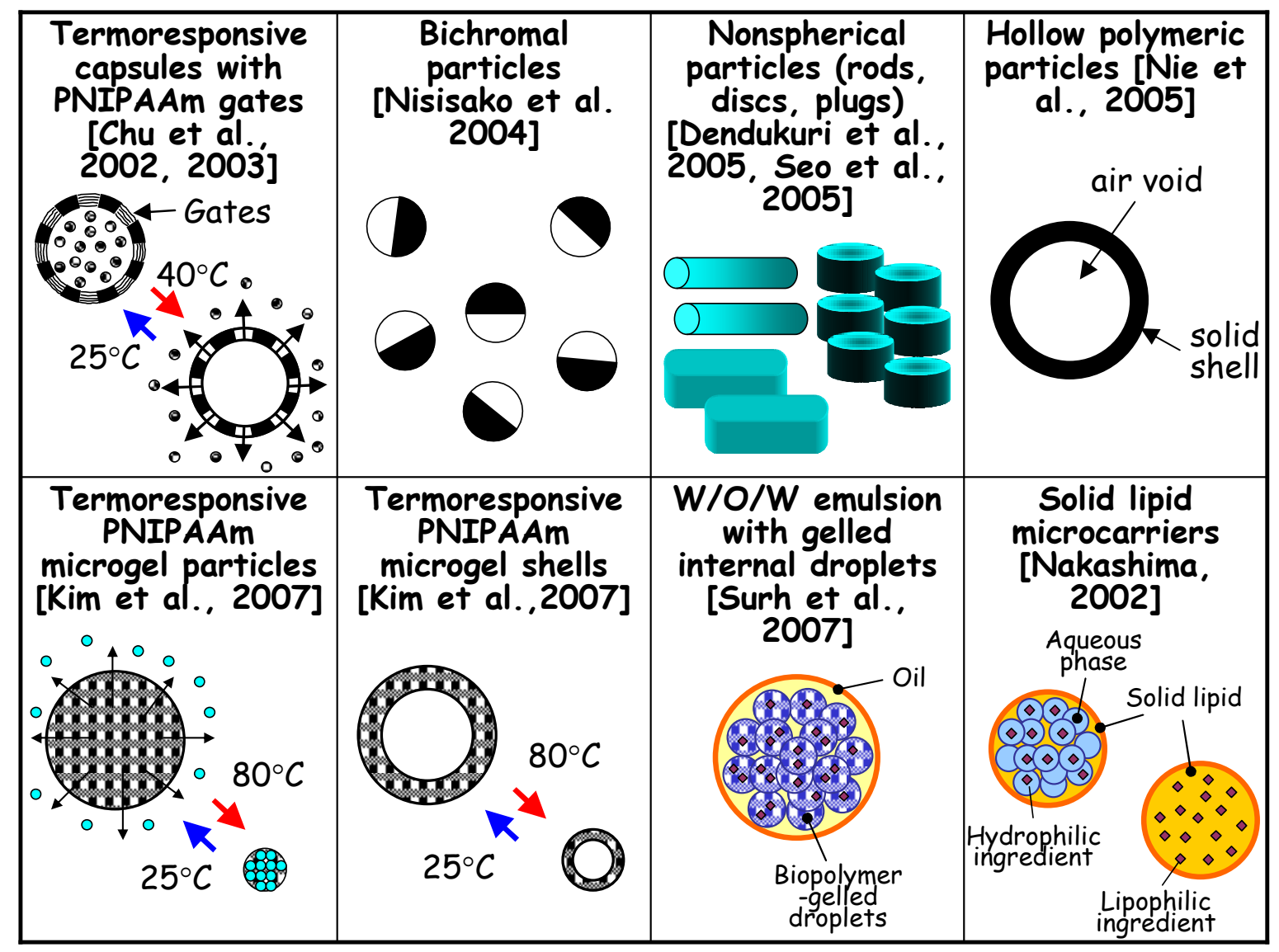

Figure 2. 
(a)

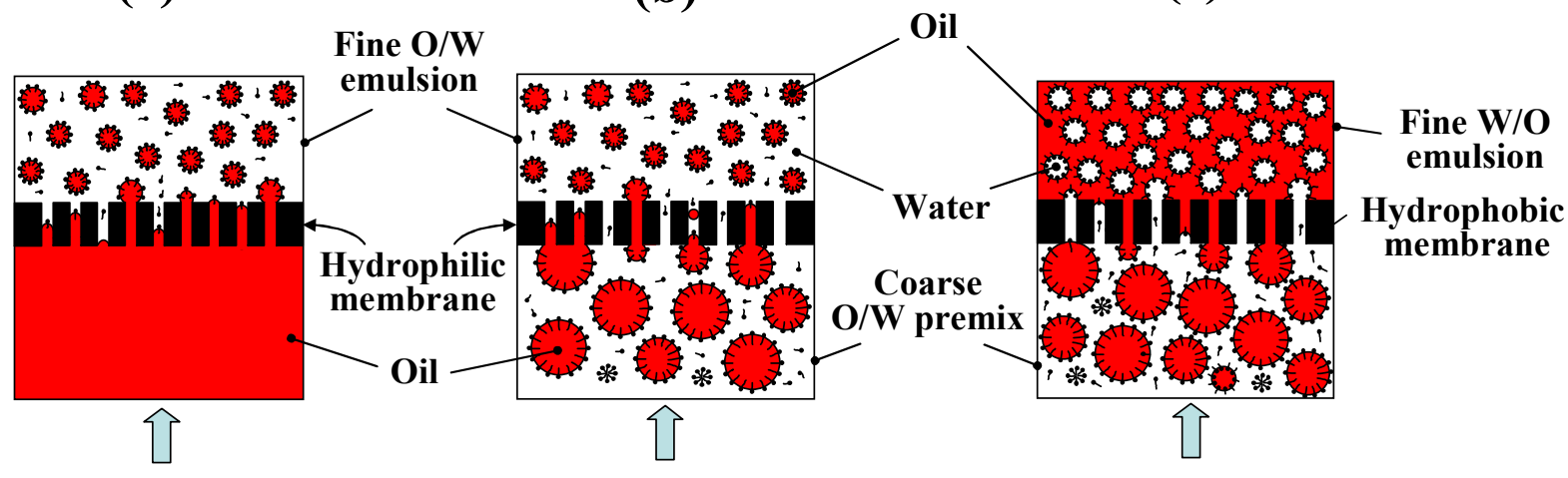

Figure 3. 


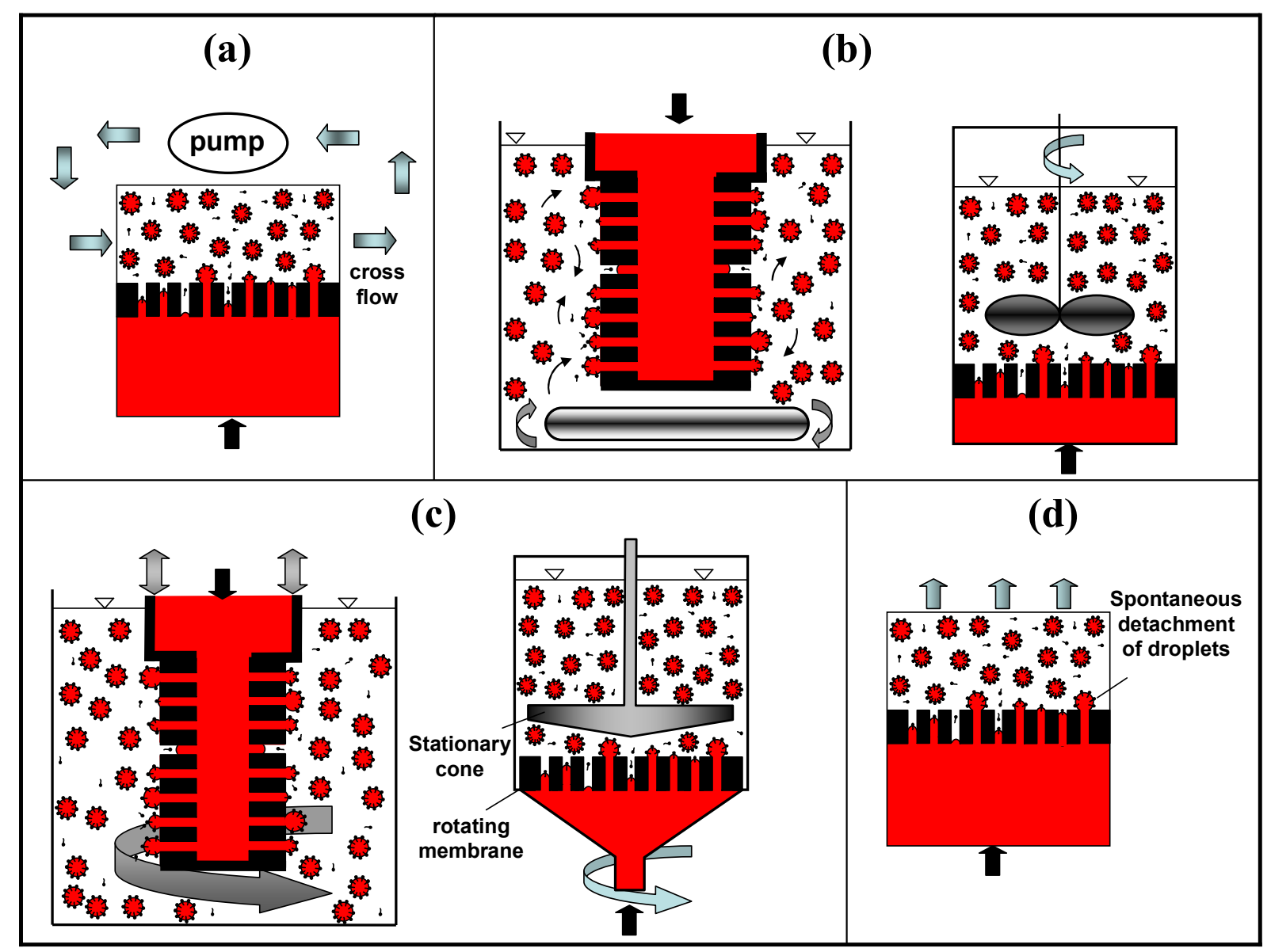

Figure 4 


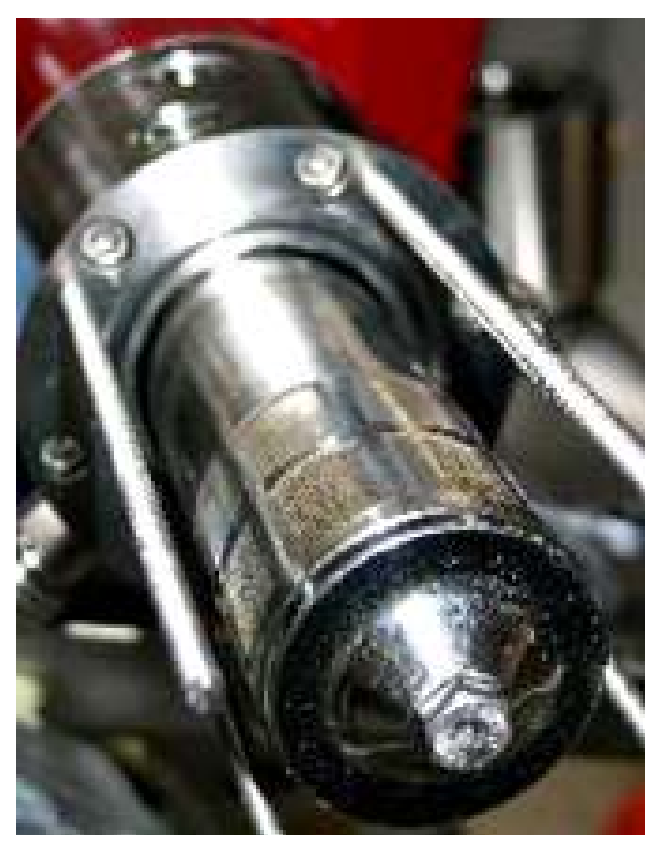

(a)

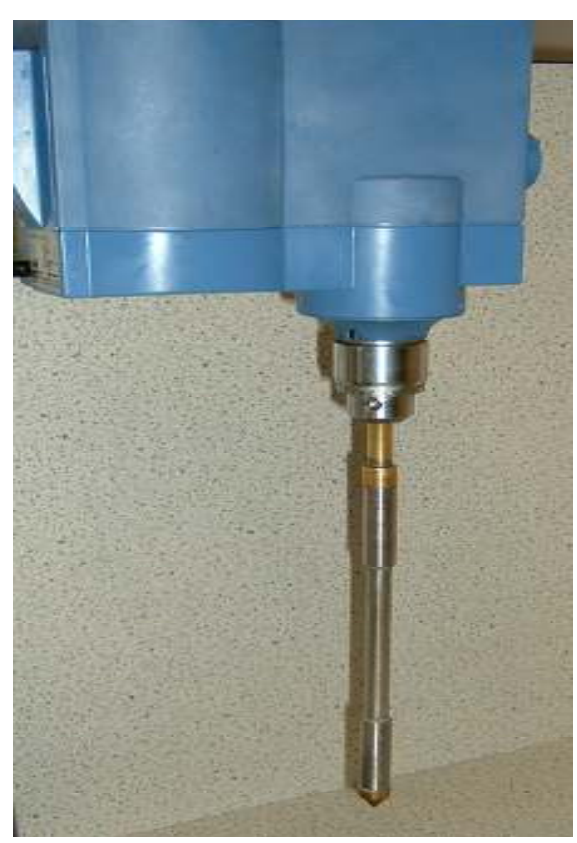

(b)

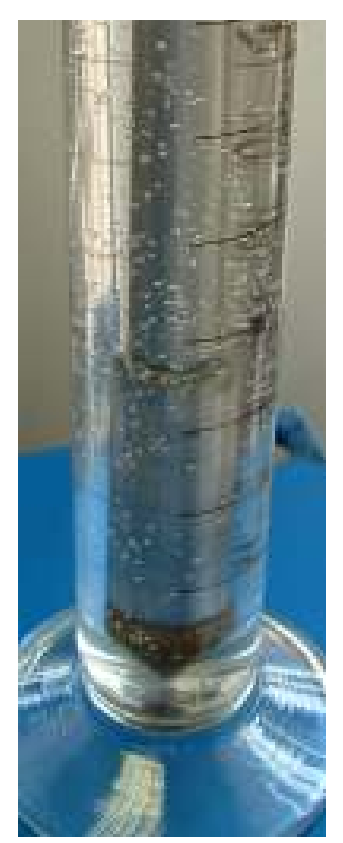

(c)

Figure 5 


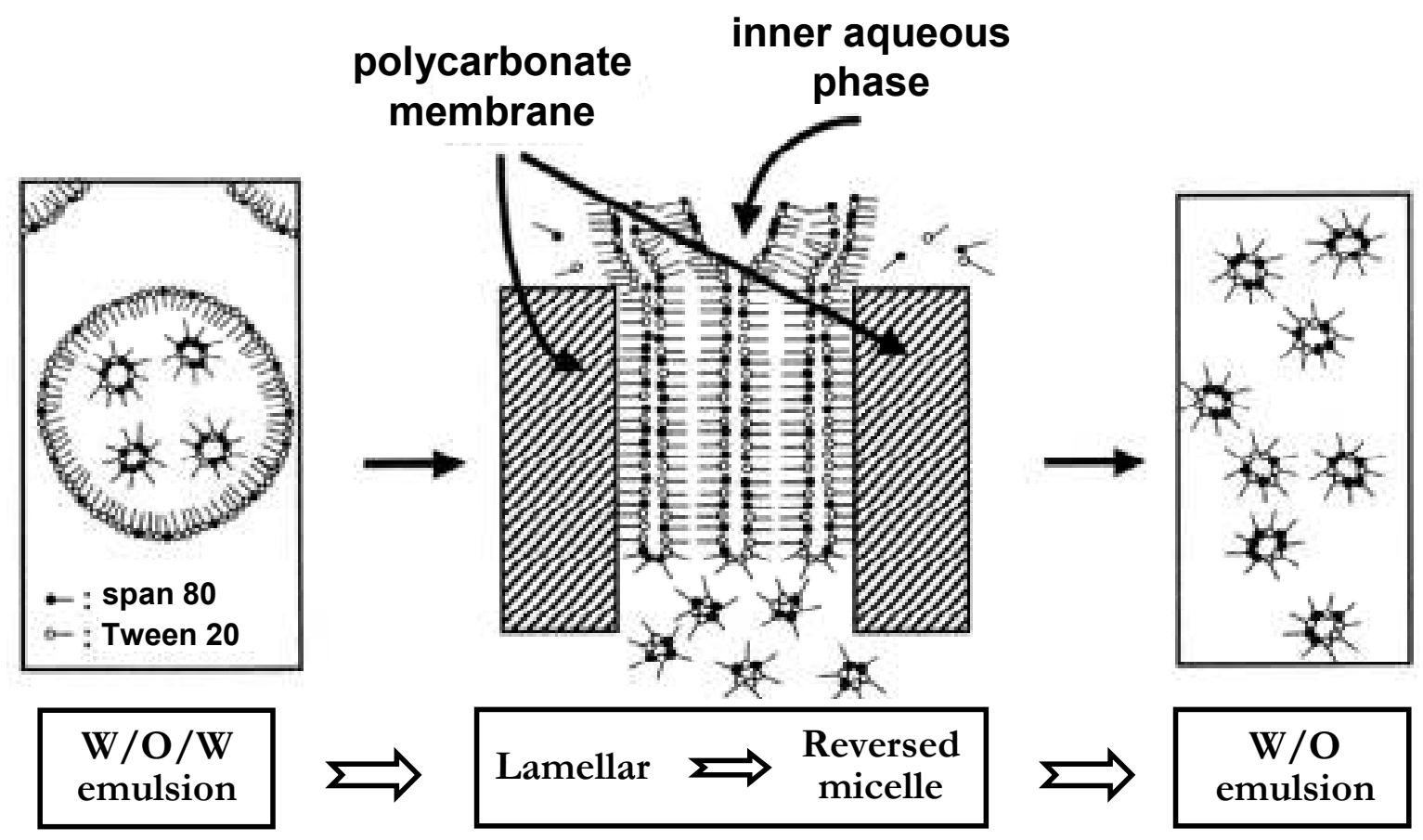

Figure 6 


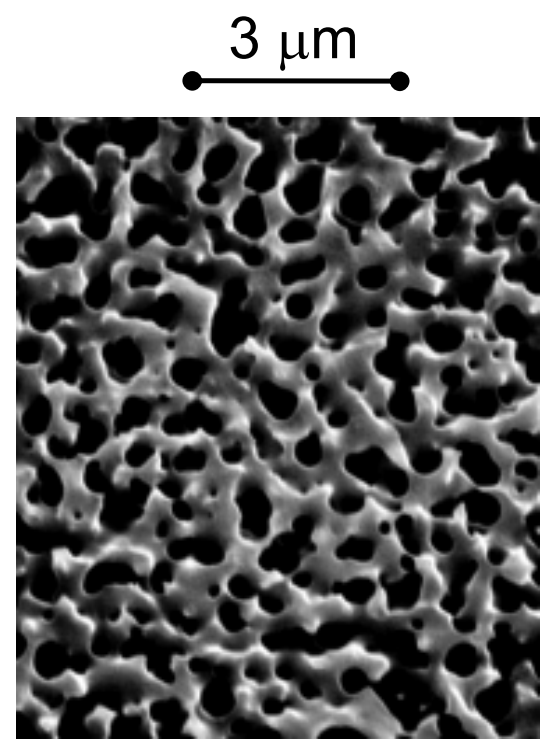

(a)

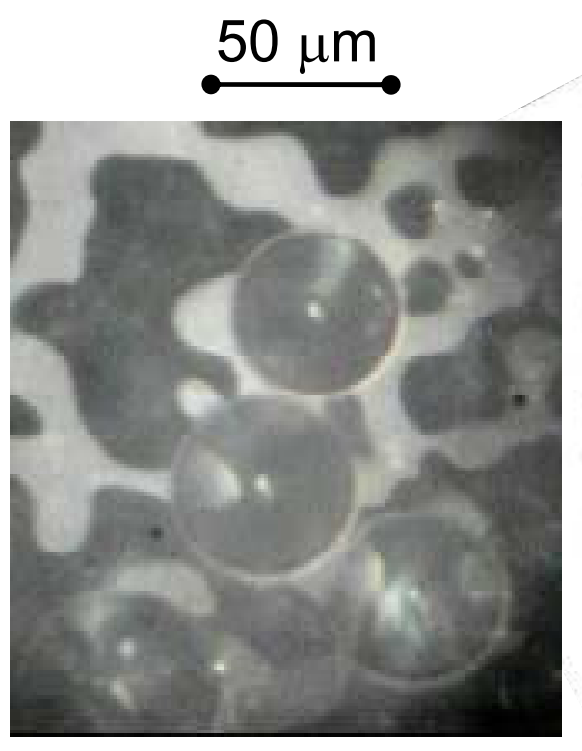

(b)

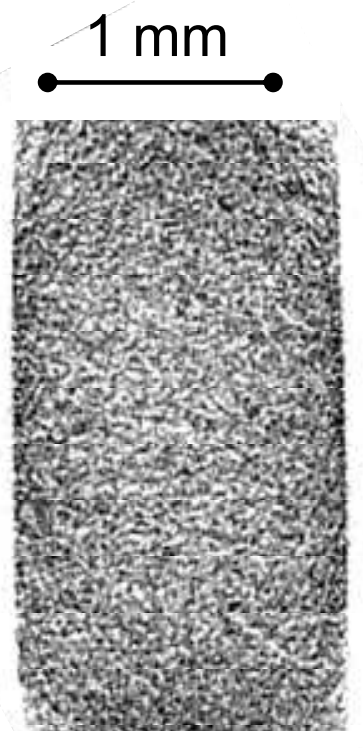

(c)

Figure 7 


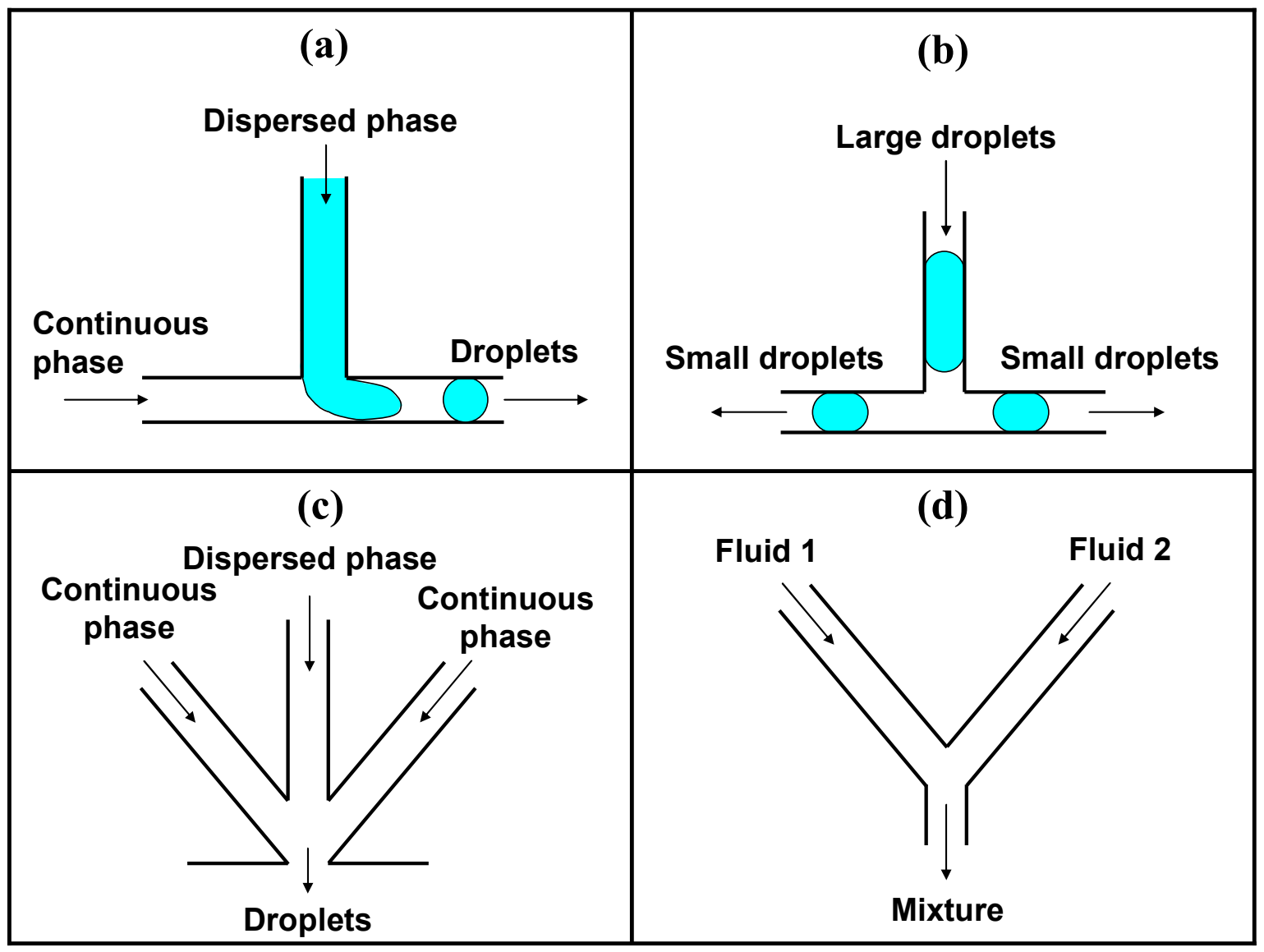

Figure 8 


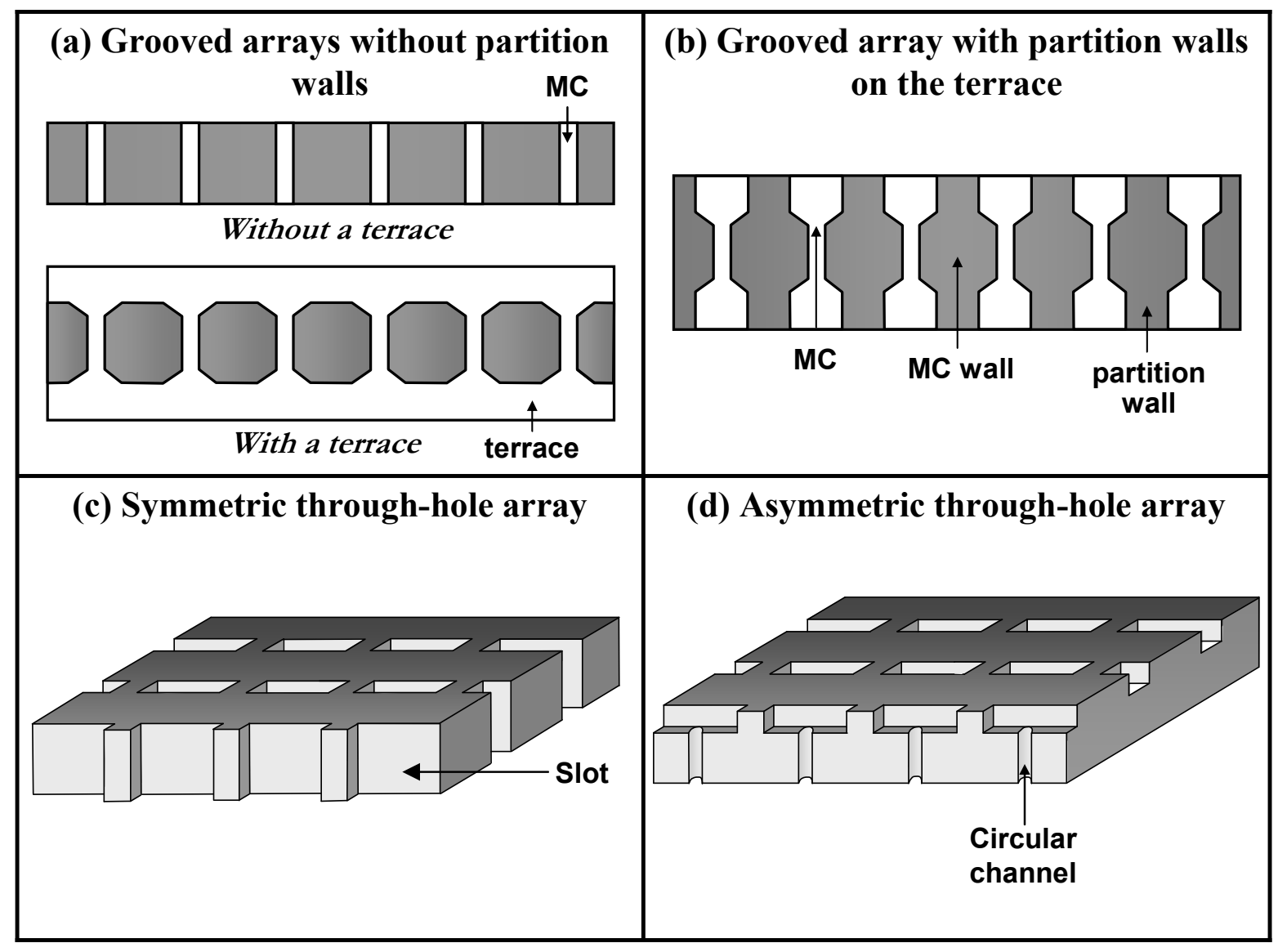

Figure 9 


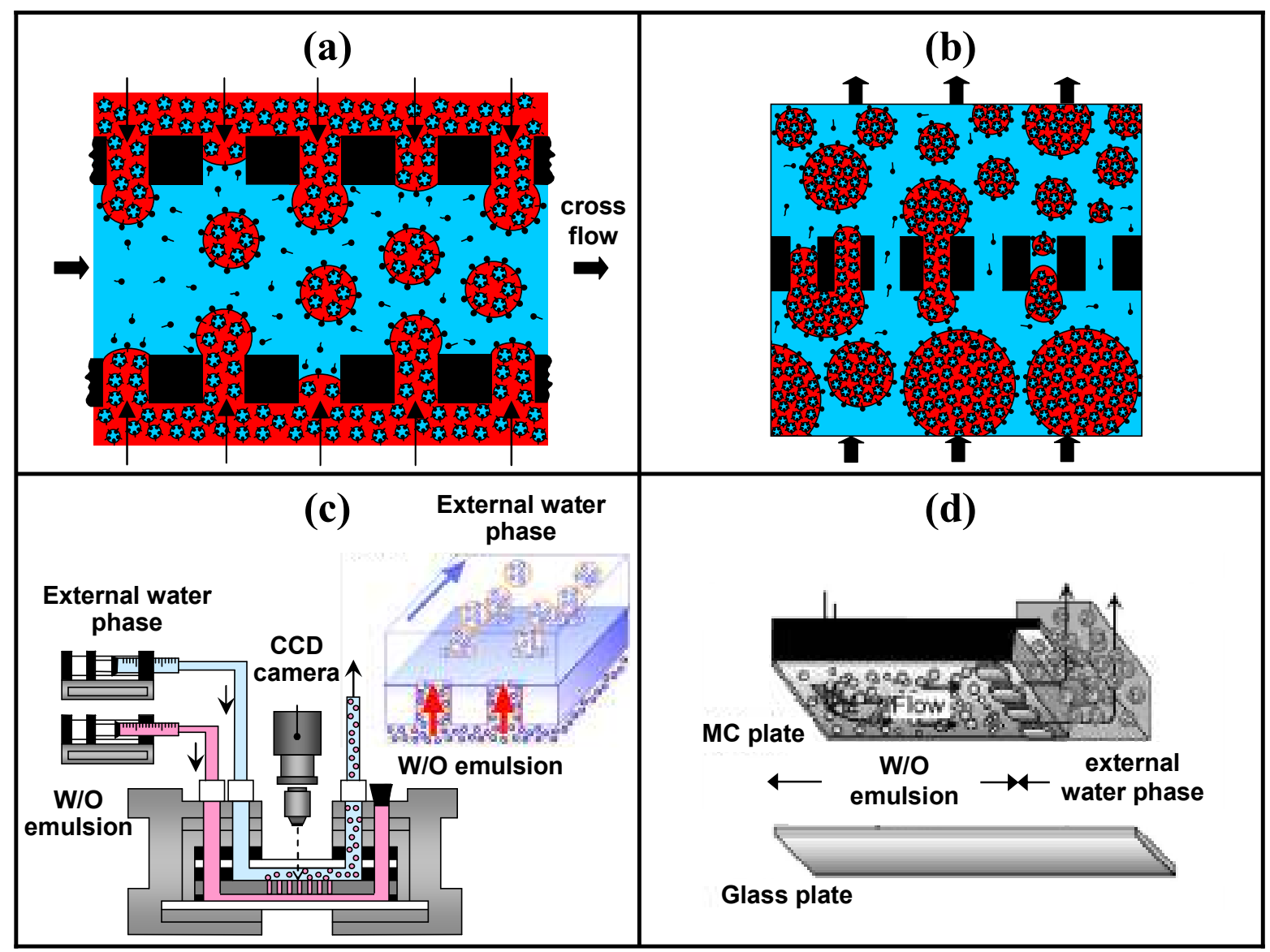

Figure 10 


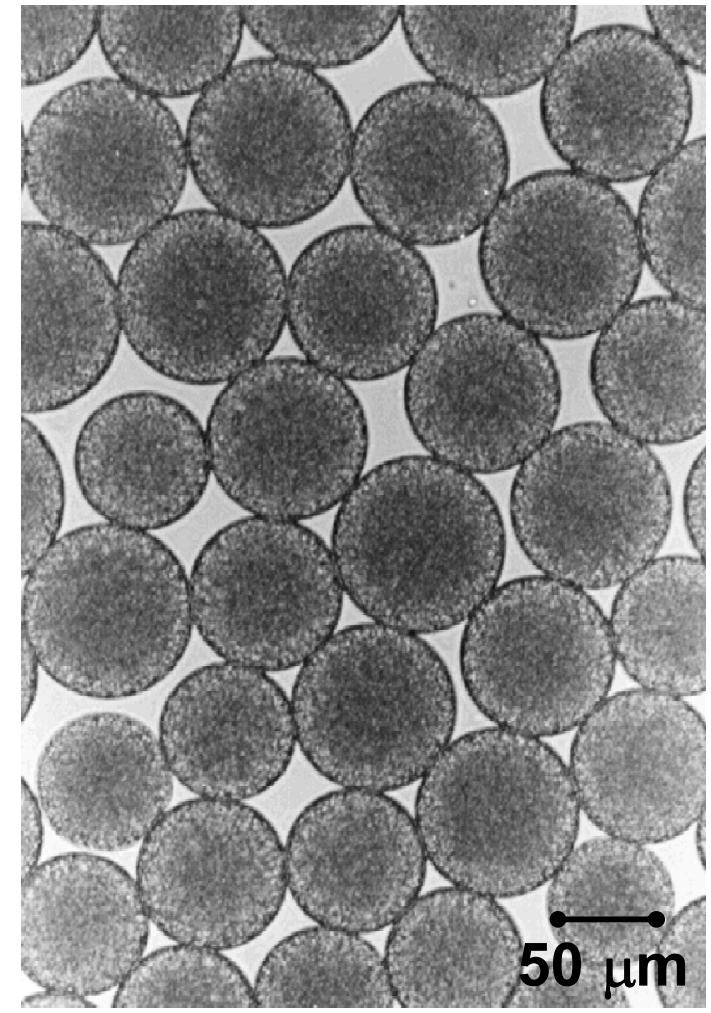

(a)

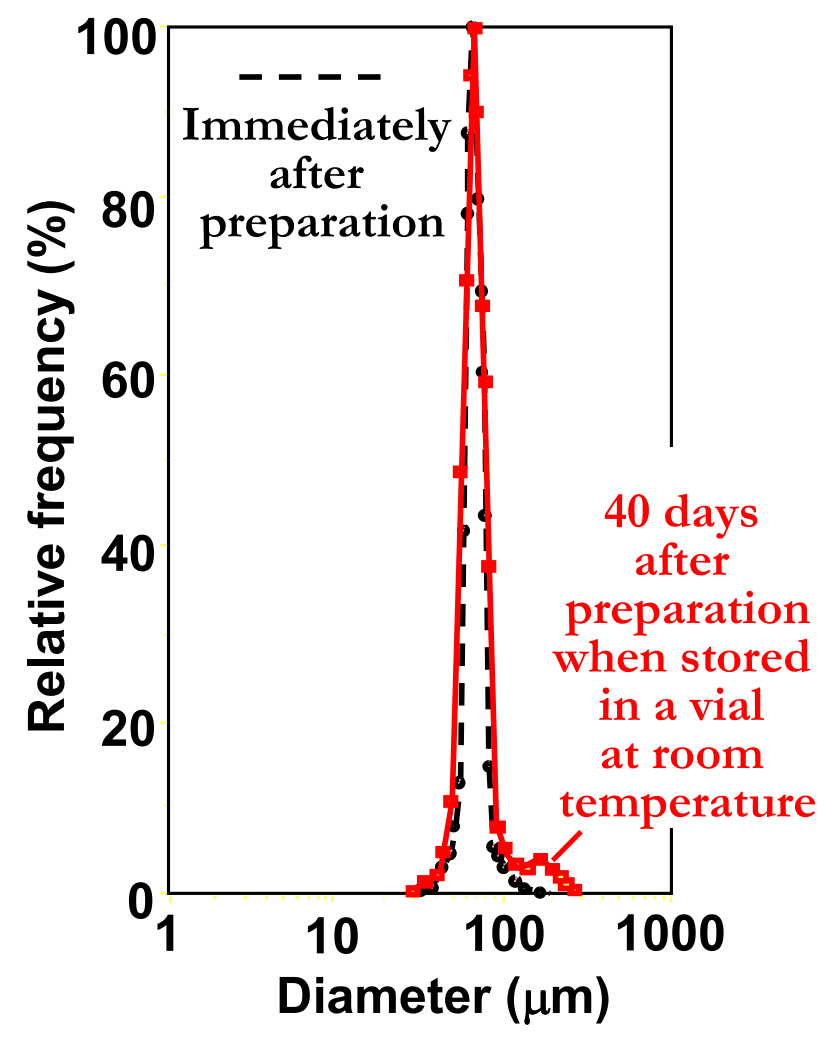

(b)

Figure 11 


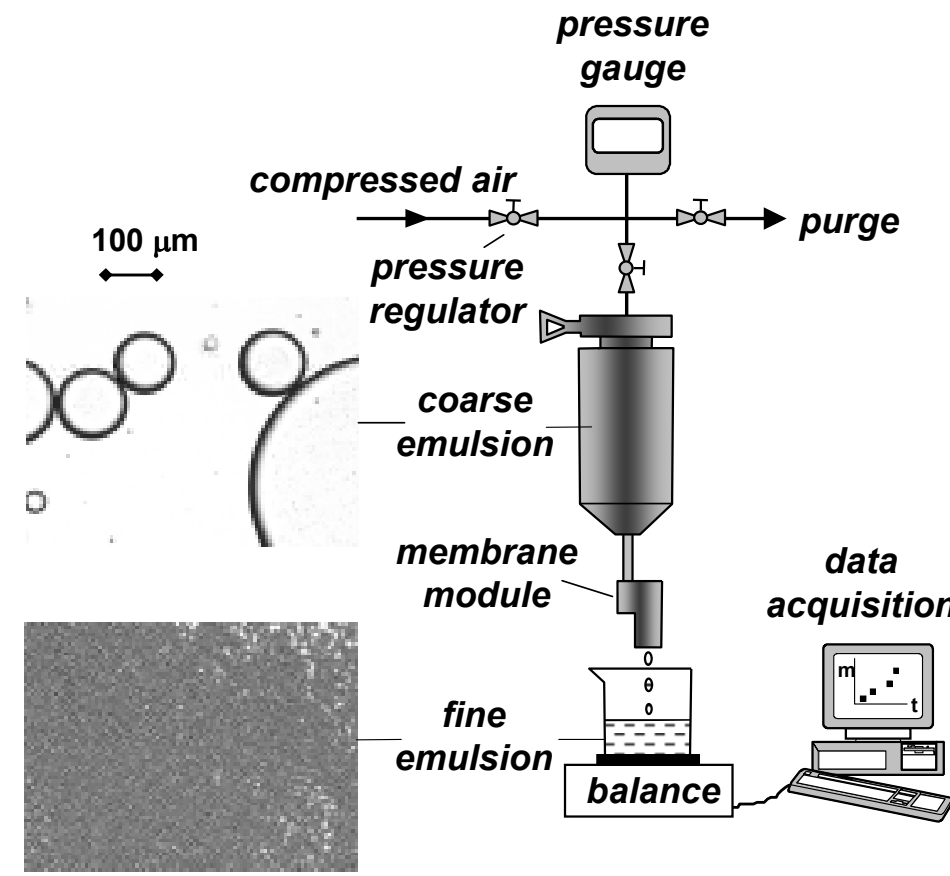

(a)

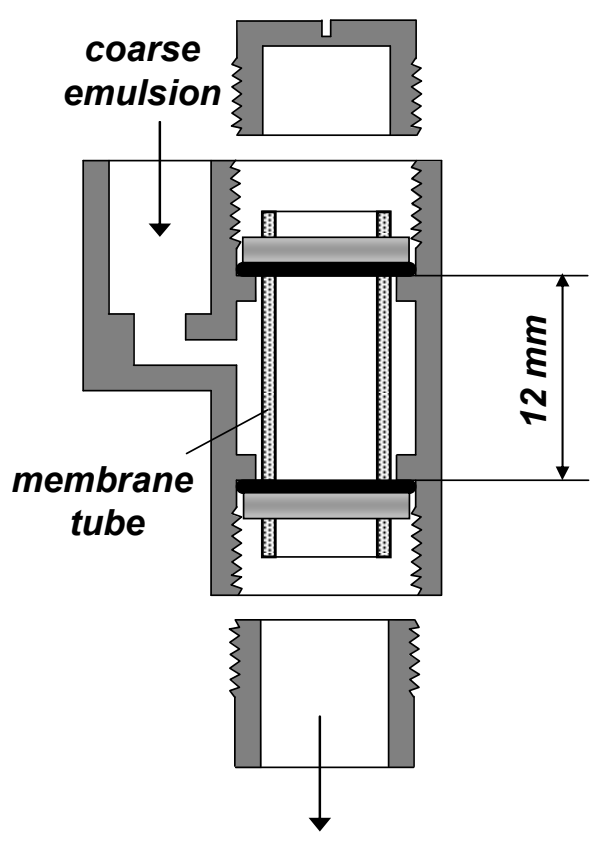

fine emulsion

(b)

Figure 12 

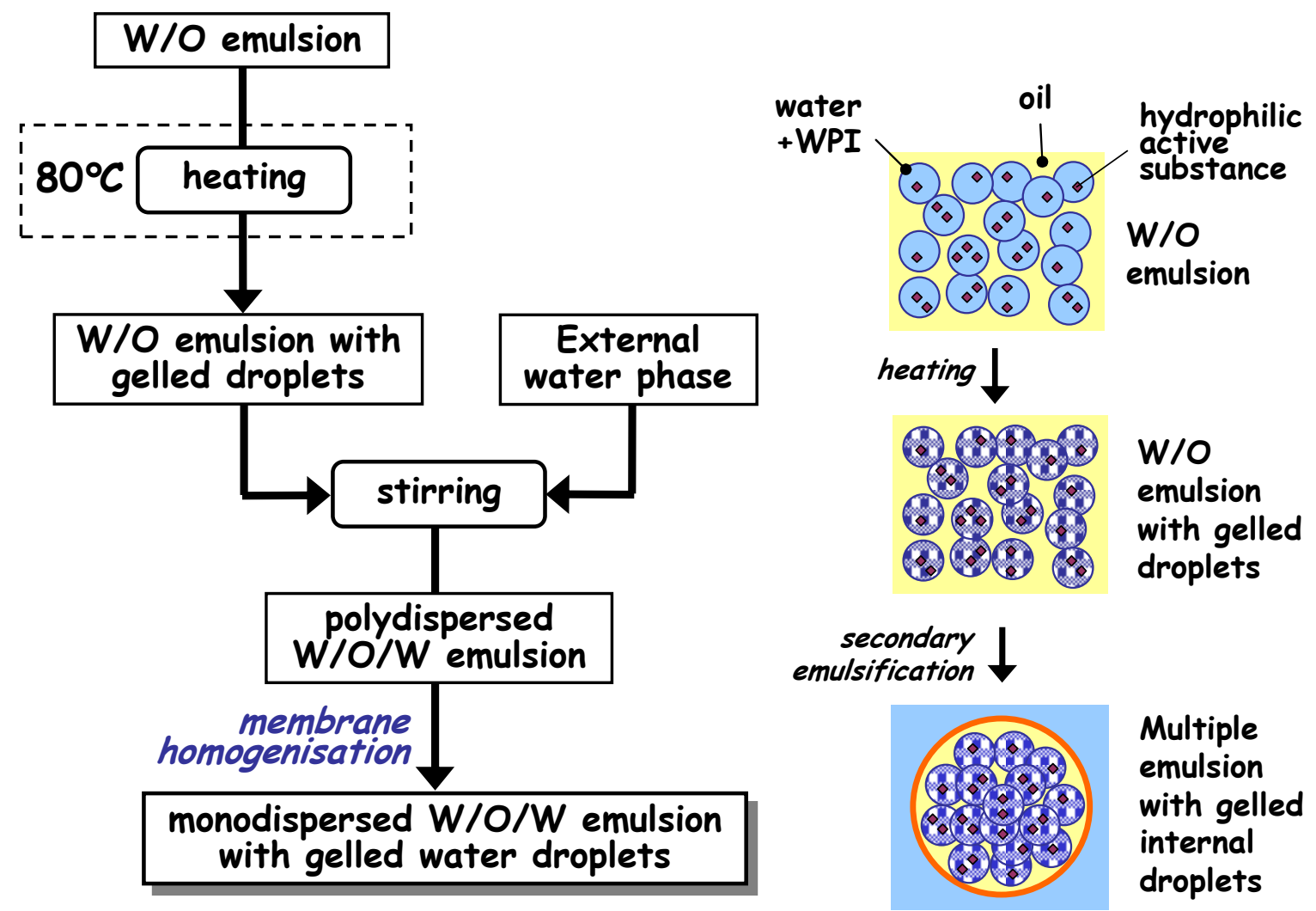

Figure 13 
(a) $\phi_{\mathrm{i}}=0 \%$

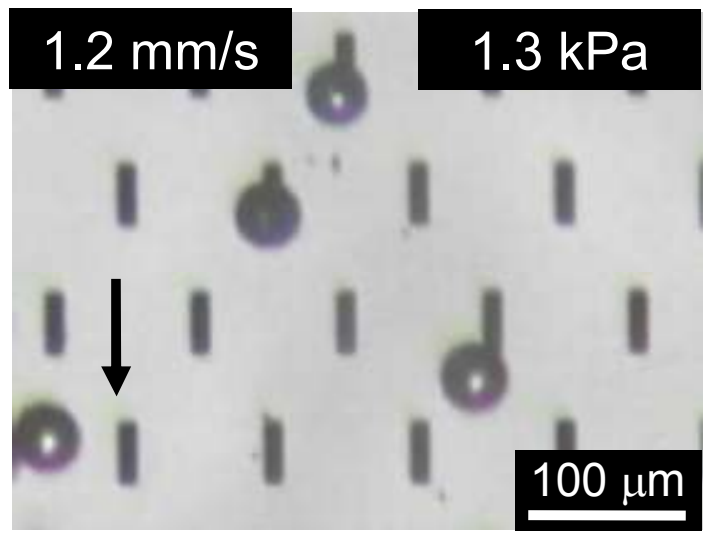

(c) $\phi_{\mathrm{i}}=20 \%$

\section{$1.2 \mathrm{~mm} / \mathrm{s}$}

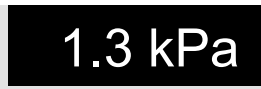

if

$100 \mu \mathrm{m}$ (b) $\phi_{\mathrm{i}}=10 \%$

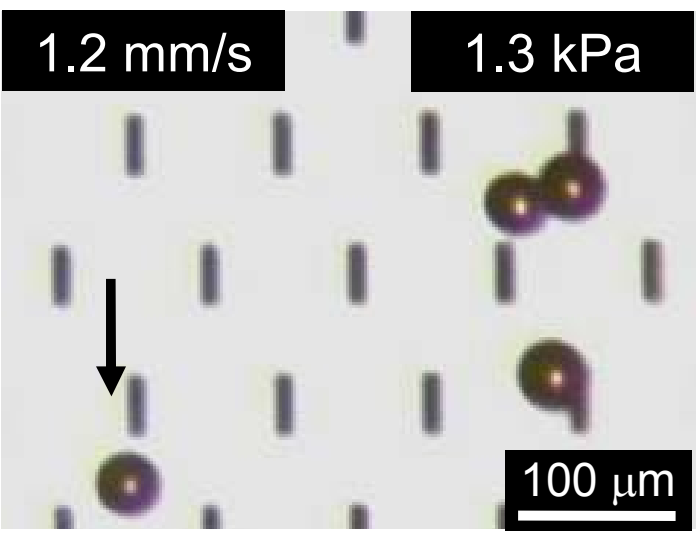

(d) $\phi_{\mathrm{i}}=30 \%$

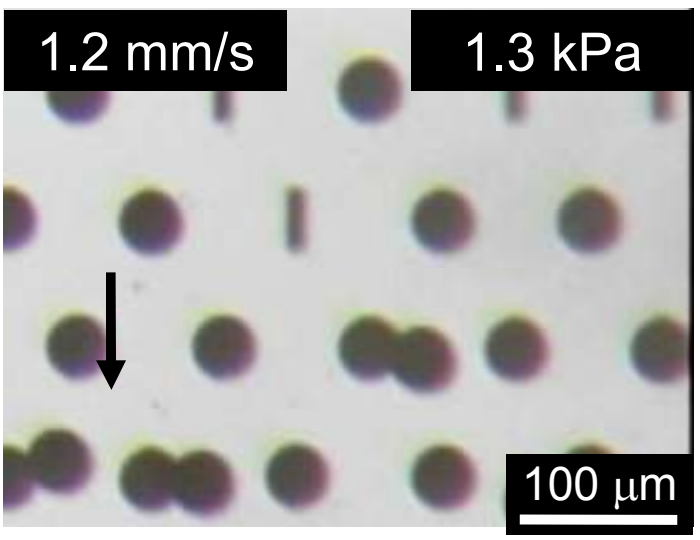




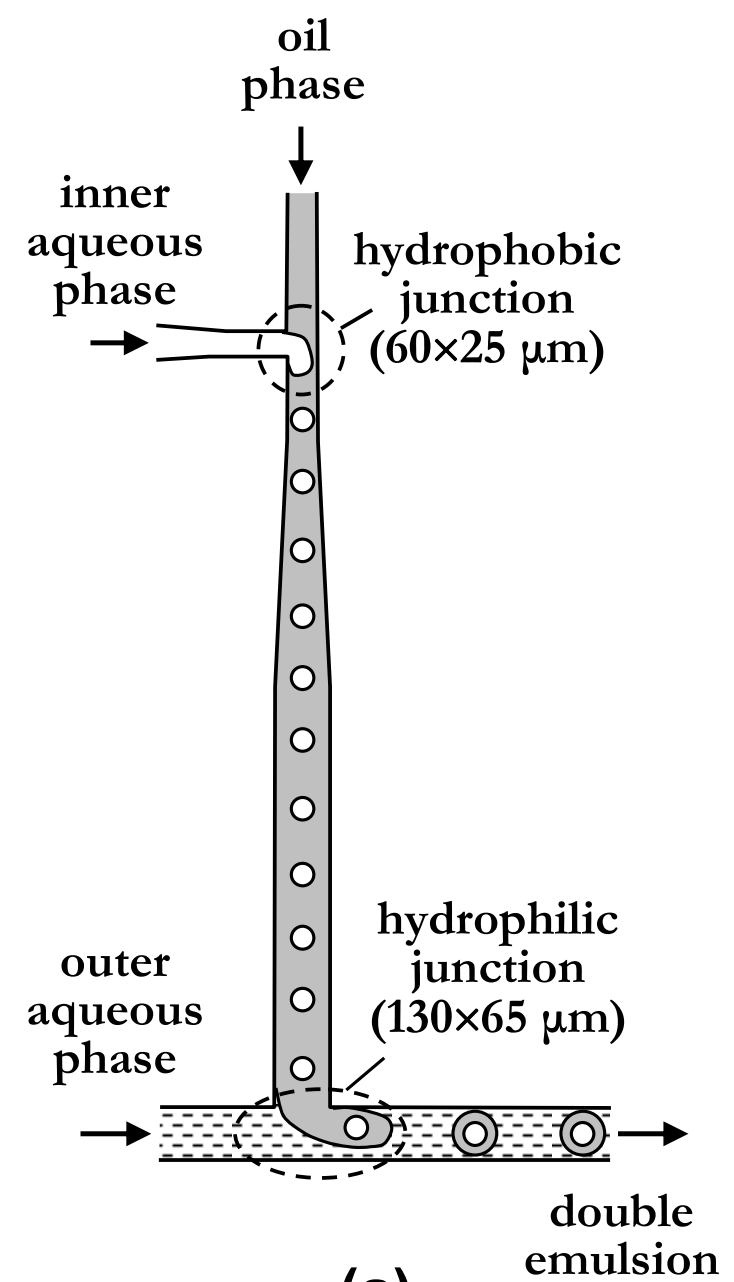

(a)

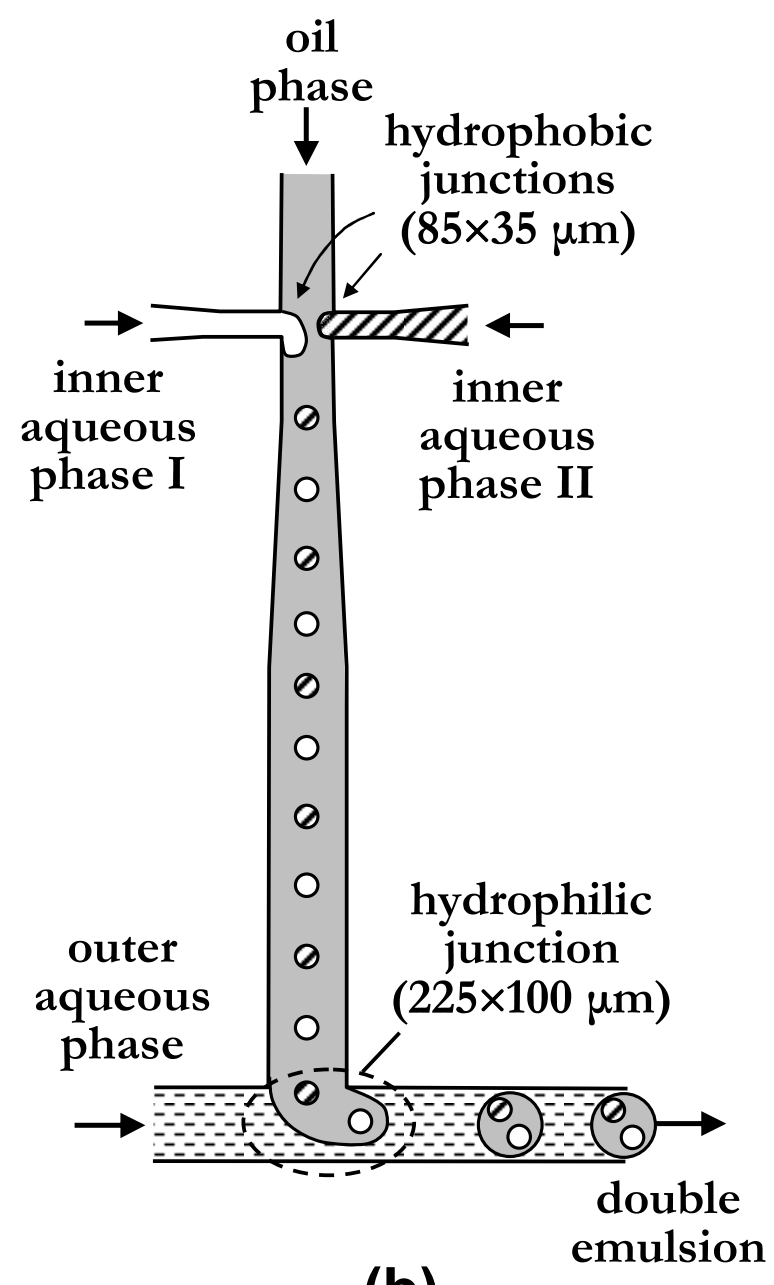

(b)

Figure 15 
(a)

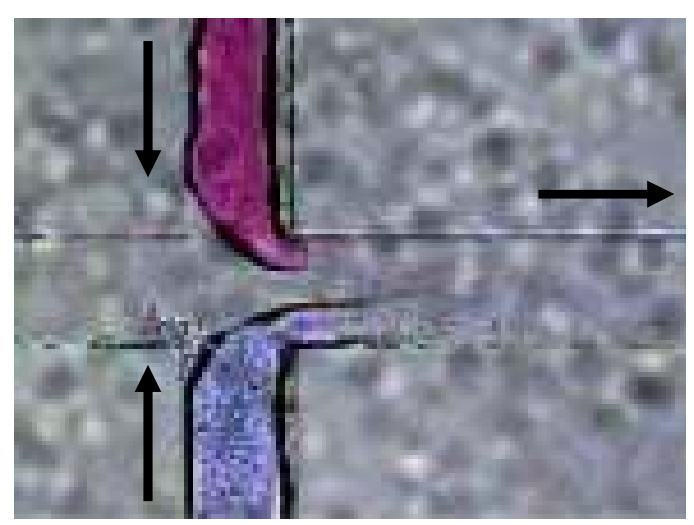

(c)

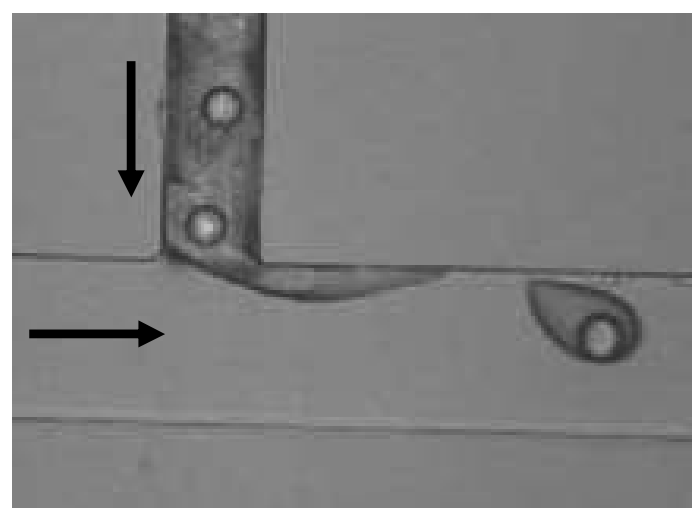

(b)

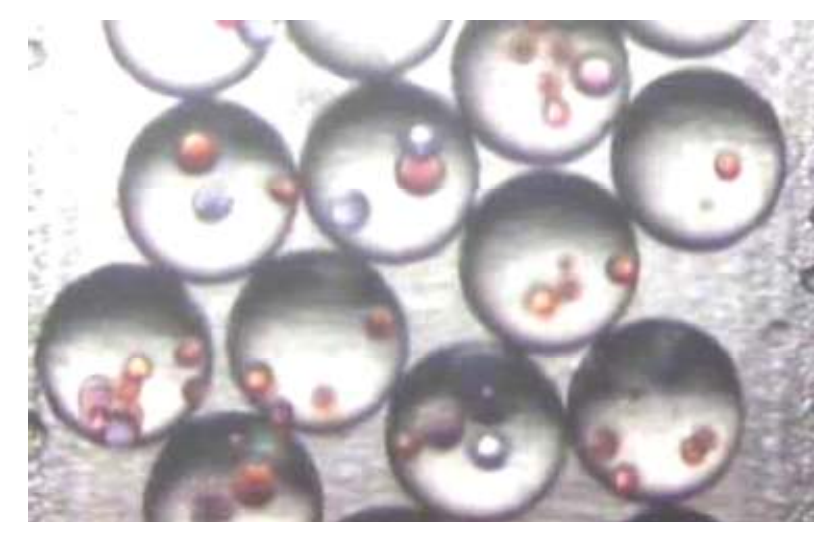

(d)

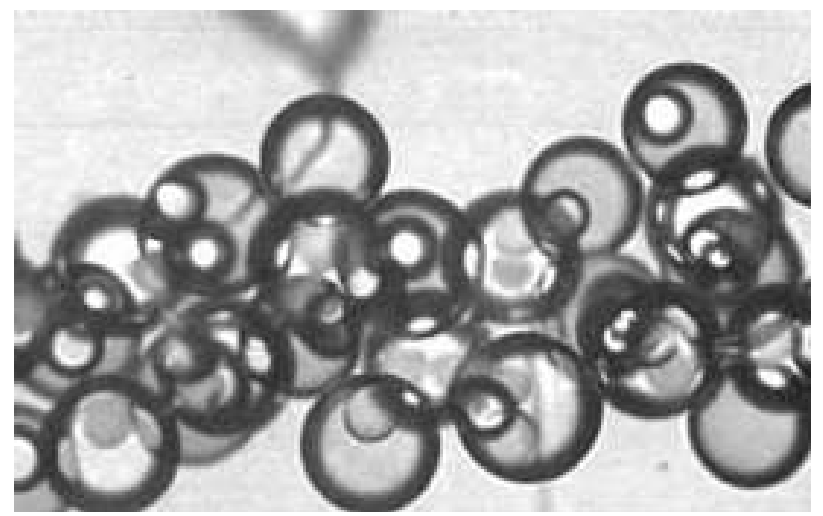

Figure 16 


\section{(a) Production of triple emulsion}

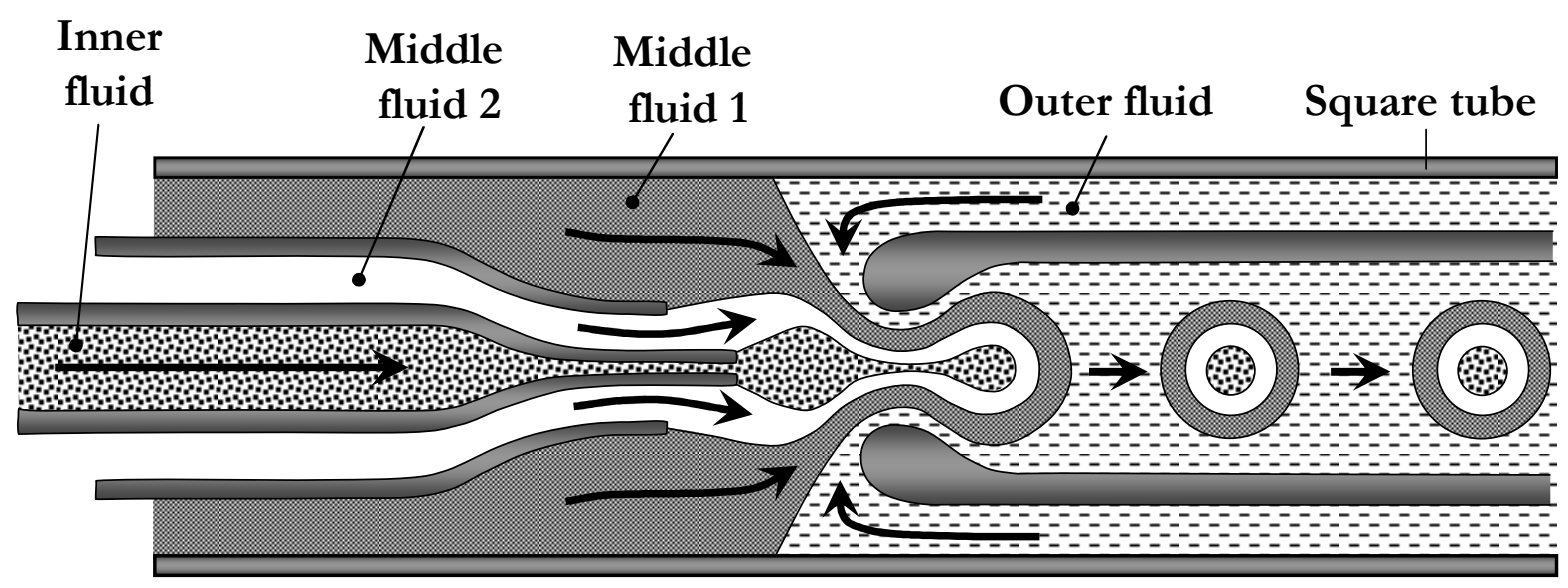

(b) Production of double emulsion

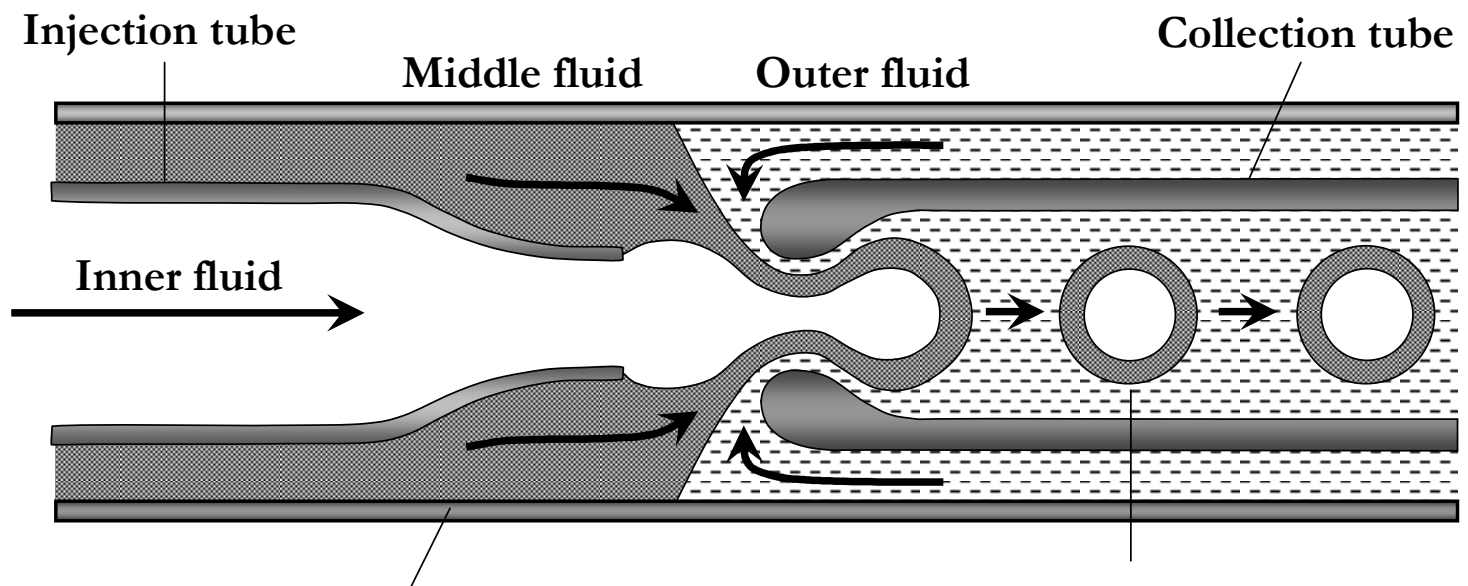

Square tube

Double emulsion

\section{(c) Production of single emulsion}

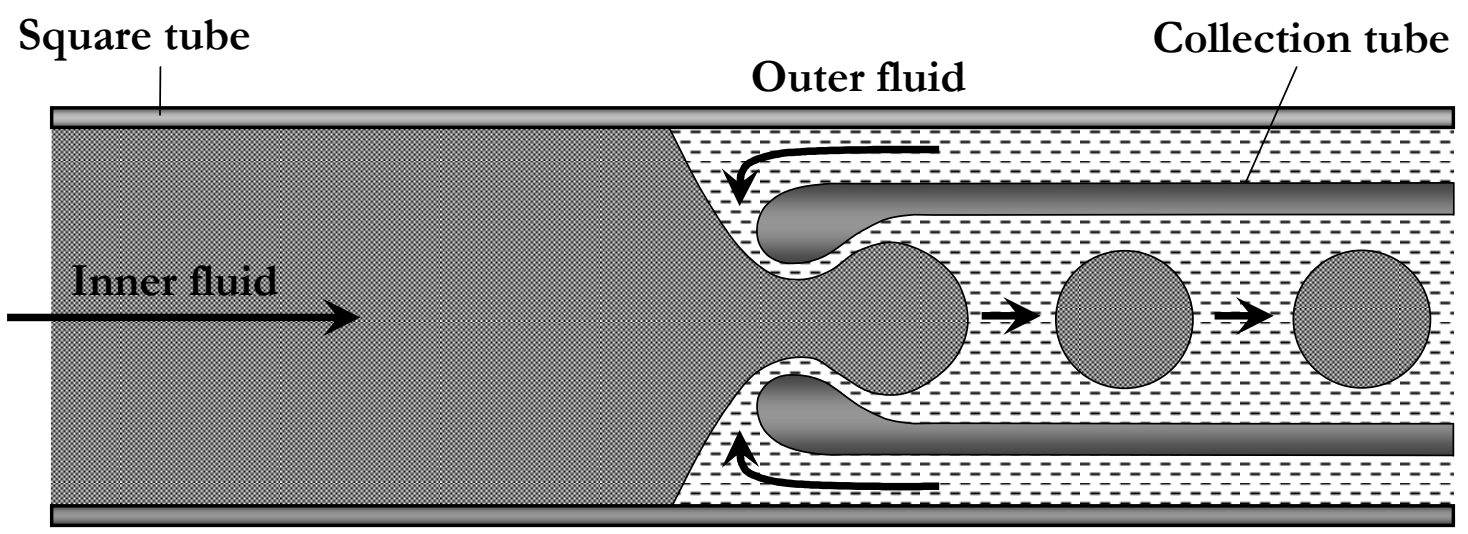




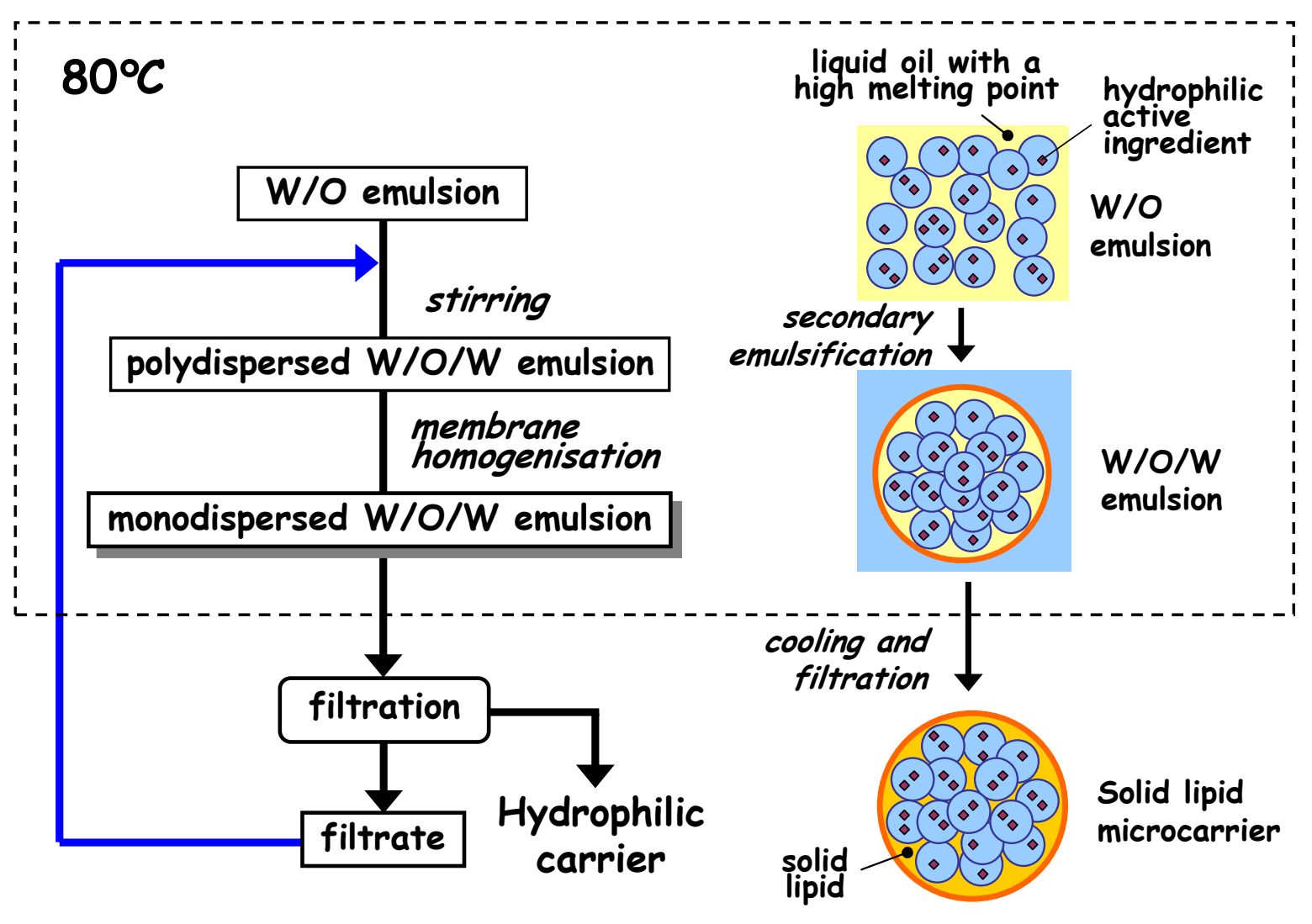

Figure 18 

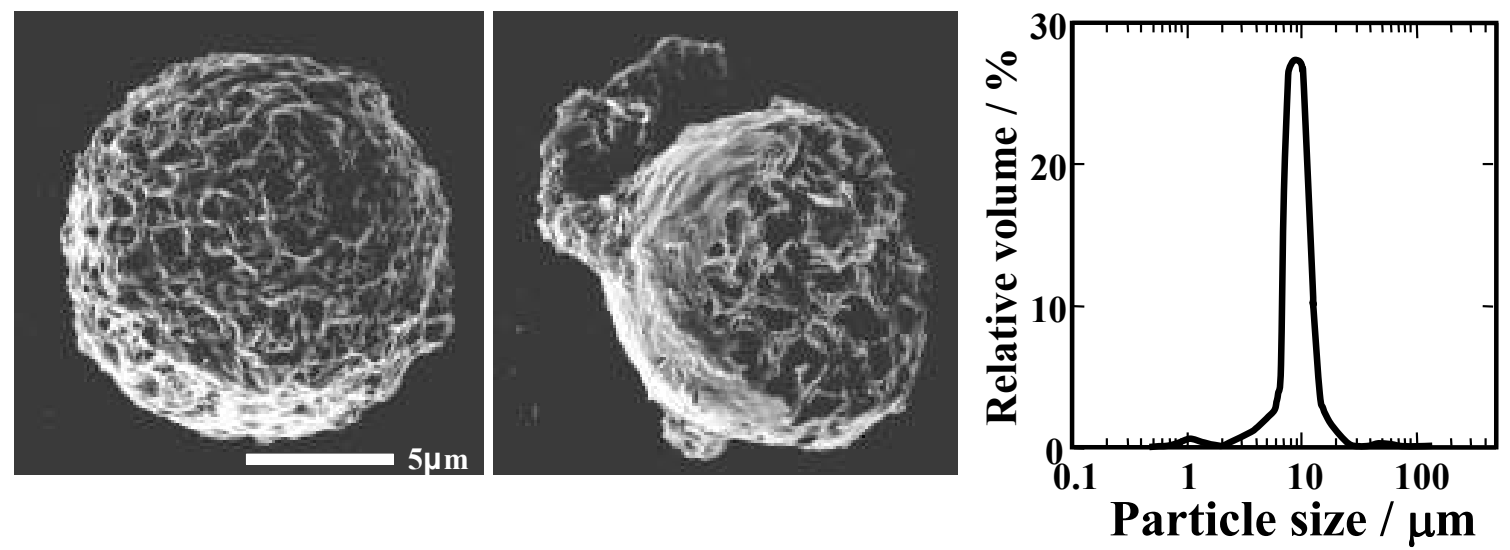

Figure 19 


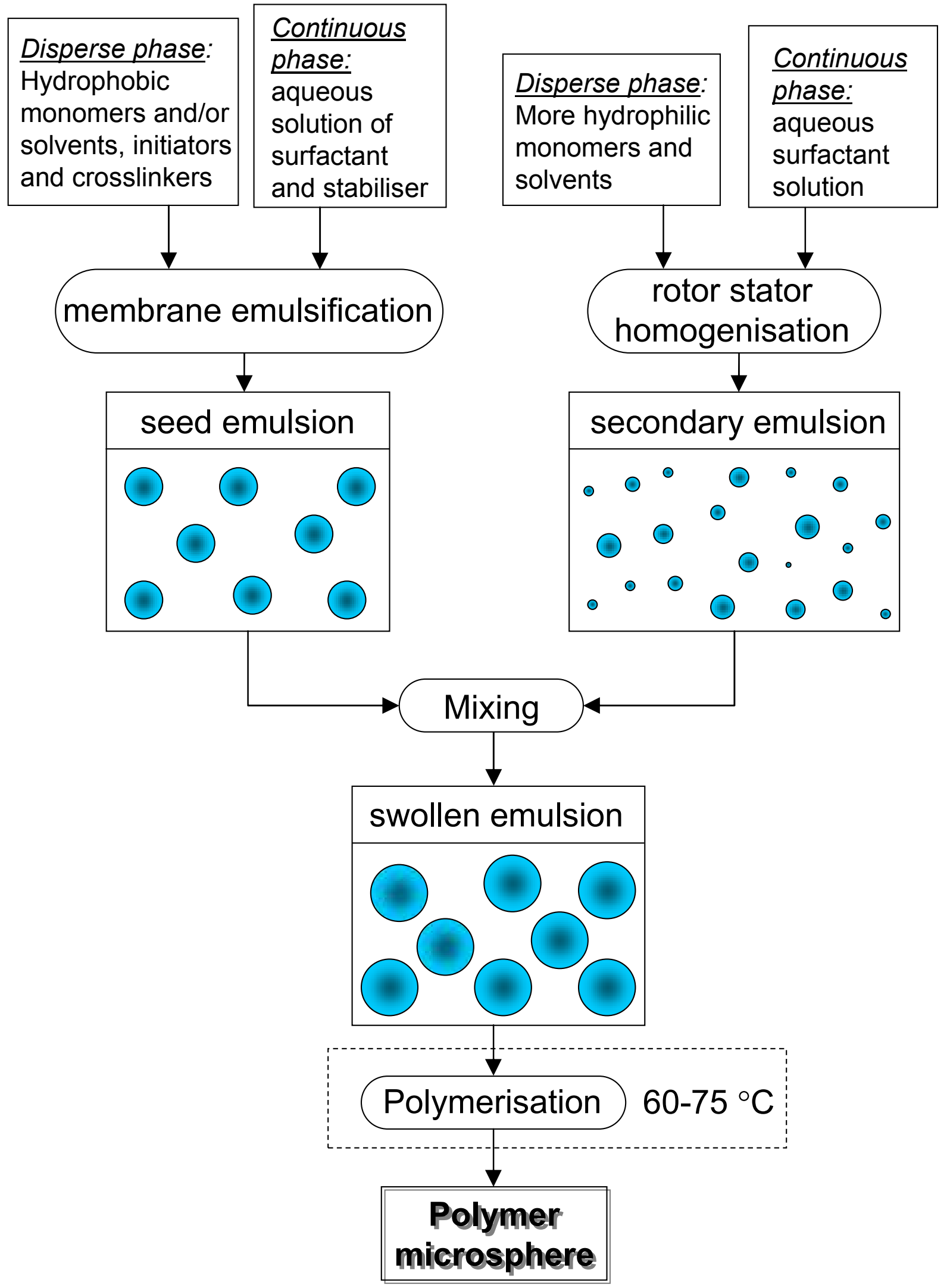

Figure 20 


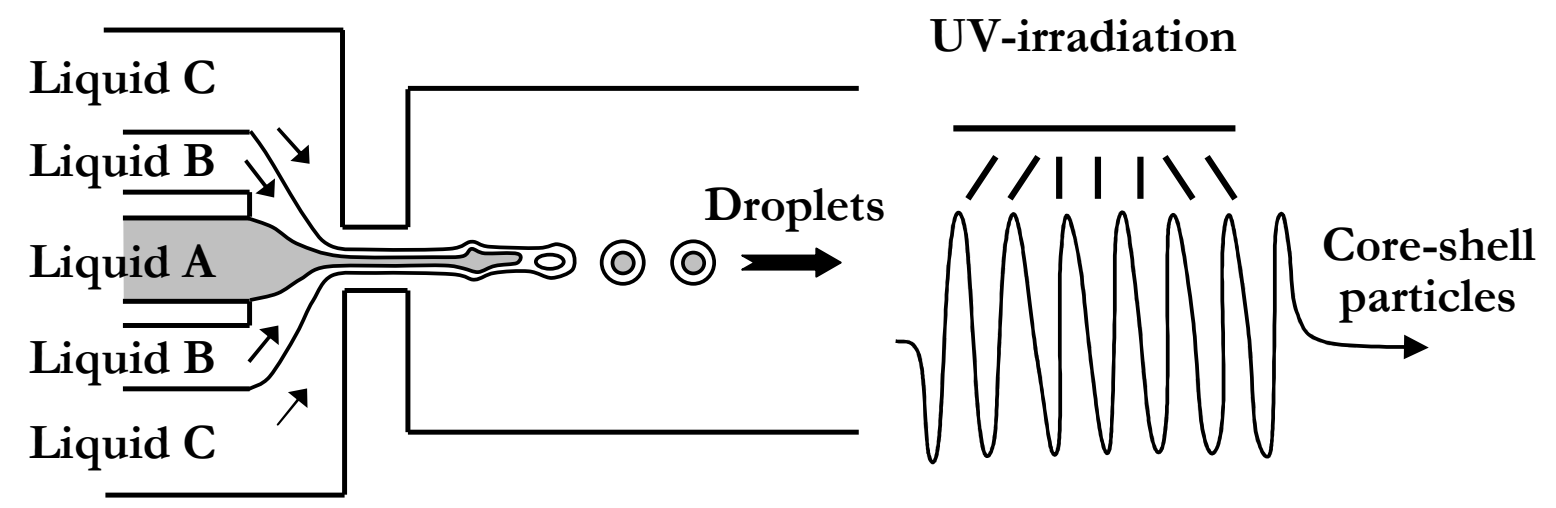

Figure 21 


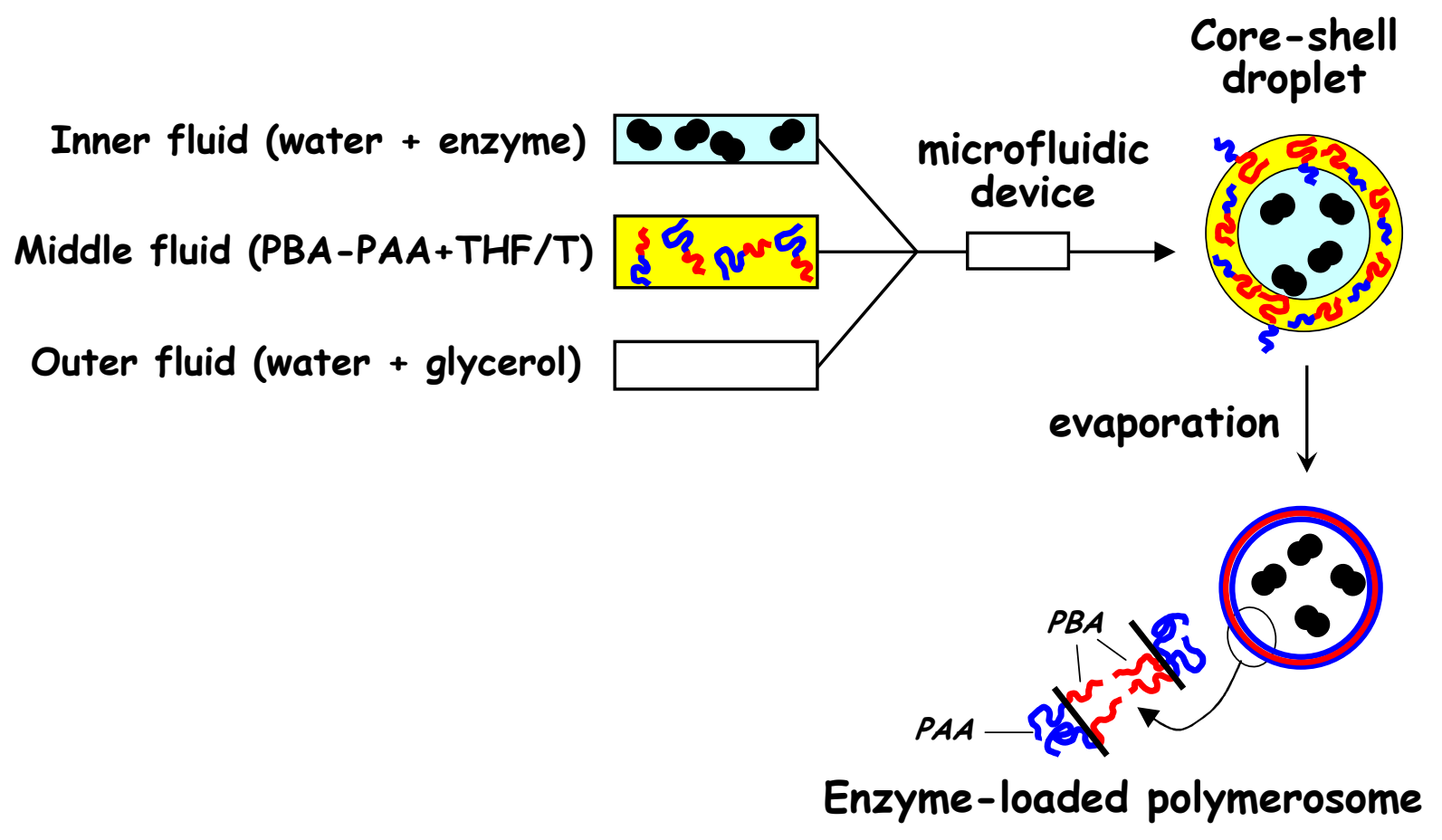

Figure 22 


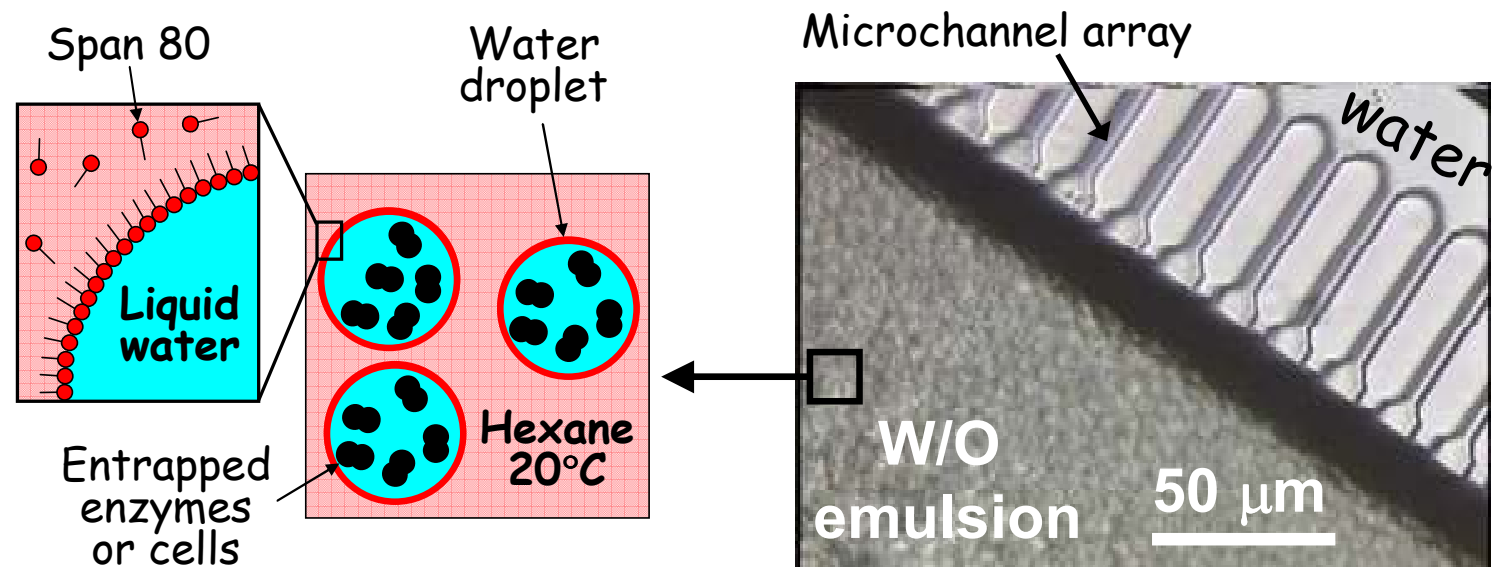

\section{(1) freezing with
liquid nitrogen}

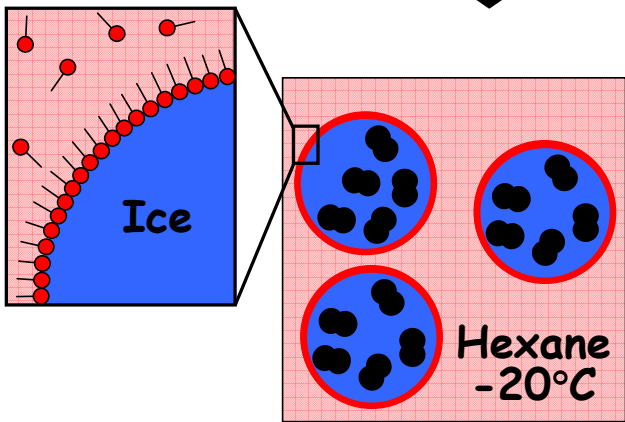

(2) surfactant replacement at $-20^{\circ} \mathrm{C}$
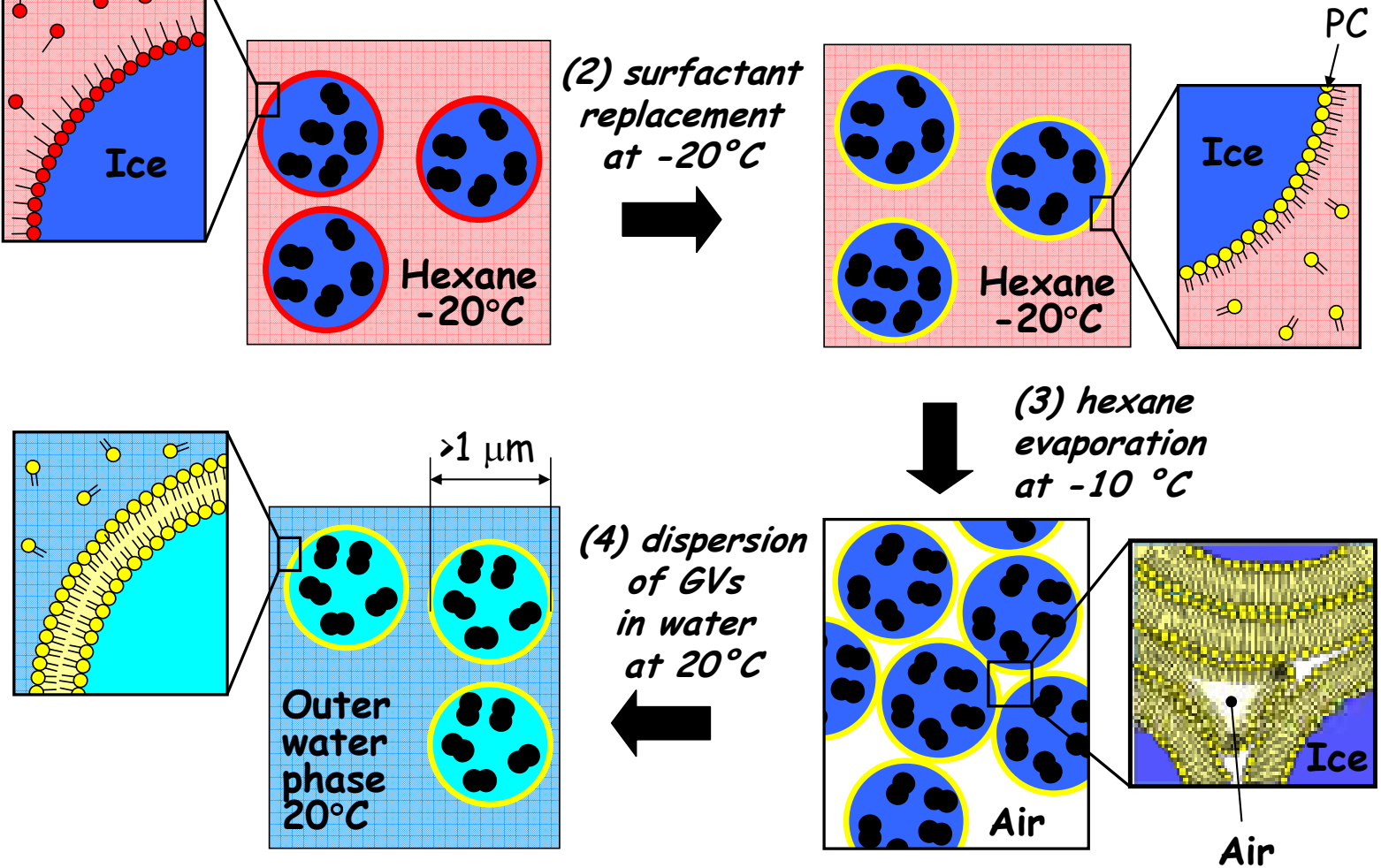

Figure 23 
Removal of hexane by evaporation

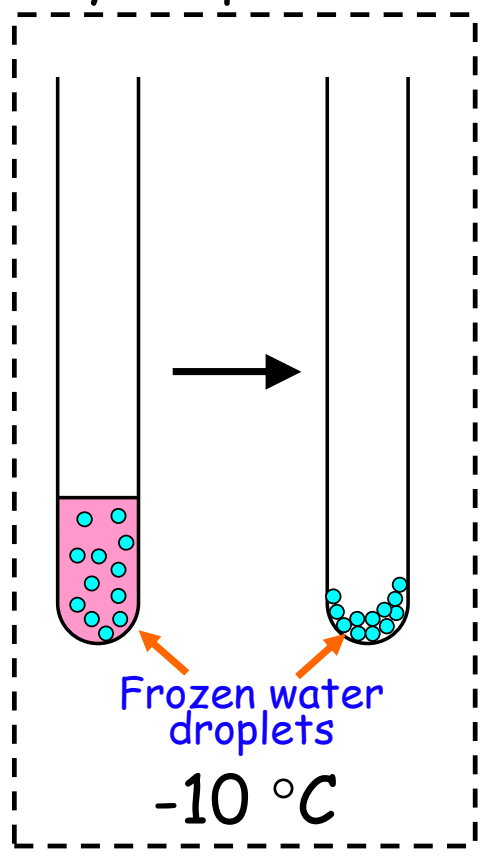

Hydration of lipid layer

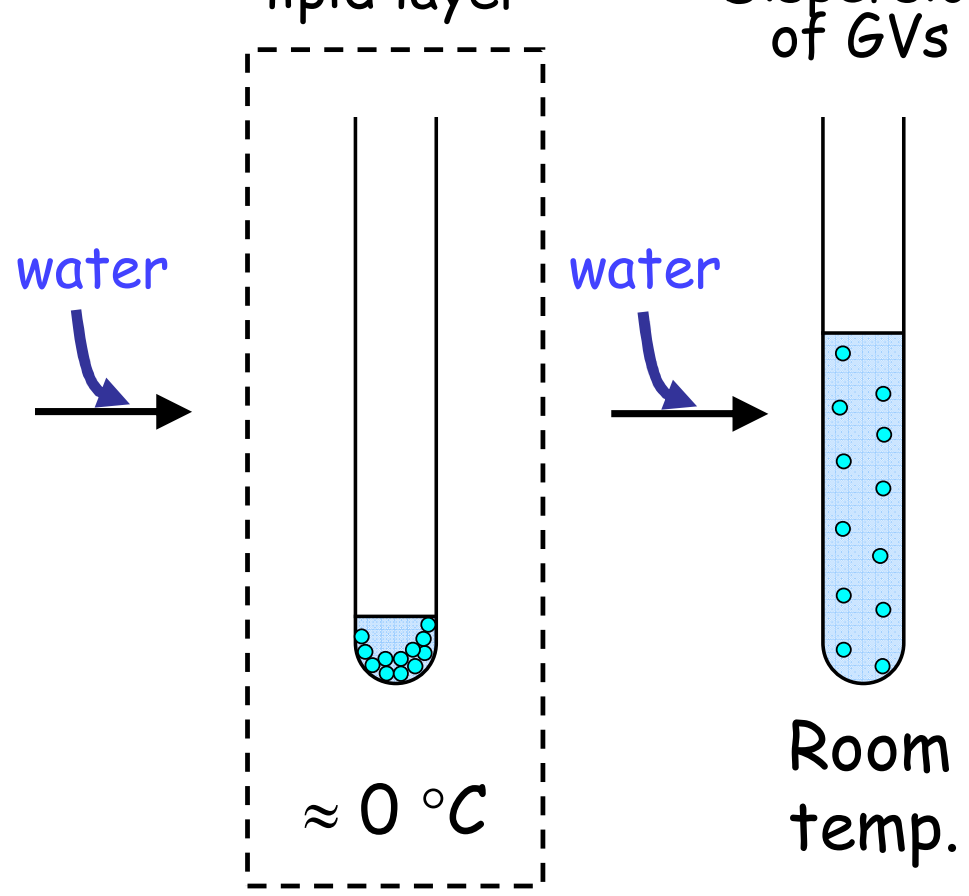

Figure 24 


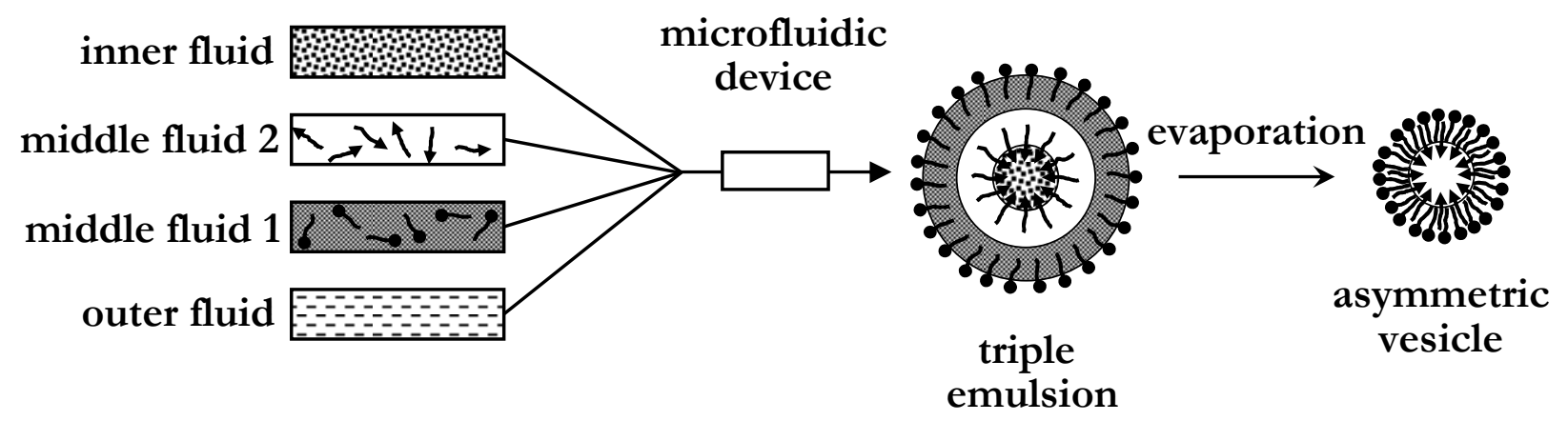

Figure 25 


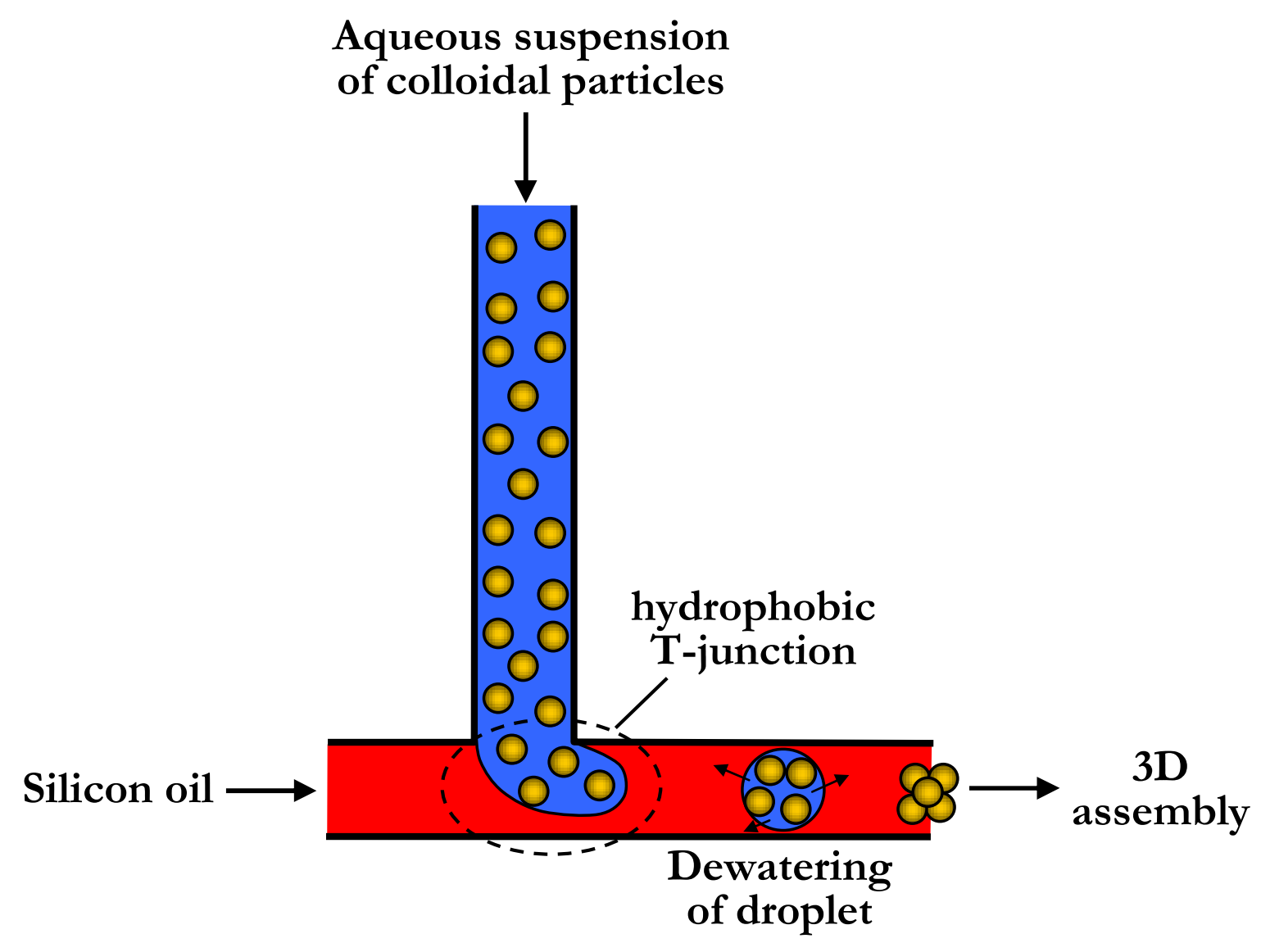

Figure 26 

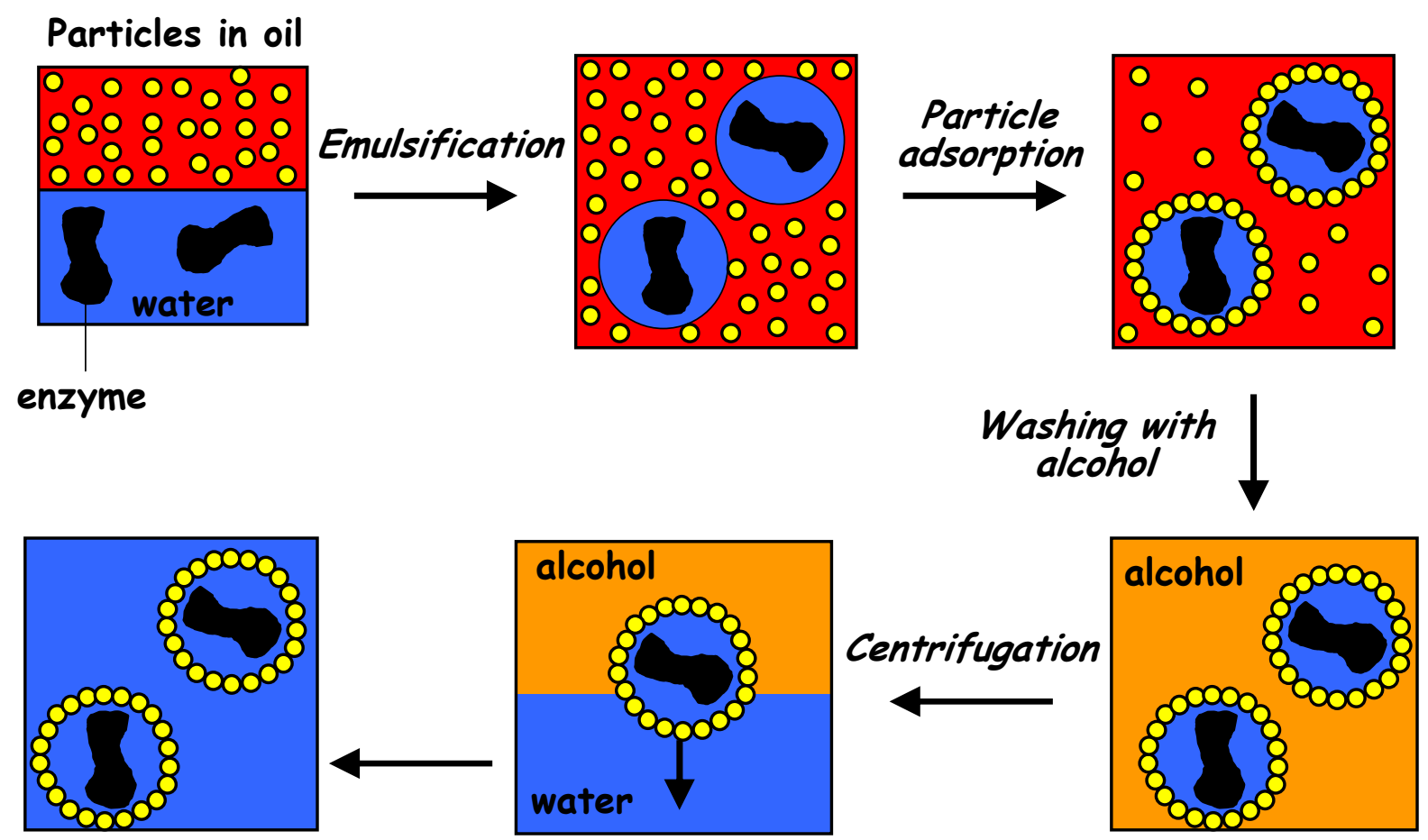

Figure 27 


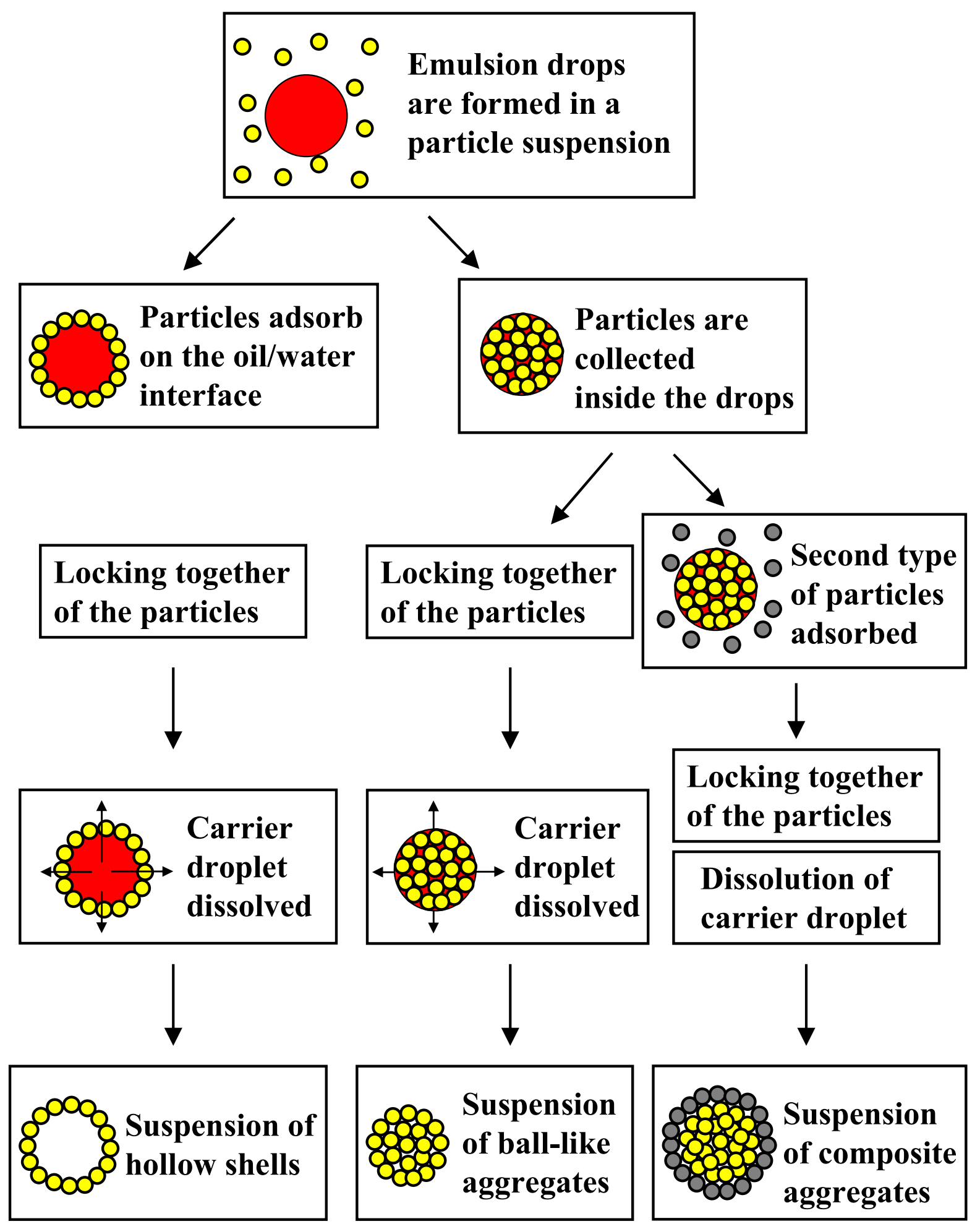

